\title{
Simulations of Lithium-Based Neutron Coincidence Counter for Gd-Loaded Fuel
}

Christian C. Cowles

Richard T. Kouzes

Edward R. Siciliano

October 2014

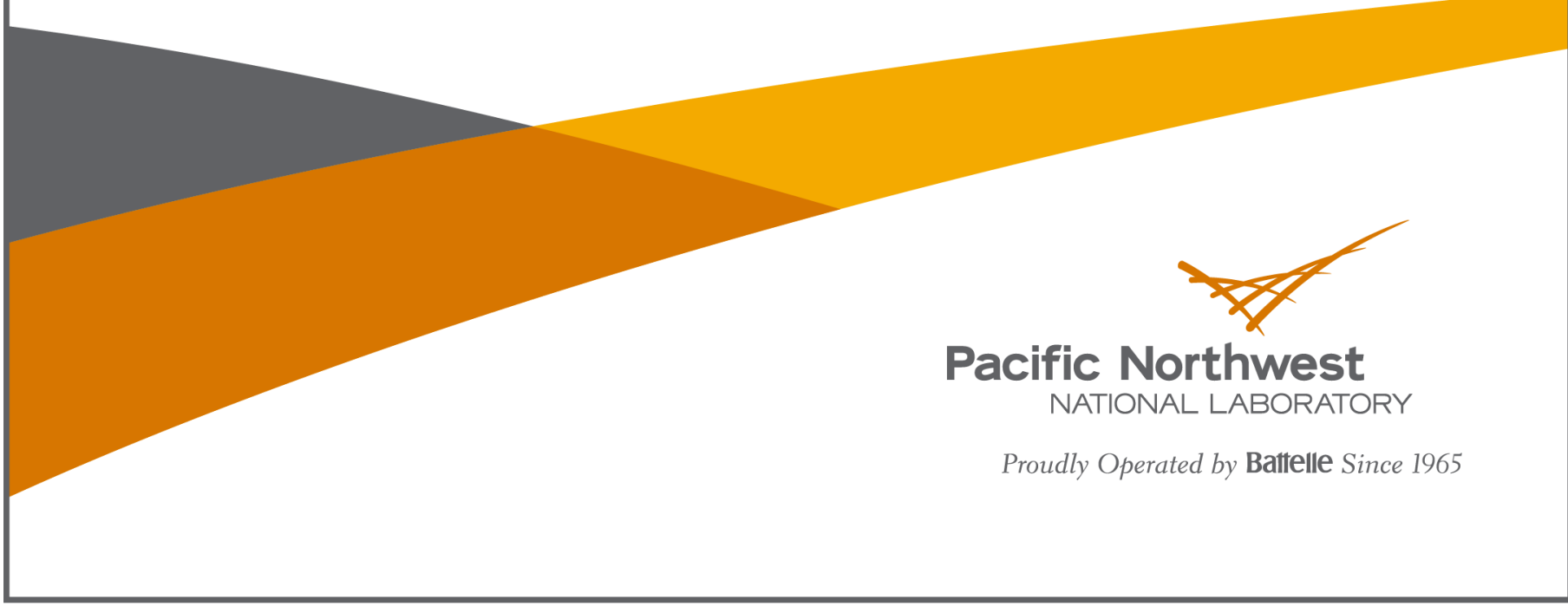




\title{
DISCLAIMER
}

This report was prepared as an account of work sponsored by an agency of the United States Government. Neither the United States Government nor any agency thereof, nor Battelle Memorial Institute, nor any of their employees, makes any warranty, express or implied, or assumes any legal liability or responsibility for the accuracy, completeness, or usefulness of any information, apparatus, product, or process disclosed, or represents that its use would not infringe privately owned rights. Reference herein to any specific commercial product, process, or service by trade name, trademark, manufacturer, or otherwise does not necessarily constitute or imply its endorsement, recommendation, or favoring by the United States Government or any agency thereof, or Battelle Memorial Institute. The views and opinions of authors expressed herein do not necessarily state or reflect those of the United States Government or any agency thereof.

\author{
PACIFIC NORTHWEST NATIONAL LABORATORY \\ operated by \\ BATTELLE \\ for the \\ UNITED STATES DEPARTMENT OF ENERGY \\ under Contract DE-AC05-76RL01830
}

Printed in the United States of America

\author{
Available to DOE and DOE contractors from the \\ Office of Scientific and Technical Information, \\ P.O. Box 62, Oak Ridge, TN 37831-0062; \\ ph: (865) 576-8401 \\ fax: (865) 576-5728 \\ email: reports@adonis.osti.gov
}

Available to the public from the National Technical Information Service, U.S. Department of Commerce, 5285 Port Royal Rd., Springfield, VA 22161

ph: (800) 553-6847

fax: (703) 605-6900

email: orders@ntis.fedworld.gov

online ordering: http://www.ntis.gov/ordering.htm 


\section{Simulations of Lithium-Based Coincidence Counter for Gd- Loaded Fuel}

Christian C. Cowles

Richard T. Kouzes

Edward R. Siciliano

October 2014

Pacific Northwest National Laboratory

Richland, Washington 99352 


\section{Executive Summary}

The Department of Energy Office of Nuclear Safeguards and Security (NA-241) is supporting the project Lithium-Based Alternative Neutron Detection Technology Coincidence Counting for Gd-loaded Fuels at Pacific Northwest National Laboratory for the development of a lithium-based neutron coincidence counter for nondestructively assaying Gd loaded nuclear fuel.

This report provides results from MCNP simulations of a lithium-based active PWR coincidence counter for the possible measurement of Gd-loaded nuclear fuel. A comparison of lithium-based coincidence counter simulations and ${ }^{3} \mathrm{He}$-based UNCL-II simulations, with and without Gd loaded fuel, is provided as summarized in the following table. All values are simulation results except the measured UNCL-II. The simulated efficiency includes a validation correction factor to take into account light losses in the system. A lithium-based model, referred to as PLNS3A-R1, showed strong promise for assaying Gd loaded fuel to $1 \%$ precision in 10 minutes, with better performance (in simulation) than a ${ }^{3} \mathrm{He}$-based UNCL modified to measure Gd-loaded fuel.

Comparison of various coincidence counter performance parameters.

\begin{tabular}{|l|l|c|c|c|c|}
\hline \multicolumn{1}{|c|}{ Detector } & Configuration & $\begin{array}{c}\text { Die Away Time } \\
(\boldsymbol{\mu} \mathbf{s})\end{array}$ & $\begin{array}{c}\boldsymbol{\varepsilon} \\
(\mathbf{\%})\end{array}$ & FOM & $\begin{array}{c}\text { Approximate Assay } \\
\text { Precision in 10 minutes }\end{array}$ \\
\hline${ }^{3} \mathrm{He}$ UNCL II & Standard & 53 & 12.3 & 2.9 & $6 \%$ \\
\hline${ }^{3} \mathrm{He}$ UNCL mod & Cd liner & 28 & 15.7 & 8.8 & $3 \%$ \\
\hline${ }^{6} \mathrm{LiF} / \mathrm{ZnS}$ & PLNS-3 & 21 & 16.7 & 13.2 & $2 \%$ \\
\hline${ }^{6} \mathrm{LiF} / \mathrm{ZnS}$ & PLNS3A-R1 & 18 & 18.7 & 18.7 & $1 \%$ \\
\hline
\end{tabular}




\section{Acronyms and Abbreviations}

\begin{tabular}{ll} 
AmLi & Americium-lithium neutron source \\
BWR & Boiling water reactor \\
cps & Counts per second \\
DOE & U.S. Department of Energy \\
DU & Depleted uranium \\
$\varepsilon$ & Detection efficiency \\
FoM & Figure of Merit \\
GERS & General Electric Reuter-Stokes \\
HDPE & High Density Polyethylene \\
IAEA & International Atomic Energy Agency \\
LANL & Los Alamos National Laboratory \\
LEC & Low-Energy Cutoff \\
LEU & Low-enriched uranium \\
LiF/ZnS & Lithium Fluoride Zinc Sulfide fixed in a hydrogenous binder \\
MCA & Multi-Channel Analyzer \\
MOX & Mixed Oxide fuel \\
NIST & National Institute of Science and Technology \\
PLNS & PNNL's LiF/ZnS-based Neutron Scintillation detector \\
PNNL & Pacific Northwest National Laboratory \\
Pu & Plutonium \\
PUF & Poly-Urethane Foam \\
$\tau$ & Die-away time \\
TCE & Total capture efficiency \\
TTL & Transistor-transistor logic \\
U & Uranium \\
UNCL & Uranium Neutron Coincidence Collar \\
\hline
\end{tabular}




\section{Contents}

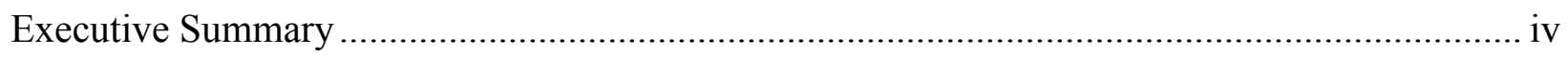

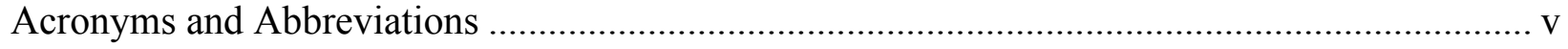

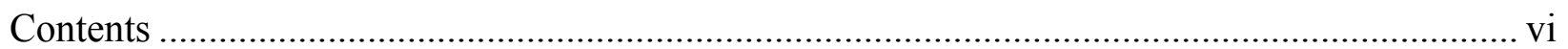

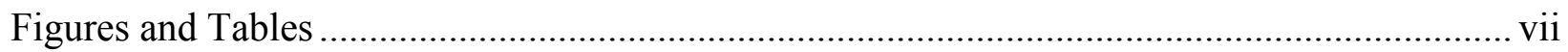

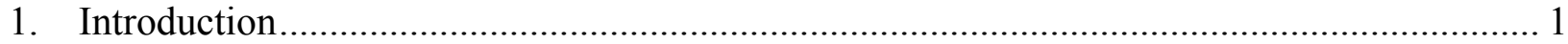

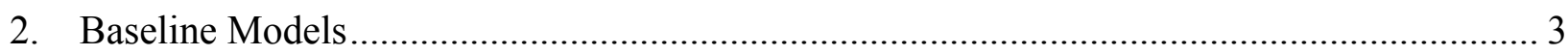

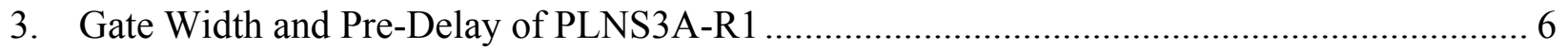

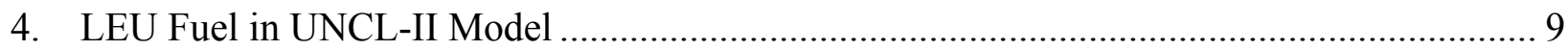

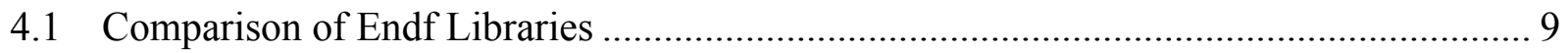

4.2 UNCL-II Baseline Performance With Fuel .................................................................. 10

4.3 Validation Correction Factor for UNCL-II............................................................... 10

5. Model of Fuel in PLNS3A-R1 Coincidence Counter ........................................................... 12

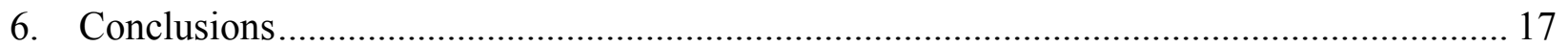

7. Appendix: Characteristics of PLNS4 Configurations Studied................................................ 18

8. Appendix: Comparison of Position and Energy Profiles ...................................................... 23

9. Appendix: Numerical Values for Variations of the PLNS4 Model ......................................... 27

10. Appendix: Studies for Examining Fuel in PLNS Coincidence Counter............................... 41

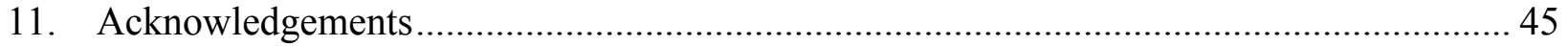

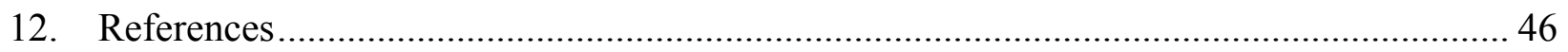




\section{Figures and Tables}

\section{Figures}

Figure 2.1. Model of the PLNS-2013 system used as a baseline for model comparison. The small red dot is depicts the location of the ${ }^{252} \mathrm{Cf}$ source point source. ......................................... 3

Figure 2.2. PLNS4 with ${ }^{252} \mathrm{Cf}$ source, polyurethane foam source stand, HDPE corners............... 4

Figure 2.3. PLNS3 with reversed detector panels and $1.0 \mathrm{~cm}$ HDPE lining and backing............ 4

Figure 2.4. PLNS3A-R1 with reversed detector panels, $+1.0 \mathrm{~cm}$ to front, and $+1.5 \mathrm{~cm}$ to lining

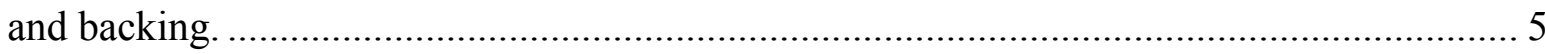

Figure 3.1. Total capture efficiency of the PLNS3A-R1 and the UNCL-II as a function of time.. 6

Figure 3.2. Doubles capture efficiency as a function of pre-delay and gate times...................... 8

Figure 4.1. UNCL-II neutron coincidence counter with a low enriched uranium nuclear fuel

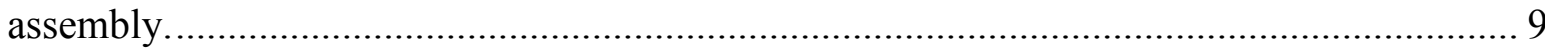

Figure 4.2. UNCL-II with steel encapsulated ${ }^{252} \mathrm{Cf}$ source on polyurethane foam stand............ 11

Figure 5.1. PLNS3A-R1 with full LEU fuel array and an active source. Wavelength shifting plastic sandwiched around $\mathrm{LiF} / \mathrm{ZnS}$ material is light orange, HDPE is light blue, LEU fuel within the fuel assembly is light blue, aluminum is dark blue, and the AmLi source is depicted as a red dot

Figure 5.2. Fuel arrays with blue LEU fuel, green Gd loaded fuel, and empty regions for tools and coolant flow. Left: array 1 with four Gd loaded fuel rods. Middle: array 2 with eight Gd loaded fuel rods. Right: array 3 with sixteen Gd loaded fuel rods. 12

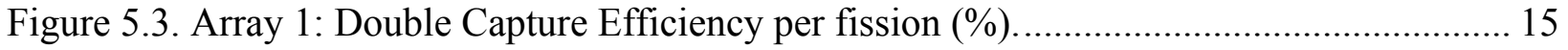

Figure 5.4. Array 2: Double Capture Efficiency per fission (\%) .......................................... 15

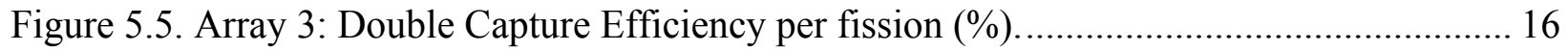

Figure 7.1. Model of the PLNS-2013 system used as a baseline for model comparison. Although a point source was used, a small red dot is depicted to designate the location of the ${ }^{252} \mathrm{Cf}$ source.

Figure 7.2. PLNS4 with ${ }^{252} \mathrm{Cf}$ source, polyurethane foam source stand, HDPE corners............. 21

Figure 7.3. Doubles rate efficiency versus gate times with fixed pre-delay and fitted curves.

These curves can be used to determine the charactaristic die-away time for conicidences.. 22

Figure 8.1. Total Capture Efficiency (TCE) vs. Neutron Energy for PLNS4 without HDPE

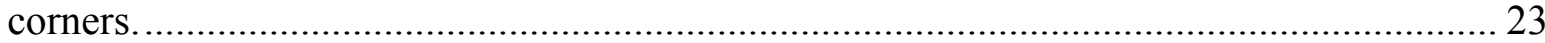

Figure 8.2 TCE vs. Source Height relative to chamber center without HDPE corners.............. 24

Figure 8.3. PLNS4 with four HDPE corner blocks for moderation and a PUF source stand....... 25

Figure 8.4. Total Capture Efficiency of PLNS4 with the addition of HDPE corner blocks........ 25 
Figure 8.5 TCE vs. Neutron Energy for PLNS4 with HDPE corners.......................................... 26

Figure 8.6. TCE vs. Source Height relative to chamber center with HDPE corners..................... 26

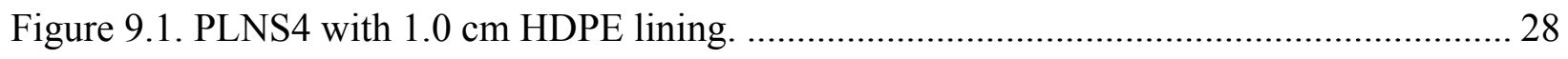

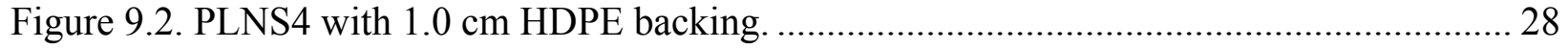

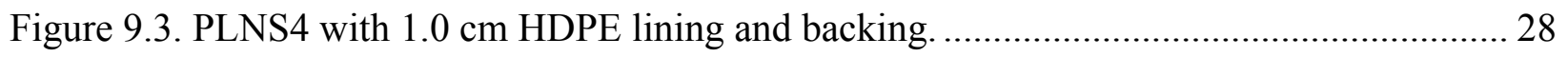

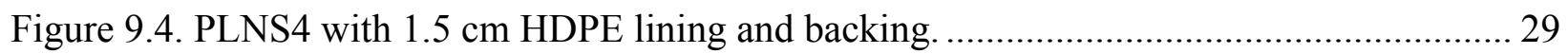

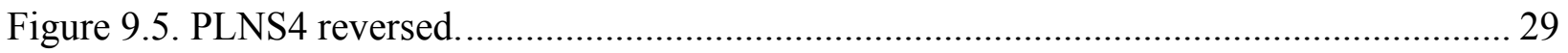

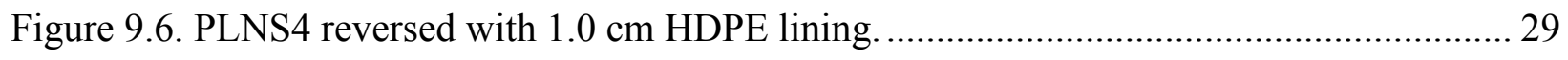

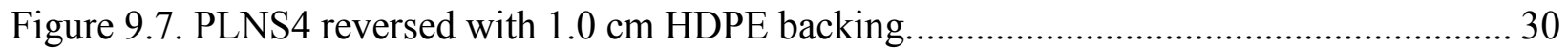

Figure 9.8. PLNS4 reversed with $1.0 \mathrm{~cm}$ HDPE lining and backing.......................................... 30

Figure 9.9. PLNS4 reversed with $1.5 \mathrm{~cm}$ HDPE lining and backing........................................ 30

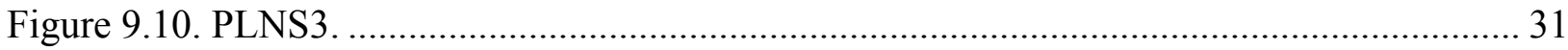

Figure 9.11. PLNS3 with $1.0 \mathrm{~cm}$ HDPE lining and backing. .................................................. 31

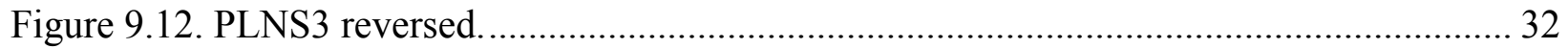

Figure 9.13. PLNS3 reversed with $1.0 \mathrm{~cm}$ HDPE lining and backing........................................ 32

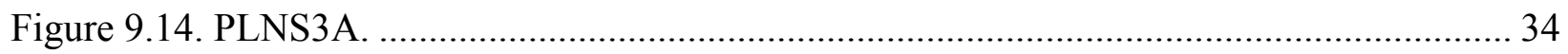

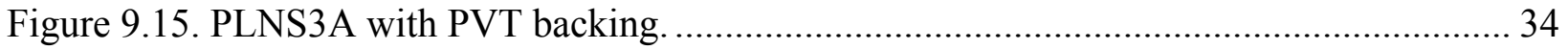

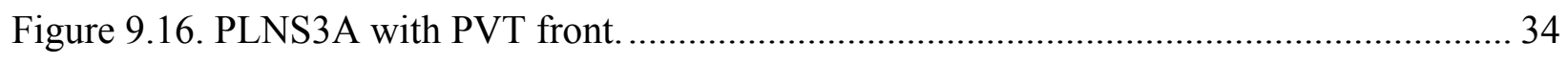

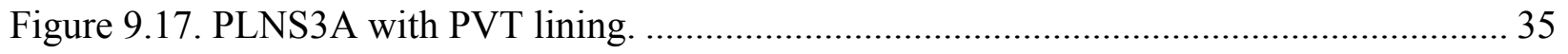

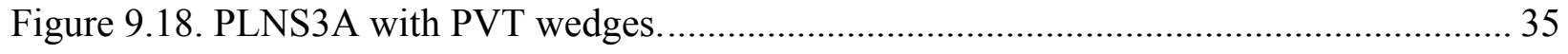

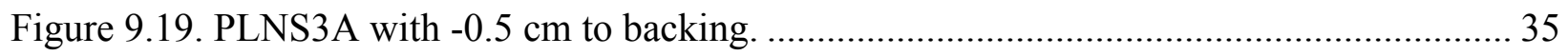

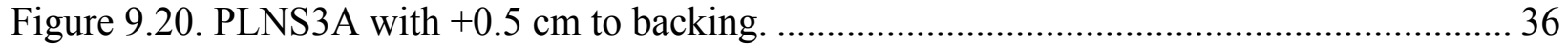

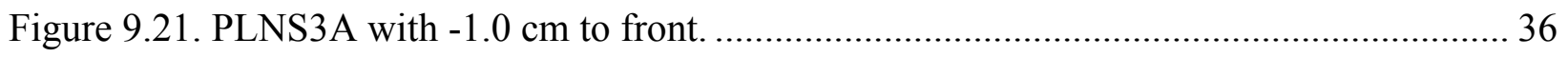

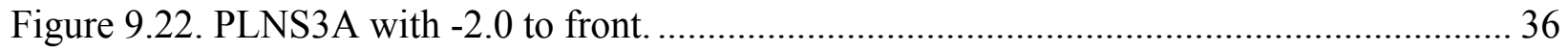

Figure 9.23. PLNS3A with $+1.0 \mathrm{~cm}$ to front. ......................................................................... 37

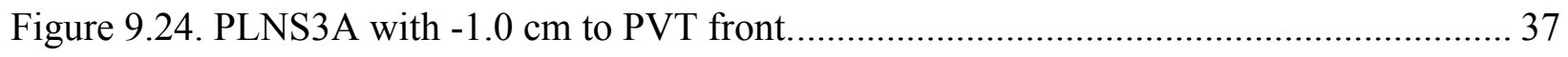

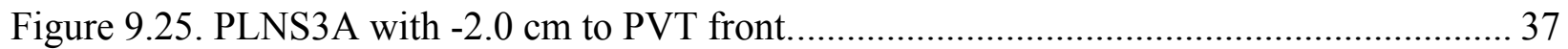

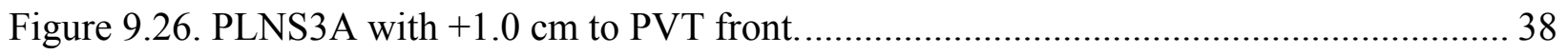

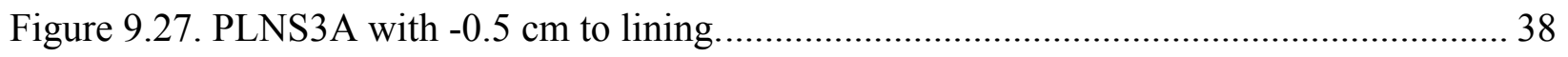

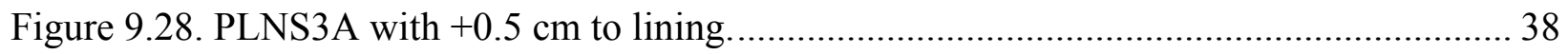


Figure 9.29. PLNS3A with $+0.5 \mathrm{~cm}$ to front, lining, and backing. ........................................... 39

Figure 9.30. PLNS3A with $+1.0 \mathrm{~cm}$ to front, lining, and backing. ............................................ 39

Figure 9.31. PLNS3A with $+1.0 \mathrm{~cm}$ to front, and $+1.5 \mathrm{~cm}$ to lining and backing. ....................... 39

Figure 9.32. PLNS3A reversed with $+1.0 \mathrm{~cm}$ to front, and $+1.5 \mathrm{~cm}$ to lining and backing......... 40

Figure 10.1. PLNS4 with LEU fuel array and AmLi source in one corner. ................................. 41

Figure 10.2. PLNS4 with full LEU fuel array, four HDPE reflectors, and four AmLi sources. .. 42

Figure 10.3. Total Capture Efficiency of PLNS4 versus number of HDPE blocks and LEU fuel

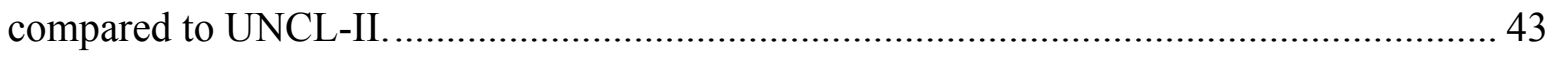

Figure 10.4. Doubles capture efficiency of PLNS4 versus number of HDPE blocks and LEU

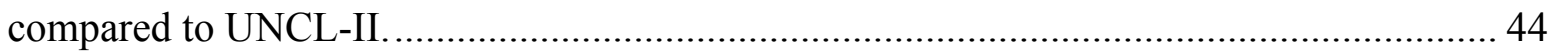

\section{Tables}

Table 3.1. Doubles capture efficiency as a function of pre-delay and gate times. ......................... 7

Table 3.2. Doubles capture efficiency as a function of pre-delay and gate times. .......................... 7

Table 4.1. Simulated results of the UNCL-II with LEU fuel.......................................................... 10

Table 4.2. Simulation results of the UNCL-II with 3.19\% and 4.50\% enriched fuel................... 10

Table 4.3. Simulation results of UNCL-II with steel encapsulated ${ }^{252} \mathrm{Cf}$ source on polyurethane

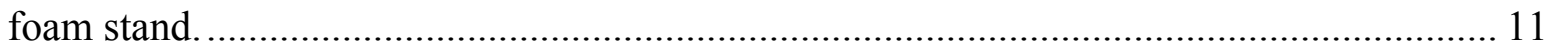

Table 5.1. Doubles capture efficiency for the UNCL-II and PLNS3A-R1 systems with 4.5\%

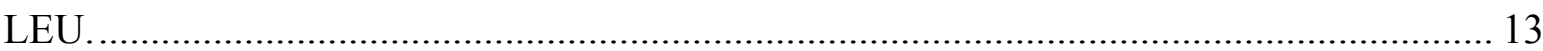

Table 5.2. Doubles capture efficiency for the UNCL-II and PLNS3A-R1 systems with 3.2\%

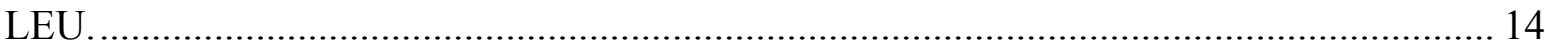

Table 6.1. Comparison of various coincidence counter performance parameters........................ 17

Table 7.1. PLNS-2013 and Baseline simulation results .............................................................. 20

Table 7.2. PLNS-4 and PLNS-2013 simulation results ............................................................... 20

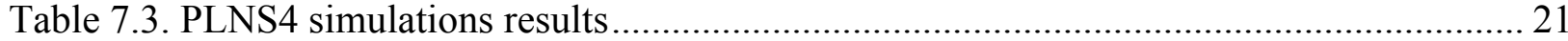

Table 9.1. Results of changes to PLNS4 compared to the unmodified PLNS4 and UNCL-II..... 27

Table 9.2. Results of changes to PLNS3 compared to the unmodified PLNS4 and UNCL-II..... 31

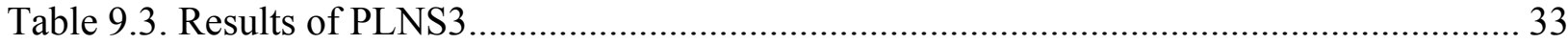

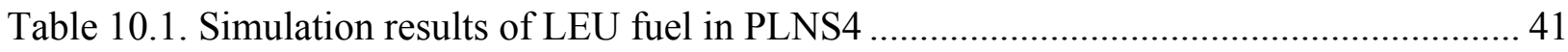

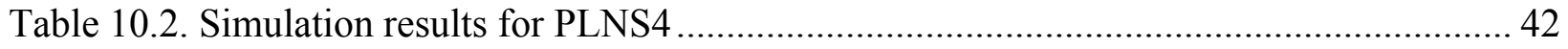




\section{Introduction}

One of the important safeguards applications of ${ }^{3} \mathrm{He}$ has been for coincidence counting instruments utilized by the International Atomic Energy Agency (IAEA). The Department of Energy Office of Nuclear Safeguards and Security (NA-241) has been supporting the project Lithium-Based Alternative Neutron Detection Technology Coincidence Counting for Gd-loaded Fuels at Pacific Northwest National Laboratory (PNNL). The goal of this project is to evaluate whether a lithium-based coincidence counter, with its short die-away-time, could be used to make measurements on Gd-loaded low enriched uranium (LEU) fuel. The coincidence counter used for this evaluation is based upon the PNNL Lithium-based Neutron Scintillator (PLNS) detector [Ely 2013a].

The shortage of ${ }^{3} \mathrm{He}$ [Kouzes 2009] has driven the need for identifying and implementing alternative neutron detection technologies for coincidence and gross neutron counters used by the International Atomic Energy Agency (IAEA). Coincidence counting is used in any application where plutonium or uranium mass needs to be determined.

One current safeguards challenge is in the assay of fresh uranium fuel doped with $3-12 \% \mathrm{Gd}$ as a burnable poison to control the fuel burn-up rate [Asou 1997, Durmazucar 2000, Espinosa 2011, Jo 2009, Kloosterman 2003, Massih 1993, Mikus 2014, Rogers 2009, Schlieck 2001, Soba 2014, van Dam 2000, Yamate 1997, Yilmaz 2006]. Currently, the IAEA uses active well coincidence counters (AWCC) based on ${ }^{3} \mathrm{He}$, but particularly for assemblies with high Gd content, systematic errors can be high and measurement times very long (hours), in contrast to about ten minutes for non-Gd loaded fuel.

Coincidence counters with short die-away times may be a solution to this Gd problem. A new uranium neutron coincidence collar (UNCL) design based on high-pressure ${ }^{3} \mathrm{He}$ tubes was developed to overcome this problem [Evans 2013]. In this counter, a Cd liner was used to reduce the sensitivity to slow neutrons, shortening the die-away-time, but also significantly reducing the detection efficiency. The result was a detector that could meet the requirements of enabling nuclear safeguards inspectors to perform a measurement on fresh fuel containing Gd within a target assay time of 15 minutes and with a precision of $2 \%$ relative uncertainty in the doubles neutron-counting rate.

Previous projects at PNNL have shown that there are a number of commercially available alternatives to ${ }^{3} \mathrm{He}$ for neutron detection applications for portal applications [Kouzes 2010]. From PNNL testing of four alternative neutron detection technologies, two were identified as most promising replacement technologies for safeguards applications: light guides coated with ${ }^{6} \mathrm{LiF}$ and $\mathrm{ZnS}$ [Lintereur 2009] and boron-lined proportional counters [Lintereur 2010]. Extensive Monte Carlo modeling of both alternatives has been performed [Siciliano 2010, Lintereur 2012, Ely 2013]. PNNL previously evaluated and tested boron-based alternative neutron coincidence counters, which led to the development and testing of an alternative-based coincidence counter prototype design. Our previous coincidence-counting system project for safeguards applications focused on the selection of the coincidence-counting instrument to be developed with boron-lined tubes [Kouzes 2012], modeling of boron-lined detector wall effects [Siciliano 2012], measurements of simple boron-lined systems for model validation [Lintereur 2012a], modeling of alternative UNCL designs [Rogers 2012], and validation of a prototype boron-based UNCL design provided by GE Reuter Stokes [Kouzes 2013].

The previous PNNL modeling search for alternatives also addressed development of multiplicity detectors and showed that minimally moderated configurations based upon neutron scintillation via thin sheets of a ${ }^{6} \mathrm{LiF}-\mathrm{ZnS}$ blend in a hydrogenous binder (abbreviated $\mathrm{LiF} / \mathrm{ZnS}$ ) may have much shorter die-away times than conventional, fully-moderated ${ }^{3} \mathrm{He}$-based multiplicity counters [Ely 2013]. Construction of the PLNS test detector has verified that characteristic [Ely 2013a], and thus indicates that a PLNS-type detector may be applicable to the problem of Gd-loaded fuel. The studies reported in this work were conducted to address this possibility. 
The work reported here began with the validated PLNS model from that previous study and then explored a number of possible active configurations for coincidence counting to determine if such a configuration can obtain reasonable efficiencies and short enough die-away-times to measure fresh fuel with a range of Gd loading. Such minimally moderated coincidence counters with short die-away times may be a solution to this problem since there is more probability of the neutrons being detected quickly and less probability for the neutrons to be reflected back into the fuel to interact with the Gd and be lost.

After determining an active configuration model that gave the best performance, named PLNS3A-R1, it was used to simulate what might be possible with the $\mathrm{LiF} / \mathrm{ZnS}$ technology by comparing models for low enriched uranium (LEU) fuel against Gd-loaded fuel. Modeling to evaluate optimization of the parameters of these assemblies was performed using MCNPX [Pelowitz 2011].

The figure of merit typically used for coincidence counters is the efficiency squared divided by the dieaway-time. Although configurations using ${ }^{6} \mathrm{LiF} / \mathrm{ZnS}$ neutron scintillation technology typically have smaller efficiencies than ${ }^{3} \mathrm{He}$-based coincidence counters, because of their shorter die-away times, simulations have indicated that their figures of merit can be comparable to those of ${ }^{3} \mathrm{He}$-based systems [Ely 2013].

This NGSI project is complementary to the NA-22 Venture Project on alternative neutron multiplicity detection techniques, and ongoing work at the IAEA to explore coincidence counter alternatives.

Section 2 of this report summarizes the PLNS baseline model and its evolution to the PLNS3A-R1 model of a high performance active coincidence counter for fuel measurements. Section 3 discusses the determination of the appropriate gate width and pre-delay based on the die-away time of the detector determined by the models. Section 4 gives a reference to how a current, ${ }^{3} \mathrm{He}$-based coincidence counter would perform by using the fuel model into the existing ${ }^{3} \mathrm{He}$-based UNCL-II coincidence counter model. And against that reference, Section 5 discusses the Li-based coincidence counter model with fuel, including the effects of Gd-loaded fuel. The Appendices contain details on the various modeling efforts that were conducted in the search for optimal configurations. 


\section{Baseline Models}

The starting point for the research performed under this project was the existing PLNS model of the demonstrator system, as described in the Final Technical Report for the Neutron Detection without Helium-3 Project [Ely 2013a]. A schematic of the PLNS model can be seen in Figure 2.1 with a ${ }^{252} \mathrm{Cf}$ point source situated on the top center of the source stand. Modeling this detector, referred to as PLNS2013, obtained agreement with the previously reported results. The results are summarized here, with further detail on this comparison provided in an Appendix.
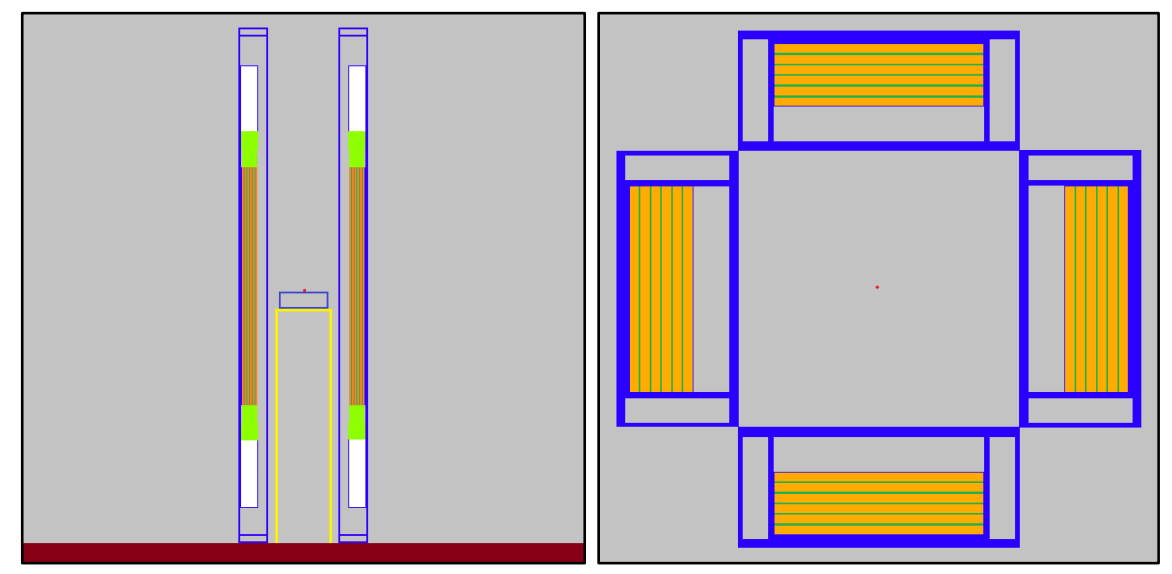

Figure 2.1. Model of the PLNS-2013 system used as a baseline for model comparison. The small red dot is depicts the location of the ${ }^{252} \mathrm{Cf}$ source point source.

It is important to note that for all the MCNPX simulations of the $\mathrm{LiF} / \mathrm{ZnS}$ based detectors, the final modeling result is simply the total number of neutron captured by the ${ }^{6} \mathrm{Li}$ in the scintillation sheets. So, the raw modeling results are referred to as the neutron total capture efficiency (TCE), as compared with the measured counting efficiency (denoted by $\varepsilon$ ). Many factors not modeled can give rise to this difference, but for the $\mathrm{LiF} / \mathrm{ZnS}$ type systems, the primary cause is omission of light collection effects. To compensate for this shortcoming in the predicted TCE values, a Validation Correction Factor (VCF) was introduced (Ely, 2013), which is simply the ratio of the measured efficiency to the simulated TCE for a model of the measured configuration. In this manner, multiplying the simulated TCE by an experimentally determined VCF is used to give the expected neutron detection efficiency $(\varepsilon)$ one would measure. The VCF for the baseline system has been measured to be $0.78 \pm 0.03 .{ }^{1}$ This VCF was applied to the results of the modeling for this project.

For coincidence counters, the primary metric of performance is the Figure-of-Merit (FoM), defined as

$$
\text { Equation 2.1 FoM }=\frac{\varepsilon^{2}}{\tau},
$$

where $\varepsilon$ is the expected counting efficiency and $\tau$ is the die-away time. The standard for determining this FoM is an un-moderated ${ }^{252} \mathrm{Cf}$ source positioned in the geometric center of the sample chamber.

\footnotetext{
${ }^{1}$ The VCF value of $0.84 \pm 0.12$ reported previously [Ely 2013] was revised to 0.82 to account for the steel capsulized source (omitted in the model), then was revised to $0.78 \pm 0.03$ after re-calibration of the source strength. This updated value of 0.78 is used in this report. Because doubles counts were also measured, using doubles instead of total neutron counts gave a VCF of $0.77 \pm 0.04$, providing confidence in the value assumed herein.
} 
Exploration began by seeking simple additions that might improve the performance of the four-module, passive PLNS model used for the 2013 results. For reference, it had a TCE of $7.5 \%$, tau of $11.9 \mu$ s, and using the VCF of 0.78 gives a starting FoM of 2.9. To distinguish the various model configurations built upon the 2013 model, they are referred to as PLNS4. This series of modifications began by adding blocks of high-density polyethylene (HDPE) in the corners, as seen in Figure 2.2. This significantly increased the FoM to 6.8 by giving a significant increase in the TCE with a very small change in the tau.

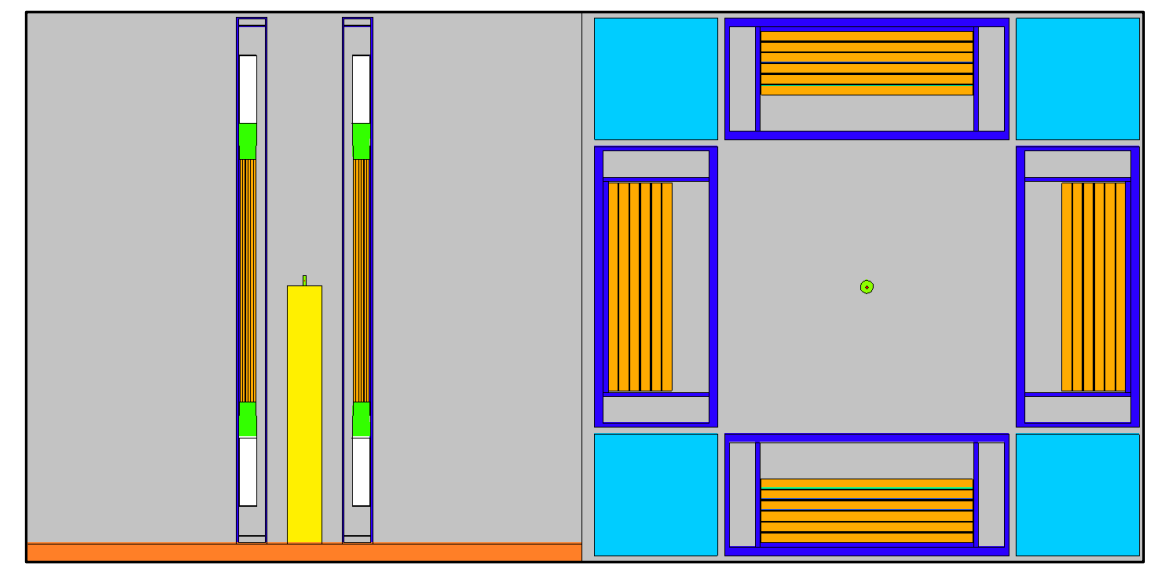

Figure 2.2. PLNS4 with ${ }^{252} \mathrm{Cf}$ source, polyurethane foam source stand, HDPE corners.

The PLNS4 model was then modified with additional HDPE to act as neutron moderators and reflectors to enhance the total and doubles neutron capture efficiency. These models showed the direction in which to evolve the model for improved performance. The FoM of the modified PLNS designs was improved from 6.8 to 24.8, compared to the UNCL-II FoM of 4.0. Details of these variations are provided in the Appendix.

The PNLS4 was modified by removing one detector panel and fully replacing that space with HDPE to better match an active interrogation configuration, which is referred to as PLNS3. The HDPE backing and lining were varied and simulated performance results were recorded. The best configuration was found to have $\varepsilon=16.7, \tau=21.1$, and $\mathrm{FoM}=13.2$, and is shown schematically in Figure 2.3.

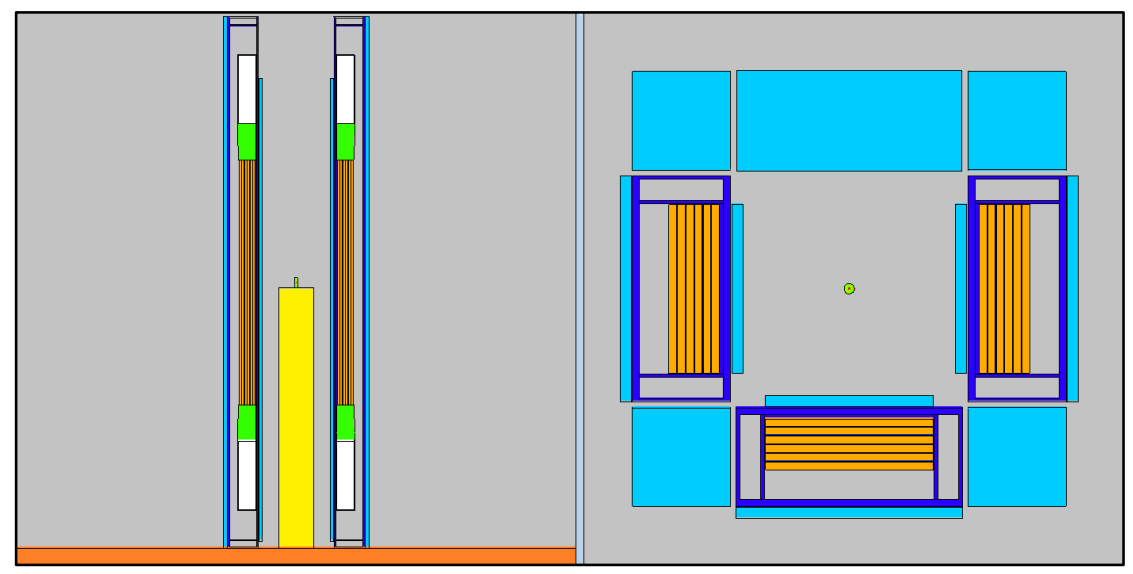

Figure 2.3. PLNS3 with reversed detector panels and $1.0 \mathrm{~cm}$ HDPE lining and backing.

Incorporating promising features from the PLNS4 models, the HDPE components in the PLNS3 model were modified to maintain the improved neutron capture efficiency, while reducing unnecessary increases in die-away time. For example, the corner blocks were reduced to wedges, and the height of all the HDPE 
was reduced to cover only the active height of the $\mathrm{LiF} / \mathrm{ZnS}$ sheets. The final modification used a protruding source cavity in the front section to place the AmLi source closer to the fuel chamber and improve the active configuration performance. This model, as depicted in Figure 2.4, is referred to as PLNS3A-R1. The PLNS3A-R1 gave $\varepsilon=18.3, \tau=18.0$, and FoM $=18.7$.

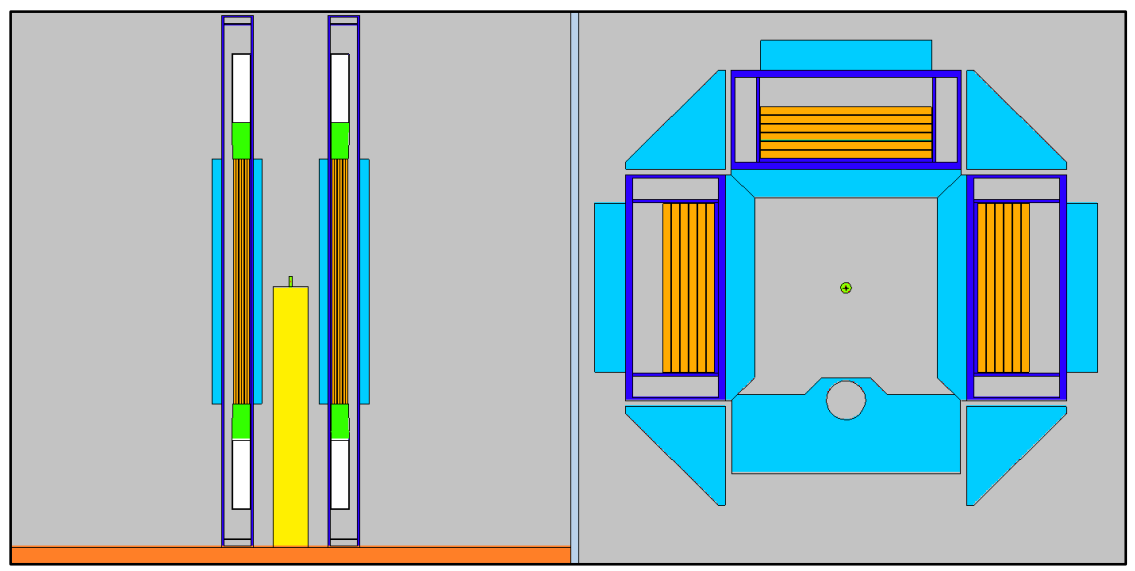

Figure 2.4. PLNS3A-R1 with reversed detector panels, $+1.0 \mathrm{~cm}$ to front, and $+1.5 \mathrm{~cm}$ to lining and backing. 


\section{Gate Width and Pre-Delay of PLNS3A-R1}

To determine and compare the die-away times of the PLNS3A-R1 and the UNCL-II, both models were simulated with an encapsulated ${ }^{252} \mathrm{Cf}$ source in the center on a polyurethane foam (PUF) stand. To show the differences in capture behavior between the fully moderated ${ }^{3} \mathrm{He}$ system and the $\mathrm{LiF} / \mathrm{ZnS}$ system, the simulated total capture efficiencies (TCE) of both models were evaluated as a function of time. The results are shown by the square and diamond shaped symbols in Figure 3.1, where the straight lines are chi-squared fits for a single exponential function.

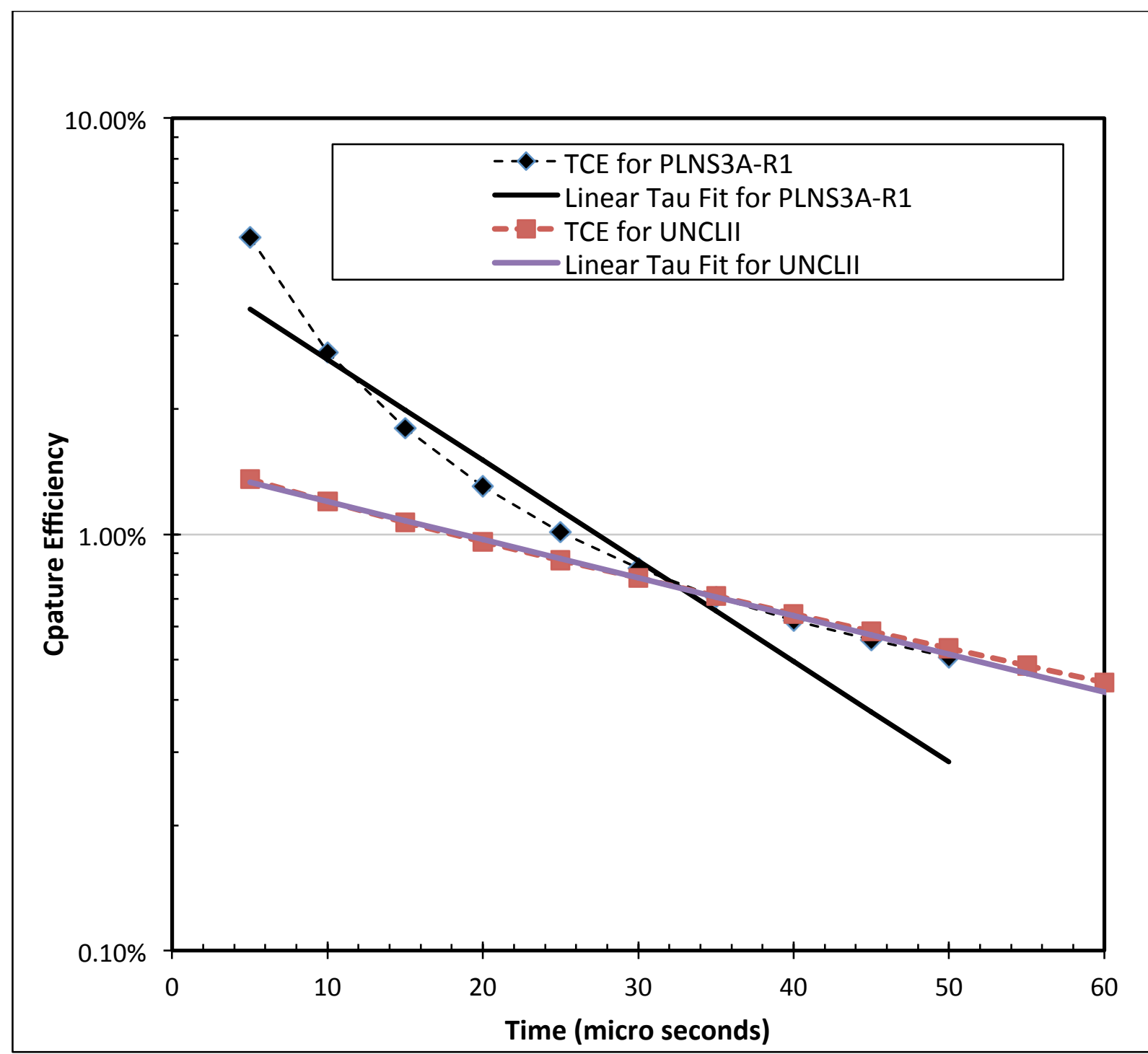

Figure 3.1. Total capture efficiency of the PLNS3A-R1 and the UNCL-II as a function of time.

As seen from this chart, the captures in the fully-moderated UNCL-II follows a single exponential decay over the full range of time, while the PLNS3A-R1 has a more rapid decay that changes over time, providing it with significantly higher total capture efficiency for the first few tens of microseconds. By about $30 \mu \mathrm{s}$, the simulated total capture efficiency of the PLNS3A-R1 has dropped to about the same total 
capture efficiency as the UNCL-II. This behavior suggests that the performance of the PLNS3A-R1should be comparable to the UNCL-II by using a shorter timing gate value for counting.

The PLNS3A-R1 model was evaluated over a range of pre-delay (PD) and gate times to determine if there was a PD and gate combinations that would maximize double counting efficiency for the PLNS family of neutron coincidence counter models, and if so then what that value would be for PLNS3A-R1. The PD times were simulated from $0.25-6.0 \mu \mathrm{s}$, and gate times were simulated from $8.0-64.0 \mu \mathrm{s}$. Two sets of investigations were performed with the first exploring a wider range of gate times, shown in Table 3.1, and the second exploring a wider range of PD times, shown in Table 3.2.

Table 3.1. Doubles capture efficiency as a function of pre-delay and gate times.

\begin{tabular}{|c|c|c|c|c|c|c|}
\hline \multicolumn{7}{|c|}{ Doubles captured/ Cf-252 fission (\%) } \\
\hline Gate $(\mu \mathrm{s})$ & 8.0 & 16.0 & 32.0 & 40.0 & 48.0 & 64.0 \\
\hline \multicolumn{7}{|l|}{$\mathrm{PD}(\mu \mathrm{s})$} \\
\hline 0.50 & 1.00 & 1.54 & 2.16 & 2.37 & 2.55 & 2.70 \\
\hline 1.00 & 0.950 & 1.47 & 2.08 & 2.29 & 2.46 & 2.61 \\
\hline 2.00 & 0.865 & 1.36 & 1.94 & 2.15 & 2.32 & 2.46 \\
\hline 3.00 & 0.793 & 1.26 & 1.82 & 2.02 & 2.19 & 2.34 \\
\hline 4.00 & 0.732 & 1.17 & 1.79 & 1.91 & 2.08 & 2.22 \\
\hline
\end{tabular}

* Values do not include the VCF

Table 3.2. Doubles capture efficiency as a function of pre-delay and gate times.

\begin{tabular}{|c|c|c|c|c|c|c|}
\hline \multicolumn{7}{|c|}{ Doubles captured/ Cf-252 fission (\%) } \\
\hline Gate $(\mu \mathrm{s})$ & 12.0 & 18.0 & 24.0 & 30.0 & 36.0 & 40.0 \\
\hline \multicolumn{7}{|l|}{$\mathrm{PD}(\mu \mathrm{s})$} \\
\hline 0.25 & 1.33 & 1.67 & 1.93 & 2.14 & 2.31 & 2.41 \\
\hline 0.50 & 1.30 & 1.64 & 1.89 & 2.10 & 2.27 & 2.37 \\
\hline 1.00 & 1.24 & 1.57 & 1.82 & 2.02 & 2.19 & 2.29 \\
\hline 2.00 & 1.14 & 1.45 & 1.69 & 1.88 & 2.05 & 2.15 \\
\hline 3.00 & 1.05 & 1.35 & 1.58 & 1.77 & 1.93 & 2.02 \\
\hline 4.00 & 0.975 & 1.26 & 1.48 & 1.66 & 1.82 & 1.91 \\
\hline 5.00 & 0.908 & 1.18 & 1.39 & 1.57 & 1.73 & 1.82 \\
\hline 6.00 & 0.850 & 1.11 & 1.32 & 1.49 & 1.64 & 1.73 \\
\hline
\end{tabular}

Minimized PD values and maximized gate values consistently provide the highest double capture efficiency values. The compiled results of the data presented in Table 3.1 and Table 3.2 can be seen in Figure 3.2. 


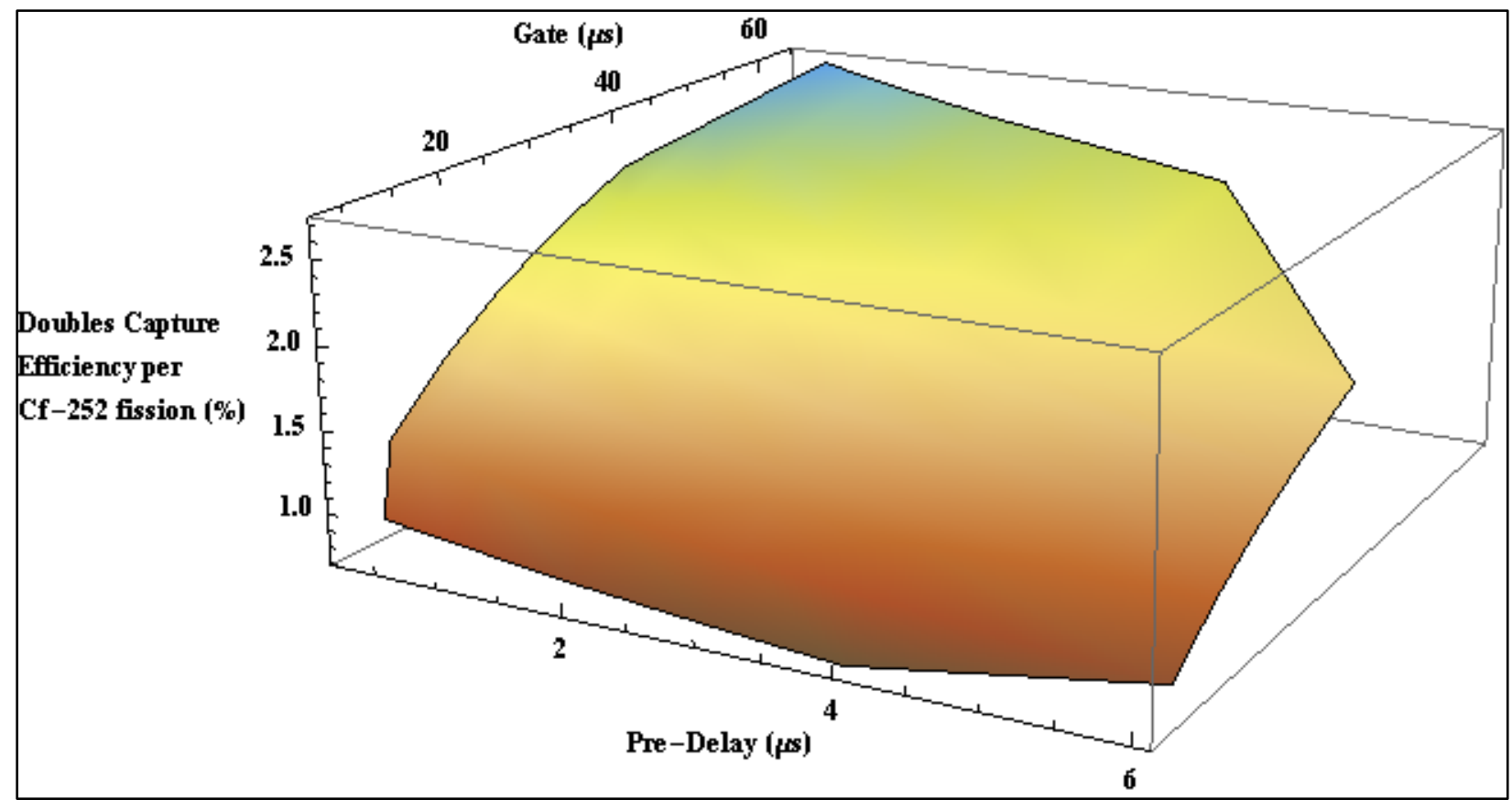

Figure 3.2. Doubles capture efficiency as a function of pre-delay and gate times.

No inflections points appear within the range of PD and gate values investigated. The gate length that gives the lowest relative error for a coincidence counter is roughly 1.26 [Ensslin 1998]. This is a very broad and shallow minimum, so setting the gate width to the nearest convenient value, considering hardware and software limitations, is usually sufficient [Ensslin 1998]. For a die-away time of $18.0 \mu \mathrm{s}$, from Table 9.3 for PLNS3A-R1, the recommended gate width is $22.7 \mu \mathrm{s}$. This was rounded up to $24.0 \mu \mathrm{s}$, which was the gate value used for subsequent simulations involving PLNS3A-R1. The PD has no specific inflection point, so it was picked to be short because of the fast die-away, but longer than a typical pulse. The PD was chosen as $1.5 \mu \mathrm{s}$. 


\section{LEU Fuel in UNCL-II Model}

The next step was to insert a fuel model into the coincidence counter model. This fuel model was first inserted into the UNCL-II model, and then into the PLNS model (see the Appendix for details).

\subsection{Comparison of Endf Libraries}

Because the MCNP cross-section libraries used for the results in this report were updated after the 2013 simulations, variations due to that change alone were important to document. For that purpose, the ${ }^{3} \mathrm{He}-$ based uranium neutron coincidence collar (UNCL-II) detector that had been tested was modeled with $3.19 \mathrm{w} \%{ }^{235} \mathrm{U}$ enriched nuclear fuel [Siciliano 2013]. The UNCL-II system was modeled in MCNPX using a LEU fuel array, as can be seen in Figure 4.1.

The results of these MCNPX model simulations of the UNCL-II with LEU fuel were compared to previous results to ensure the validity of these models. The schematic of the UNCL-II with a LEU fuel array as depicted in Figure 4.1 shows the ${ }^{3} \mathrm{He}$ tubes in dark blue in the HDPE moderator surrounding the fuel bundle. The AmLi source is placed in the open hole in the HDPE block that has no ${ }^{3} \mathrm{He}$ tubes in it.

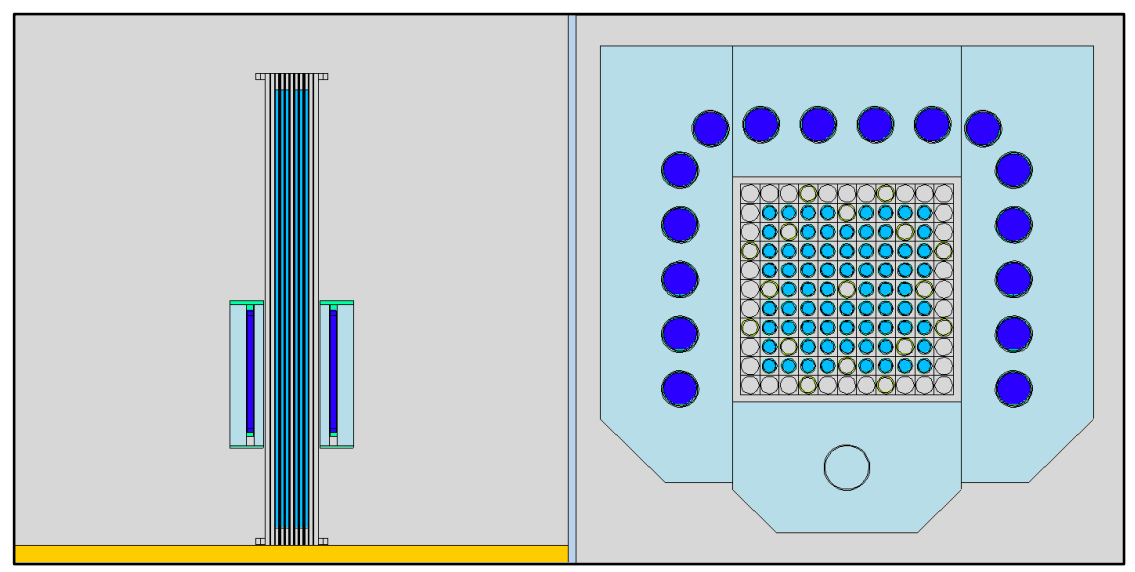

Figure 4.1. UNCL-II neutron coincidence counter with a low enriched uranium nuclear fuel assembly.

To compare to the previous work with this model, simulations were run with the Geiger Zwan and Oblinsk2 AmLi neutron spectra and compared to previous baseline results [Siciliano 2013]. Simulations were run using the Endf 7.0 and the newer Endf 7.1 cross-section libraries to ensure similar results were obtained with the Endf 7.1 library under these conditions. Simulation and previous data results can be seen in Table 4.1, where baseline refers to the data from previous simulations [Siciliano 2013] results.

The data from Table 4.1 displays good agreement between the baseline data sets and the new data with Endf 7.0 and Endf 7.1 with the Geiger Zwan and the Oblinsk2 neutron energy spectra. There is also good agreement between Endf 7.0 and Endf 7.1 data. The Geiger Zwan model will subsequently be used for simulations because of its general acceptance as a valid data set and its good agreement with measured AmLi spectra [Tagziria 2012]. The Endf 7.1 library will be used for subsequent simulations since it is the most complete cross section library at the time of this writing. 
Table 4.1. Simulated results of the UNCL-II with LEU fuel.

\begin{tabular}{|l|l|l|}
\hline \multicolumn{1}{|c|}{ Model } & \multicolumn{1}{|c|}{$\begin{array}{c}\text { cps/ emitted AmLi } \\
\text { neutron (\%) }\end{array}$} & \multicolumn{1}{|c|}{$\begin{array}{c}\text { Doubles captured/ emitted } \\
\text { AmLi neutron (\%) }\end{array}$} \\
\hline Geiger Zwan Baseline & 7.0 & 0.347 \\
\hline Geiger Zwan Endf 7.0 & $6.98 \pm 0.01$ & $0.347 \pm 0.002$ \\
\hline Geiger Zwan Endf 7.1 & $6.98 \pm 0.01$ & $0.349 \pm 0.002$ \\
\hline \multicolumn{2}{|c|}{} \\
\hline Oblinsk2 Baseline & 6.8 & 0.347 \\
\hline Oblinsk2 Endf 7.0 & $6.82 \pm 0.01$ & $0.347 \pm 0.002$ \\
\hline Oblinsk2 Endf 7.1 & $6.80 \pm 0.01$ & $0.345 \pm 0.002$ \\
\hline
\end{tabular}

* Values do not include the VCF

\subsection{UNCL-II Baseline Performance With Fuel}

For the purpose of establishing a baseline of performance UNCL-II was modeled with both $3.19 \mathrm{w} \%{ }^{235} \mathrm{U}$ enriched fuel and $4.50 \mathrm{w} \%{ }^{235} \mathrm{U}$ enriched fuel. Results from these simulations are in Table 4.2.

Table 4.2. Simulation results of the UNCL-II with $3.19 \%$ and $4.50 \%$ enriched fuel

\begin{tabular}{|l|l|l|}
\hline Enrichment & $\begin{array}{l}\text { Total cps/emitted } \\
\text { AmLi neutron (\%) }\end{array}$ & $\begin{array}{l}\text { Doubles captured/ AmLi } \\
\text { neutron (\%) }\end{array}$ \\
\hline $3.19 \mathrm{w} \%{ }^{235} \mathrm{U}$ & $7.20 \pm 0.01$ & $0.321 \pm 0.002$ \\
\hline $4.50 \mathrm{w} \%{ }^{235} \mathrm{U}$ & $7.49 \pm 0.01$ & $0.378 \pm 0.002$ \\
\hline
\end{tabular}

* Values do not include the VCF

Increasing the LEU enrichment form $3.19 \mathrm{w} \%$ to $4.5 \mathrm{w} \%$ is predicted to provide a measurable increase in the total neutron capture efficiency and the doubles capture efficiency of the UNCL-II system.

\subsection{Validation Correction Factor for UNCL-II}

The UNCL-II was also modeled with a steel encapsulated ${ }^{252} \mathrm{Cf}$ source at the center of the system on a polyurethane foam (PUF) stand, similarly to PLNS3A-R1 models, to provide a baseline of TCE, die-away time, and FoM for comparison, as depicted in Figure 4.2.

Results from simulating the UNCL-II with a steel encapsulated ${ }^{252} \mathrm{Cf}$ source on a PUF stand can be seen in the first row of data in Table 4.3. The second and third rows of data in the table contain data from previous measurements and simulations under identical conditions [Siciliano 2013, Croft 2011]. Comparing the previous measurement and simulation a VCF of 0.97 can be determined for UNCL-II systems, which is applied to get the predicted neutron count efficiency and the FoM for the simulation with a steel encapsulated source on a PUF stand (the predicted $\varepsilon=$ VCF $\times$ TCE). This FoM for the steel encapsulated source on a PUF stand in the UNCL-II will be used for comparison to PLNS systems with identical source and stand configurations. 


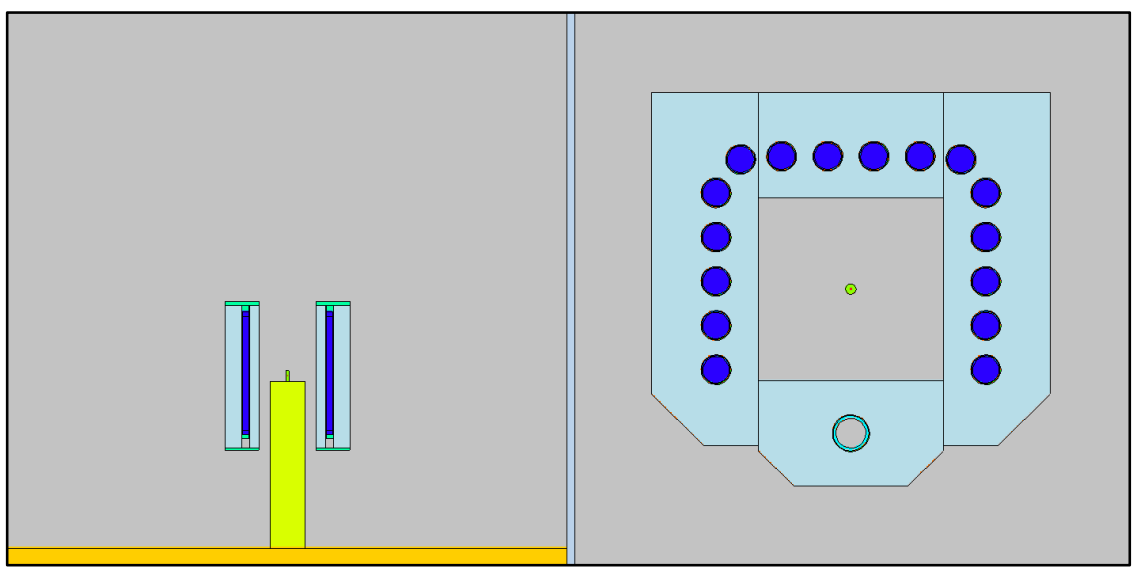

Figure 4.2. UNCL-II with steel encapsulated ${ }^{252} \mathrm{Cf}$ source on polyurethane foam stand.

Table 4.3. Simulation results of UNCL-II with steel encapsulated ${ }^{252} \mathrm{Cf}$ source on polyurethane foam stand.

\begin{tabular}{|l|l|l|l|l|}
\hline \multicolumn{1}{|c|}{ Data Source } & Die-away Time $(\boldsymbol{\mu s})$ & Simulated TCE (\%) & Predicted $\boldsymbol{\varepsilon}(\%)$ & FoM \\
\hline $\begin{array}{l}\text { Simulation with PUF } \\
\text { stand }\end{array}$ & 47.3 & $14.87 \pm 0.01$ & $14.42 \pm 0.01$ & $4.40 \pm 0.004$ \\
\hline $\begin{array}{l}\text { Previous } \\
\text { Measurement }\end{array}$ & $53.0^{*}$ & 14.9 & - & 4.2 \\
\hline Previous Simulation & $58.0^{* *}$ & \multicolumn{1}{|c|}{-} & 15.3 & 4.0 \\
\hline
\end{tabular}

* From [Siciliano 2013]

** From [Croft 2011]

Because there is only a 3\% difference between previously simulated and measured total neutron count efficiency for the UNCL-II, no VCF will be applied to further UNCL-II simulation results in this work. 


\section{Model of Fuel in PLNS3A-R1 Coincidence Counter}

The PLNS3A-R1 model was modified to include the LEU fuel, and then the fuel model was modified to include Gd loaded LEU fuel for select fuel rods. These Gd burnable-poisoned fuel arrays were inserted into the PLNS3A-R1 and UNCL-II models to estimate the doubles capture efficiency (DCE) and assay time of the PLNS3A-R1 and the UNCL-II for various fuel configurations, the PLNS3A-R1 with a nonpoisoned fuel array is depicted in Figure 5.1. Three configurations of positioning Gd loaded fuel within fuel arrays were used, as depicted in Figure 5.2. Array 1 contains four Gd loaded rods, array 2 contains eight Gd loaded rods, and array 3 contains sixteen Gd loaded rods. Each Gd loaded rods consists of $2.0 \mathrm{w} \%{ }^{235} \mathrm{U}$ and an amount of $\mathrm{Gd}$ that varies form $0-12 \mathrm{w} \%$. These simulations were run with the normal fuel rods containing 4.5\% LEU and 3.2\% LEU in an array of 72 total rods. Empty places in the arrays were reserved for instruments and coolant flow through a reactor core.

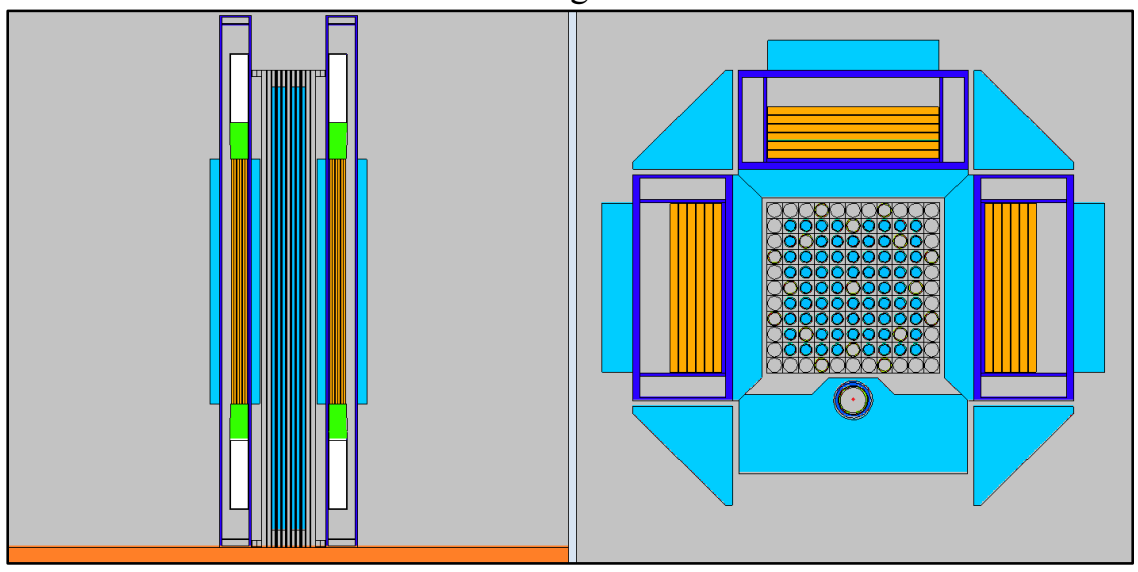

Figure 5.1. PLNS3A-R1 with full LEU fuel array and an active source. Wavelength shifting plastic sandwiched around $\mathrm{LiF} / \mathrm{ZnS}$ material is light orange, HDPE is light blue, LEU fuel within the fuel assembly is light blue, aluminum is dark blue, and the AmLi source is depicted as a red dot.

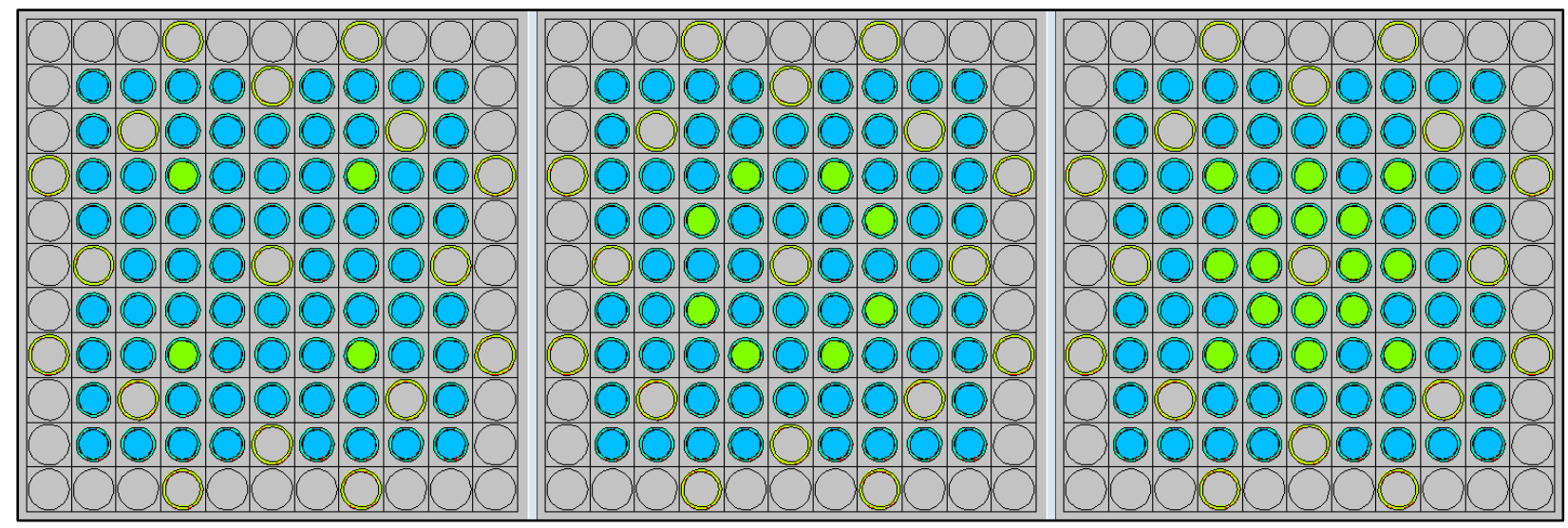

Figure 5.2. Fuel arrays with blue LEU fuel, green Gd loaded fuel, and empty regions for tools and coolant flow. Left: array 1 with four Gd loaded fuel rods. Middle: array 2 with eight Gd loaded fuel rods. Right: array 3 with sixteen Gd loaded fuel rods.

Table 5.1 is divided into sections according to fuel array configuration and LEU enrichment, with fuel arrays with more LEU rods and higher LEU enrichments towards the top and arrays with fewer LEU rods 
and lower LEU enrichment towards the bottom. Each fuel configuration and enrichment set has corresponding simulated doubles capture efficiency per ${ }^{252} \mathrm{Cf}$ fission, which was used as the active source. The PLNS3A-R1 has a column to convert the simulated DCE into predicted doubles capture efficiency (predicted doubles capture efficiency $=\mathrm{VCF}^{2} \mathrm{x} \mathrm{DCE}$ ), which was not included for the UNCL-II since the ratio of the simulated to experimental measurements for the UNCL-II is close to unity. Finally a column was included for the PLNS3A-R1 and the UNCL-II showing the percent double capture efficiency change for a given configuration. Arrays without Gd are used as references.

Table 5.1. Doubles capture efficiency for the UNCL-II and PLNS3A-R1 systems with 4.5\% LEU.

\begin{tabular}{|c|c|c|c|c|c|}
\hline $\begin{array}{l}\text { Fuel Enrichment } \\
\text { and Configuration }\end{array}$ & $\begin{array}{l}\text { UNCL-II } \\
\text { Doubles } \\
\text { Count } \\
\text { Efficiency per } \\
\text { Fission (\%) }\end{array}$ & $\begin{array}{l}\text { UNCL-II Gd } \\
\text { effect change } \\
\text { from } \\
\text { references }(\%)\end{array}$ & $\begin{array}{l}\text { PLNS3A-R1 } \\
\text { Simulated } \\
\text { Doubles } \\
\text { Capture } \\
\text { Efficiency per } \\
\text { Fission (\%) }\end{array}$ & $\begin{array}{l}\text { PLNS3A-R1 } \\
\text { Predicted } \\
\text { Doubles } \\
\text { Count } \\
\text { Efficiency per } \\
\text { Fission (\%) }\end{array}$ & $\begin{array}{l}\text { PLNS3A- } \\
\text { R1 effect } \\
\text { change } \\
\text { from } \\
\text { references } \\
(\%)\end{array}$ \\
\hline All LEU 4.5 fuel & $0.378 \pm 0.002$ & N/A & $0.863 \pm 0.004$ & $0.525 \pm 0.026$ & $\mathrm{~N} / \mathrm{A}$ \\
\hline \multicolumn{6}{|l|}{ Array 1} \\
\hline Gd $0 \%$ (reference) & $0.369 \pm 0.002$ & $\mathrm{~N} / \mathrm{A}$ & $0.845 \pm 0.003$ & $0.514 \pm 0.026$ & $\mathrm{~N} / \mathrm{A}$ \\
\hline Gd 5\% & $0.319 \pm 0.002$ & $-13.6 \pm 0.1$ & $0.733 \pm 0.003$ & $0.446 \pm 0.022$ & $-13.3 \pm 0.1$ \\
\hline Gd 7\% & $0.317 \pm 0.002$ & $-14.1 \pm 0.1$ & $0.729 \pm 0.003$ & $0.444 \pm 0.022$ & $-13.8 \pm 0.2$ \\
\hline $\mathrm{Gd} 9 \%$ & $0.316 \pm 0.002$ & $-14.4 \pm 0.1$ & $0.728 \pm 0.003$ & $0.443 \pm 0.022$ & $-13.9 \pm 0.2$ \\
\hline Gd 10\% & $0.315 \pm 0.002$ & $-14.6 \pm 0.1$ & $0.727 \pm 0.003$ & $0.442 \pm 0.022$ & $-14.0 \pm 0.2$ \\
\hline Gd $11 \%$ & $0.315 \pm 0.002$ & $-14.6 \pm 0.1$ & $0.726 \pm 0.003$ & $0.442 \pm 0.022$ & $-14.1 \pm 0.2$ \\
\hline Gd $12 \%$ & $0.315 \pm 0.002$ & $-14.6 \pm 0.1$ & $0.726 \pm 0.003$ & $0.442 \pm 0.022$ & $-14.1 \pm 0.2$ \\
\hline \multicolumn{6}{|l|}{ Array 2} \\
\hline Gd $0 \%$ (reference) & $0.362 \pm 0.002$ & N/A & $0.827 \pm 0.003$ & $0.503 \pm 0.025$ & N/A \\
\hline Gd 5\% & $0.284 \pm 0.002$ & $-21.5 \pm 0.2$ & $0.660 \pm 0.003$ & $0.401 \pm 0.020$ & $-20.2 \pm 0.2$ \\
\hline Gd 7\% & $0.283 \pm 0.002$ & $-21.8 \pm 0.2$ & $0.656 \pm 0.003$ & $0.399 \pm 0.020$ & $-20.6 \pm 0.2$ \\
\hline Gd 9\% & $0.281 \pm 0.002$ & $-22.4 \pm 0.2$ & $0.651 \pm 0.003$ & $0.396 \pm 0.020$ & $-21.2 \pm 0.2$ \\
\hline Gd 10\% & $0.280 \pm 0.002$ & $-22.7 \pm 0.2$ & $0.649 \pm 0.003$ & $0.395 \pm 0.020$ & $-21.4 \pm 0.2$ \\
\hline Gd 11\% & $0.279 \pm 0.002$ & $-22.9 \pm 0.2$ & $0.648 \pm 0.003$ & $0.394 \pm 0.020$ & $-21.6 \pm 0.2$ \\
\hline Gd 12\% & $0.279 \pm 0.002$ & $-22.9 \pm 0.2$ & $0.647 \pm 0.003$ & $0.394 \pm 0.020$ & $-21.7 \pm 0.2$ \\
\hline \multicolumn{6}{|l|}{ Array 3} \\
\hline Gd $0 \%$ (reference) & $0.345 \pm 0.002$ & $\mathrm{~N} / \mathrm{A}$ & $0.786 \pm 0.003$ & $0.478 \pm 0.024$ & N/A \\
\hline Gd 5\% & $0.246 \pm 0.002$ & $-28.7 \pm$ & $0.576 \pm 0.003$ & $0.351 \pm 0.017$ & $-26.6 \pm 0.3$ \\
\hline Gd 7\% & $0.245 \pm 0.002$ & $-29.0 \pm 0.3$ & $0.568 \pm 0.003$ & $0.345 \pm 0.017$ & $-27.7 \pm 0.3$ \\
\hline Gd 9\% & $0.243 \pm 0.002$ & $-29.6 \pm 0.3$ & $0.562 \pm 0.003$ & $0.342 \pm 0.017$ & $-28.4 \pm 0.3$ \\
\hline Gd 10\% & $0.242 \pm 0.002$ & $-29.9 \pm 0.3$ & $0.560 \pm 0.003$ & $0.341 \pm 0.017$ & $-28.7 \pm 0.3$ \\
\hline Gd 11\% & $0.241 \pm 0.002$ & $-30.1 \pm 0.3$ & $0.558 \pm 0.003$ & $0.340 \pm 0.017$ & $-29.0 \pm 0.3$ \\
\hline Gd $12 \%$ & $0.240 \pm 0.002$ & $-30.4 \pm 0.3$ & $0.556 \pm 0.003$ & $0.338 \pm 0.017$ & $-29.2 \pm 0.3$ \\
\hline
\end{tabular}

$*$ Predicted doubles capture efficiency $=\mathrm{VCF}^{2} \mathrm{x}$ DCE 
Table 5.2. Doubles capture efficiency for the UNCL-II and PLNS3A-R1 systems with 3.2\% LEU.

\begin{tabular}{|c|c|c|c|c|c|}
\hline $\begin{array}{l}\text { Fuel Enrichment and } \\
\text { Configuration }\end{array}$ & $\begin{array}{l}\text { UNCL-II } \\
\text { Doubles } \\
\text { Count } \\
\text { Efficiency per } \\
\text { Fission (\%) }\end{array}$ & $\begin{array}{l}\text { UNCL-II Gd } \\
\text { effect change } \\
\text { from } \\
\text { references } \\
(\%)\end{array}$ & $\begin{array}{l}\text { PLNS3A-R1 } \\
\text { Simulated } \\
\text { Doubles } \\
\text { capture } \\
\text { Efficiency per } \\
\text { Fission (\%) }\end{array}$ & $\begin{array}{l}\text { PLNS3A-R1 } \\
\text { Predicted } \\
\text { Doubles } \\
\text { Count } \\
\text { Efficiency per } \\
\text { Fission (\%) }\end{array}$ & $\begin{array}{l}\text { PLNS3A- } \\
\text { R1 effect } \\
\text { change } \\
\text { from } \\
\text { references } \\
(\%)\end{array}$ \\
\hline All LEU fuel & $0.321 \pm 0.002$ & $\mathrm{~N} / \mathrm{A}$ & $0.733 \pm 0.003$ & $0.446 \pm 0.022$ & N/A \\
\hline \multicolumn{6}{|l|}{ Array 1} \\
\hline Gd $0 \%$ (reference) & $0.313 \pm 0.002$ & $\mathrm{~N} / \mathrm{A}$ & $0.716 \pm 0.003$ & $0.436 \pm 0.022$ & $\mathrm{~N} / \mathrm{A}$ \\
\hline Gd 5\% & $0.264 \pm 0.002$ & $-15.7 \pm 0.2$ & $0.605 \pm 0.003$ & $0.368 \pm 0.018$ & $-15.6 \pm 0.1$ \\
\hline Gd 7\% & $0.264 \pm 0.002$ & $-15.7 \pm 0.2$ & $0.603 \pm 0.003$ & $0.367 \pm 0.018$ & $-15.8 \pm 0.1$ \\
\hline Gd 9\% & $0.263 \pm 0.002$ & $-16.0 \pm 0.2$ & $0.602 \pm 0.003$ & $0.366 \pm 0.018$ & $-16.0 \pm 0.1$ \\
\hline Gd $10 \%$ & $0.262 \pm 0.002$ & $-16.3 \pm 0.2$ & $0.600 \pm 0.003$ & $0.365 \pm 0.018$ & $-16.2 \pm 0.2$ \\
\hline Gd 11\% & $0.262 \pm 0.002$ & $-16.3 \pm 0.2$ & $0.601 \pm 0.003$ & $0.365 \pm 0.018$ & $-16.2 \pm 0.2$ \\
\hline Gd $12 \%$ & $0.262 \pm 0.002$ & $-16.3 \pm 0.2$ & $0.599 \pm 0.003$ & $0.364 \pm 0.018$ & $-16.4 \pm 0.2$ \\
\hline \multicolumn{6}{|l|}{ Array 2} \\
\hline Gd $0 \%$ (reference) & $0.308 \pm 0.002$ & N/A & $0.703 \pm 0.003$ & $0.427 \pm 0.021$ & $\mathrm{~N} / \mathrm{A}$ \\
\hline $\mathrm{Gd} 5 \%$ & $0.231 \pm 0.002$ & $-25.0 \pm 0.3$ & $0.535 \pm 0.003$ & $0.325 \pm 0.016$ & $-23.9 \pm 0.2$ \\
\hline Gd 7\% & $0.231 \pm 0.002$ & $-25.0 \pm 0.3$ & $0.531 \pm 0.003$ & $0.323 \pm 0.016$ & $-24.4 \pm 0.2$ \\
\hline Gd 9\% & $0.230 \pm 0.002$ & $-25.3 \pm 0.3$ & $0.528 \pm 0.003$ & $0.321 \pm 0.016$ & $-24.9 \pm 0.2$ \\
\hline Gd 10\% & $0.229 \pm 0.002$ & $-25.6 \pm 0.3$ & $0.526 \pm 0.003$ & $0.320 \pm 0.016$ & $-25.1 \pm 0.2$ \\
\hline Gd $11 \%$ & $0.228 \pm 0.002$ & $-26.0 \pm 0.3$ & $0.527 \pm 0.003$ & $0.320 \pm 0.016$ & $-25.0 \pm 0.2$ \\
\hline Gd $12 \%$ & $0.228 \pm 0.002$ & $-26.0 \pm 0.3$ & $0.525 \pm 0.003$ & $0.319 \pm 0.016$ & $-25.3 \pm 0.2$ \\
\hline \multicolumn{6}{|l|}{ Array 3} \\
\hline Gd 0\% (reference) & $0.290 \pm 0.002$ & N/A & $0.662 \pm 0.003$ & $0.403 \pm 0.020$ & N/A \\
\hline Gd 5\% & $0.199 \pm 0.002$ & $-31.4 \pm 0.4$ & $0.457 \pm 0.003$ & $0.278 \pm 0.014$ & $-30.9 \pm 0.2$ \\
\hline Gd 7\% & $0.198 \pm 0.002$ & $-31.7 \pm 0.4$ & $0.452 \pm 0.002$ & $0.275 \pm 0.014$ & $-31.7 \pm 0.3$ \\
\hline Gd 9\% & $0.197 \pm 0.002$ & $-32.1 \pm 0.4$ & $0.450 \pm 0.002$ & $0.274 \pm 0.014$ & $-32.0 \pm 0.3$ \\
\hline Gd $10 \%$ & $0.195 \pm 0.002$ & $-32.8 \pm 0.4$ & $0.449 \pm 0.002$ & $0.273 \pm 0.014$ & $-32.2 \pm 0.3$ \\
\hline Gd $11 \%$ & $0.195 \pm 0.002$ & $-32.8 \pm 0.4$ & $0.448 \pm 0.002$ & $0.273 \pm 0.014$ & $-32.3 \pm 0.3$ \\
\hline Gd $12 \%$ & $0.194 \pm 0.002$ & $-33.1 \pm 0.4$ & $0.444 \pm 0.002$ & $0.270 \pm 0.013$ & $-32.9 \pm 0.3$ \\
\hline
\end{tabular}

$*$ Predicted doubles capture efficiency $=\mathrm{VCF}^{2} \mathrm{x}$ DCE

Data from Table 5.1 and Table 5.2 shows a significant increase in doubles capture efficiency when going from the UNCL-II to the PLNS3A-R1, across all fuel configurations, enrichments, and Gd concentrations.

Figures 5.3, 5.4, and 5.5 depict the predicted doubles capture efficiency of PLNS3A-R1 and the UNCL-II as a function of $\mathrm{Gd} \mathrm{w} \%$. Each figure depicts data for a different fuel array configuration, displayed in order of highest to lowest number of LEU rods. 


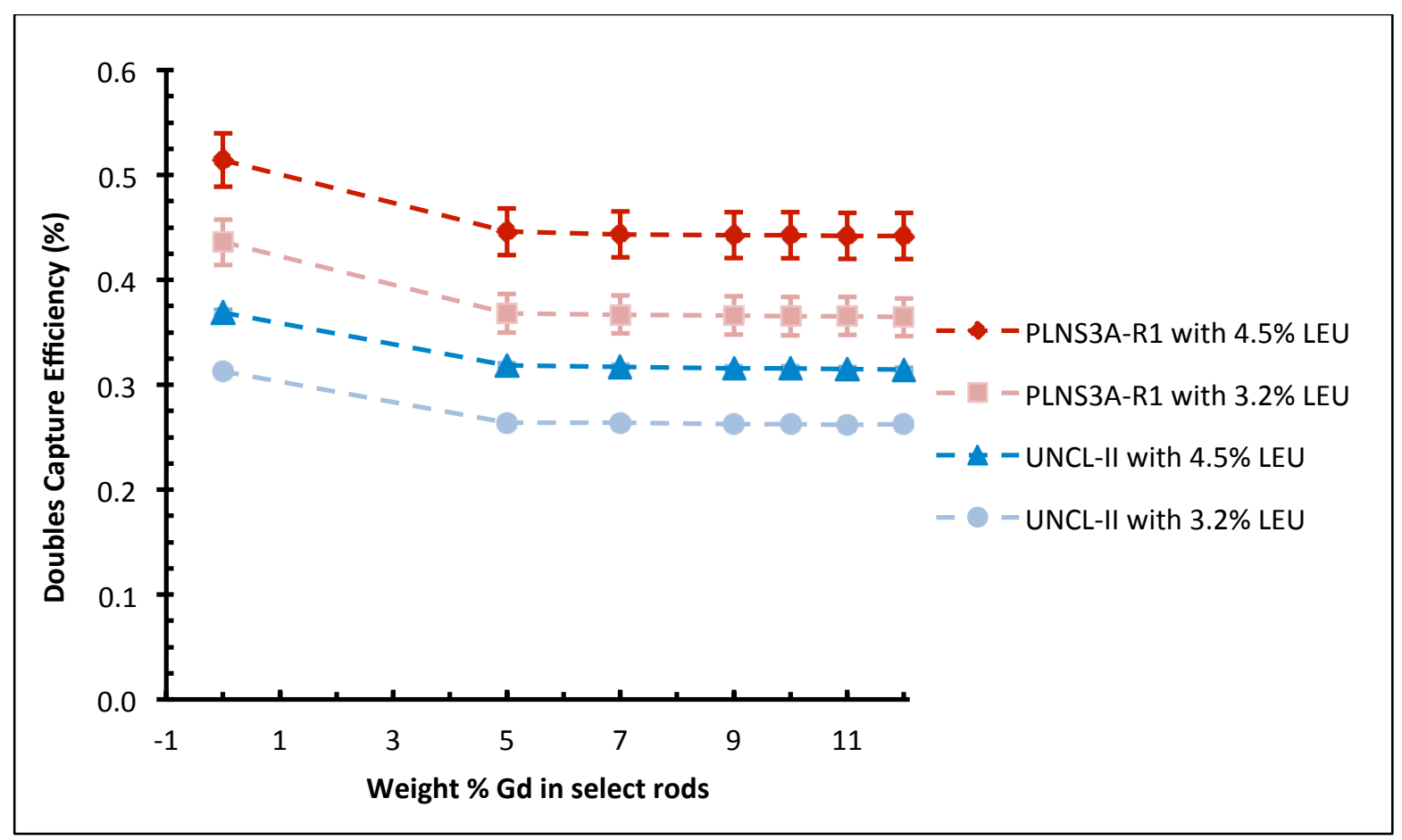

Figure 5.3. Array 1: Double Capture Efficiency per fission (\%).

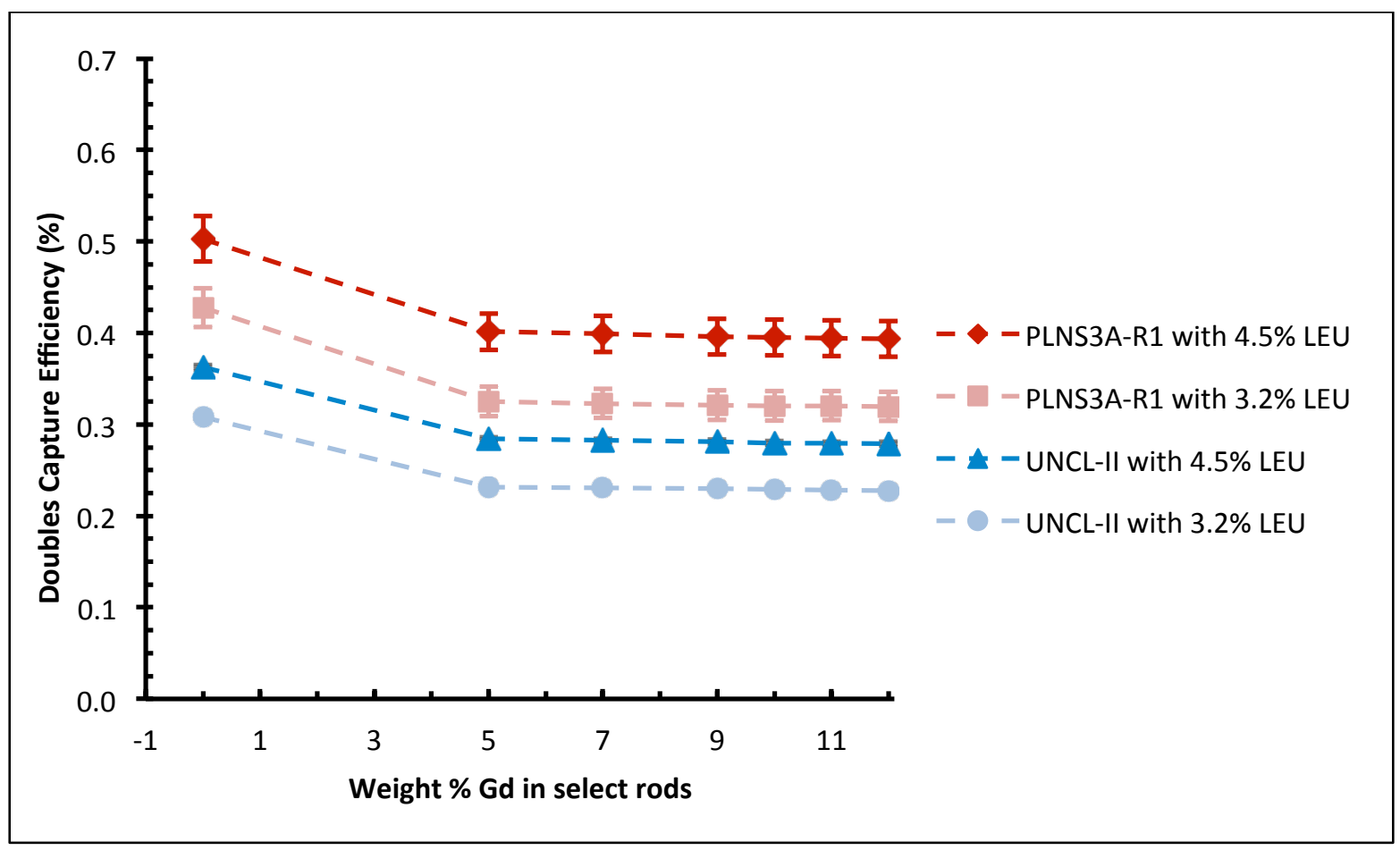

Figure 5.4. Array 2: Double Capture Efficiency per fission (\%). 


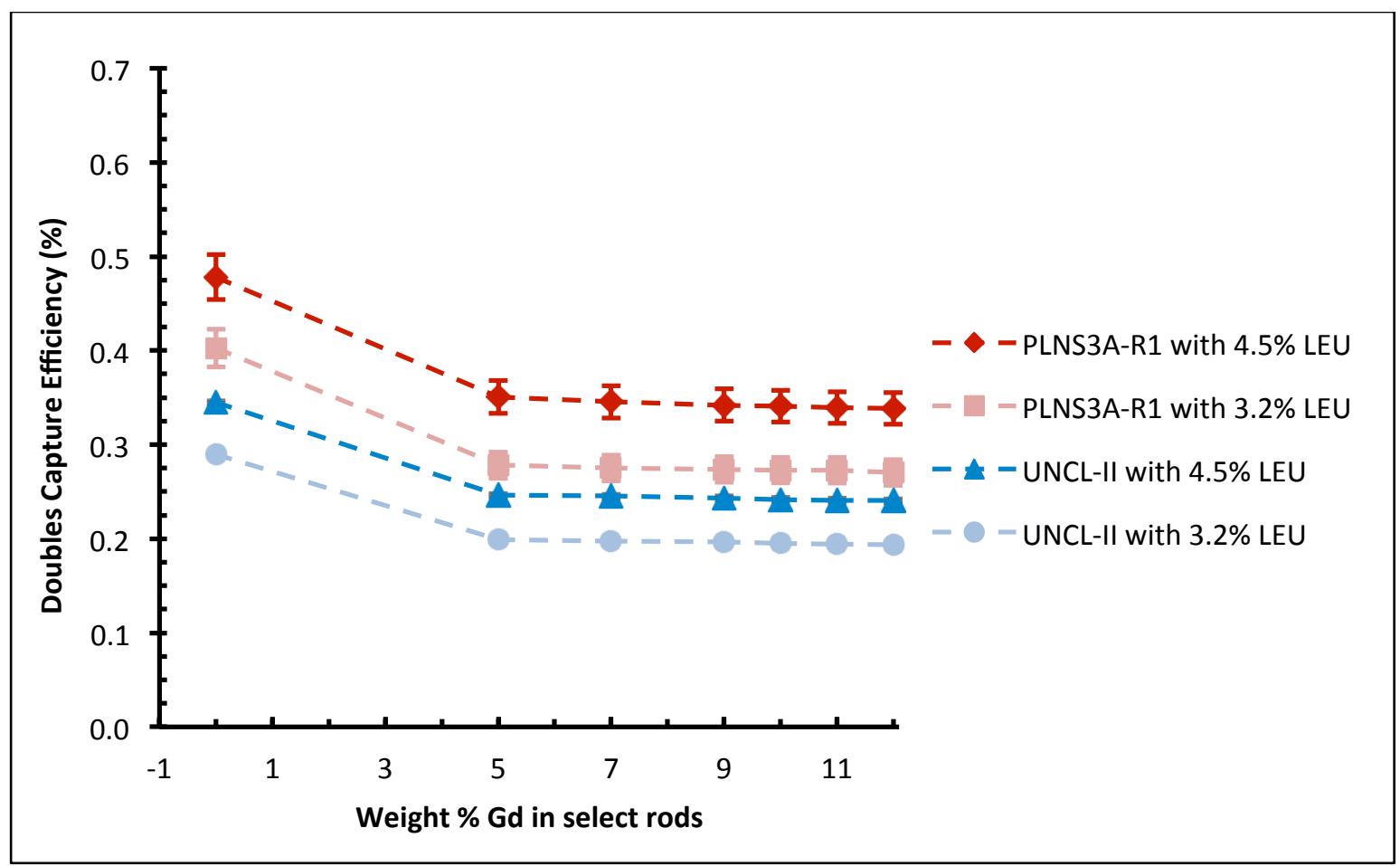

Figure 5.5. Array 3: Double Capture Efficiency per fission (\%).

The UNCL-II and PLNS3A-R1 both display a rapid saturation trend in response to increasing Gd concentration in the fuel. Addition of Gd beyond 5\% into fuel does not significantly reduce the doubles capture efficiency of the system for the UNCL-II and the PLNS3A-R1.

The statistical precision of assay measurements was estimated for an AmLi source of $2 \times 10^{4} \mathrm{n} / \mathrm{s}$, for a $600 \mathrm{~s}(10$ minute) measurement period and the predicted doubles capture efficiency, in the normal manner as the square root of counts over counts, as in Equation 5.1.

$$
\text { Equation 5.1 Assay Precision }=\left(\sqrt{\varepsilon_{\text {Doubles }} * A * t}\right)^{-1}
$$

Where $\varepsilon_{\text {Double }}$ is the predicted doubles count efficiency, $\mathrm{A}$ is the AmLi source neutron activity, and $\mathrm{t}$ is the assay time. Assay precision estimates were performed over the range of configurations form Table 5.1 and Table 5.2. The UNCL-II had a statistical uncertainty of $0.5-0.7 \%$ for assays, and the PLNS3A-R1 had a statistical uncertainty of $0.4-0.6 \%$ for assays. 


\section{Conclusions}

This report presented results of simulations based upon the PNNL Li-based Neutron Scintillation counter (PLNS) - a demonstration system using $\mathrm{LiF} / \mathrm{ZnS}$ sheets for neutron detection. The results of this study indicate that a lithium-based active PWR coincidence counter, with its short die-away time, may be capable of making measurements on Gd-loaded low enriched uranium fuel in a reasonable period of time.

Starting with a validated model of this system, a number of variations were constructed to explore improvements for use as both a passive and active applications. An optimized active configuration was used to evaluate its performance in examining LEU fuel in a BWR fuel array with and without Gd loaded fuel. Simulation results were compared to those evaluated for a model of the UNCL-II, one of the standard ${ }^{3} \mathrm{He}$-based counters used for such applications.

The PLNS3A-R1 model displayed the most promise as a potential system capable of meeting or exceeding UNCL-II performance for passive and active coincidence counting. The PLNS3A-R1 had a FoM of 18.7, four times greater than the UNCL-II's FoM of 4.4. The PLNS3A-R1 also displayed improved performance in counting fission events from Gd loaded fuel compared to UNCL-II. Future research will be required to measures the performance of the PLNS3A-R1, or a similar configuration, and the performance of the UNCL-II with identical fuel configurations. Future research may also be used to further refine the PLNS3A-R1 design to optimize the figure-of-merit.

A comparison of lithium-based coincidence counter simulations and ${ }^{3} \mathrm{He}$-based UNCL-II simulations with and without Gd loaded fuel is provided in Table 6.1. All values are simulation results except the measured UNCL-II. The lithium-based PLNS3A-R1, showed strong promise for assaying Gd loaded fuel to 1\% precision in 10 minutes, with better performance (in simulation) than a ${ }^{3} \mathrm{He}$-based UNCL modified to measure Gd-loaded fuel. This detector should be able to obtain 1\% precision in 10 minutes, which cannot be obtained with the other detectors evaluated.

Future work would be to assemble the prototype of this detector and test its performance against the predictions provided in this study.

Table 6.1. Comparison of various coincidence counter performance parameters.

\begin{tabular}{|l|l|c|c|c|c|}
\hline \multicolumn{1}{|c|}{ Detector } & Configuration & $\begin{array}{c}\text { Die Away Time } \\
(\boldsymbol{\mu} \mathbf{s})\end{array}$ & $\begin{array}{c}\boldsymbol{\varepsilon} \\
(\mathbf{\%})\end{array}$ & FOM & $\begin{array}{c}\text { Approximate Assay } \\
\text { Precision in 10 minutes }\end{array}$ \\
\hline${ }^{3} \mathrm{He}$ UNCL II & Standard & 53 & 12.3 & 2.9 & $6 \%$ \\
\hline $\mathrm{UNCL}$ & Cd liner & 28 & 15.7 & 8.8 & $3 \%$ \\
\hline${ }^{6} \mathrm{LiF} / \mathrm{ZnS}$ & PLNS-3 & 21 & 16.7 & 13.2 & $2 \%$ \\
\hline${ }^{6} \mathrm{LiF} / \mathrm{ZnS}$ & PLNS3A-R1 & 18 & 18.7 & 18.7 & $1 \%$ \\
\hline
\end{tabular}

* Values for efficiency include the VCF 


\section{Appendix: Characteristics of PLNS4 Configurations Studied}

To ensure the validity of future simulation results and the validity of using the Endf 7.1 cross section library, simulation results were compared to previous simulation results presented in the Final Technical Report for the Neutron Detection Without Helium-3 Project [Ely 2013a], which is used as a baseline of comparison. These models of the PLNS system use a ${ }^{252} \mathrm{Cf}$ point source situated on top center of the source stand consisting of cellulose and aluminum. A schematic of the PLNS model can be seen in Figure 7.1. An initial comparison was performed by modeling and simulating PLNS with identical source and environmental conditions to those of the simulation used for the Final Report. This comparison model will be referred to a PLNS-2013.

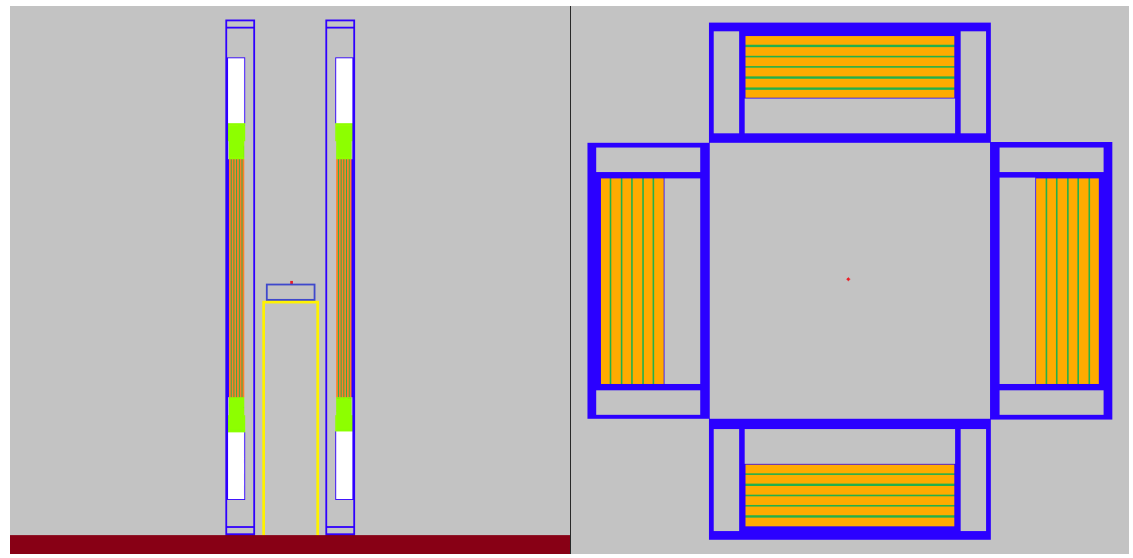

Figure 7.1. Model of the PLNS-2013 system used as a baseline for model comparison. Although a point source was used, a small red dot is depicted to designate the location of the ${ }^{252} \mathrm{Cf}$ source.

Excel Workbooks have been designed to interface with MCNPX mctal files for the simulations used in this study for automating reading, analyzing, and charting results. Such analysis tools have enabled rapid and consistent comparisons of changes made in the search for optimal alternative configurations. These Excel Workbooks (called "MCTALreaders") were developed, tested, and put into use for all subsequent evaluations.

The MCTALreaders take advantage of a simulated shift register ${ }^{2}$ to determine doubles rates. A pulse train of neutron events may contain relatively few real coincidences (R) and many accidental coincidences (A). The real events do not stand out in any obvious way from the background of accidental events in the pulse train. When an event from a pulse train is detected, pulse pileup and electronic dead times can perturb the detection system, so it is customary to begin analysis after a pre-delay time (P). Additional coincidences will be recorded for a predetermined gate width $(\mathrm{G})$, which will be a combination of real and accidental coincidences. In order to correct for these accidental events, it is necessary to add a long delay and then measure coincidences from a second gate. If this delay (D) is much longer than the die-away time $(\tau)$ in the detector, the pulses from the second gate will only be accidental events. Taking these time lengths and the singles pulse train signal (S) into account, the number of real coincidences can be calculated, and

\footnotetext{
${ }^{2}$ A shift register inspects the signal pulses produced by a neutron detector, a pulse train, where each pulse represents a single neutron detection event. This input is a distribution of events in time. The observed distribution is produced by some combination of spontaneous fissions, induced fissions, $(\alpha, n)$ reactions, and background events. Fission events produce neutrons that are time correlated and the $(\alpha, n)$ reactions and background tend to yield uncorrelated single neutrons.
} 
taking the number of accidentals and reals into account, then the die-away time can be calculated from Equations 7.1 and 7.2 [Reilly 1991].

$$
\begin{array}{ll}
\text { Equation 7.1 } & R=\frac{(R+A) \text { scalar }-(A) \text { scalar }}{e^{-P / \tau}\left(1-e^{-G / \tau}\right)\left(1-e^{-(D+G) / \tau}\right)} e^{\mathrm{GT}} \\
\text { Equation 7.2 } & S(t)=A+\mathrm{Re}^{-t / \tau}
\end{array}
$$

where $t$ is time and $T$ is the accidental rate. These two equations together can be used to determine the number of real doubles, and the die-away time, for any given set of gate and pre-delay values. The dieaway time is typically determined by fitting the results from varying the gate width. The MCTALreaders utilize the pre-delay and gate width along with the simulation results to estimate the doubles rate and the die-away time for the configuration being simulated, assuming a single exponential represents the dieaway time.

Minimizing the gate time minimizes the number of accidental coincidences counted but also excludes identifications of coincident neutrons detected beyond the gate width. Maximizing the pre-delay time minimizes the perturbation from pulse pile up and electronics dead time but increases the number of pulses left uncounted in the pre-delay. A system should be simulated over a range of gates and pre-delays to determine the optimal gate and pre-delay values for that specific model.

In the simulation data, the doubles rates as a function of the gate width and pre-delay times are used to determine the values for the die-away time $(\tau)$. Using the doubles rates provides a more direct comparison to values resulting from actual shift register measurements, and gives more accurate die-away values, particularly for the few-microsecond region in the response of the PLNS system.

The MCNPX simulations end with the neutron capture in ${ }^{6} \mathrm{Li}$, and so the result is the total capture efficiency, which does not include the light collection effects. In the ideal physical system the neutrons captured in ${ }^{6} \mathrm{Li}$ will produce oppositely directed triton and alpha particles. These energetic particles deposit energy in the $\mathrm{ZnS}(\mathrm{Ag})$ scintillator material causing the release of light. This scintillation light leaves the $\mathrm{LiF} / \mathrm{ZnS}(\mathrm{Ag})$ mixture and is partially absorbed in the wavelength shifting plastic, which then emits green light isotropically. This green light will scatter within the light guide and be absorbed, lost or produce a signal in a photomultiplier tube (PMT). The electrical signal from the PMT is recorded with electronics for analysis. Because physical systems are never ideal systems, there are signal losses between the neutron capture in ${ }^{6} \mathrm{Li}$ and the final signal recoded for analysis. The ratio of the measured to the simulated total neutron capture efficiency (TCE) is taken as the Validation Correction Factor (VCF), which is determined by a specific measurement compared with the model result for the same configuration. For further models, multiplying the simulated TCE by the VCF provides the predicted neutron detection efficiency $(\varepsilon)$. After accounting for the steel encapsulated ${ }^{252} \mathrm{Cf}$ source and re-assaying the source activity, the VCF for the baseline system has been measured to be $0.78 \pm 0.03$. ${ }^{3}$ This VCF is assumed to be reasonably consistent for all systems closely related to the baseline, and was applied for the results of this project.

For this project, the Figure-of-Merit (FoM) defined in the past for an optimized ${ }^{3}$ He based coincidence counters was used, which provides a metric for optimization. The formula for this metric uses the neutron detection efficiency (as a measure of the signal) and the die-away time. Neutron capture efficiency is dependent on the location and energy distribution of the source. For this project the source was assumed to always be located in the middle of the vertical center of the detector system except when otherwise

\footnotetext{
${ }^{3}$ The VCF value of $0.84 \pm 0.12$ reported previously [Ely 2013] was revised to 0.82 to account for the non-point source, then was revised to $0.78 \pm 0.03$, due to an accurate measurement of the source strength, and this value is used in this report. Using doubles counts instead of total neutron counts gave a VCF of $0.77 \pm 0.04$, similar to the singles result.
} 
stated, and a ${ }^{252} \mathrm{Cf}$ energy spectrum was used for determining the FoM. For the comparison of models the following formula was used to determine FoM:

$$
\text { Equation } 7.3 \quad F O M=\frac{\varepsilon^{2}}{\tau}
$$

A statistical identity between the total neutron capture efficiency and die-away time are required to ensure validity the PLNS-2013 model compared to the baseline model. The baseline simulation analysis relied on die-away time estimates from total capture efficiency rather than coincidences, therefore the die-away times in this section were determined with the same method. Results of the baseline simulation and new model simulations can be seen in Table 7.1, showing the die-away time, the total capture efficiency, and the resulting predicted efficiency that includes the VCF of 0.78 . Table 7.1 and subsequent tables use the full numeric results from MCNPX outputs for calculations, although rounded numbered are reported in the tables.

Table 7.1. PLNS-2013 and Baseline simulation results

\begin{tabular}{|l|l|l|l|l|}
\hline Data Source & Die-away time $(\boldsymbol{\mu s})$ & Simulated TCE $(\%)$ & Predicted $\boldsymbol{\varepsilon}(\%)$ & FoM \\
\hline Baseline [Ely 2013a] & 11.8 & $7.50 \pm 0.08$ & $5.85 \pm 0.51$ & $2.88 \pm 0.27$ \\
\hline $\begin{array}{l}\text { PLNS-2013 } \\
\text { simulation }\end{array}$ & 11.9 & $7.50 \pm 0.01$ & $5.85 \pm 0.20$ & $2.88 \pm 0.14$ \\
\hline
\end{tabular}

* Values for efficiency include the VCF

From Table 7.1 a high level of agreement can been seen between the total neutron capture efficiency and the die-away time between the baseline and PLNS-2013 results. Minor differences in total neutron capture efficiency uncertainty and die-away time can be attributed to using Endf 7.1 cross section libraries instead of the Endf 7.0 libraries that were used when models for the Final Report were being simulated. This agreement of data validates the use of this PLNS-2013 model as a baseline for further model development.

The comparison model was then modified to replace the ${ }^{252} \mathrm{Cf}$ point source with a non-point-sized ${ }^{252} \mathrm{Cf}$ source encapsulated in steel, called PLNS-4. This source configuration matches the physical sources often used in experiments and will be used in later models and simulations.

The addition of steel encapsulation around the ${ }^{252} \mathrm{Cf}$ source is expected to provide some neutron moderation, and thus increase the total neutron capture efficiency in under moderated systems, such as the PLNS system. The change in die-away time from this small addition of steel should have minimal effects on the die-away time. A comparison of the PLNS-2013 simulation results to PLNS-4 simulation results can be seen in Table 7.2. As seen from this table, the addition of the encapsulated ${ }^{252} \mathrm{Cf}$ source into the PLNS-2013 model causes small changes to the efficiency and die-away-time that are within statistical variations.

Table 7.2. PLNS-4 and PLNS-2013 simulation results

\begin{tabular}{|l|l|l|l|c|}
\hline \multicolumn{1}{|c|}{ Data Source } & Die-away time $(\boldsymbol{\mu} \mathbf{s})$ & Simulated TCE (\%) & Predicted $\boldsymbol{\varepsilon}(\mathbf{\%})$ & FoM \\
\hline $\begin{array}{l}\text { PLNS-2013 } \\
\text { Simulation }\end{array}$ & 11.9 & $7.50 \pm 0.01$ & $5.85 \pm 0.20$ & $2.88 \pm 0.14$ \\
\hline PLNS-4 Simulation & 11.9 & $7.74 \pm 0.01$ & $6.04 \pm 0.21$ & $3.07 \pm 0.15$ \\
\hline
\end{tabular}

* Values for predicted efficiency include the VCF 
The first modification to the PLNS 2013 starting model was displacement of the four detection "panels" by $0.5 \mathrm{~cm}$ each, to accommodate the dimensions of a BWR fuel assembly holder. This slightly wider configuration and all others based upon it are referred to as PLNS4. A ${ }^{252} \mathrm{Cf}$ source was used for comparison to previous simulations. The cellulose and aluminum stand used for the 2013 model and experiments were replaced with low-density polyurethane foam (PUF) to minimize the interactions of the source support in the simulations, and another model was created with no source holder. Because PLNS is an under moderated system, the first modification was to add four blocks of high-density polyethylene (HDPE) to the corners of the system. But addition of HDPE, particularly from the sides of the detection panels, not only increases neutron capture efficiency, but also the die-away time. A schematic of PLNS4 with poly can be seen in Figure 7.2. PLNS4 was modeled with and without HDPE blocks for comparison. A comparison of the PLNS4 simulation results is shown in Table 7.3. The VCF value used to convert from TCE to efficiency $\varepsilon$ was 0.78 .

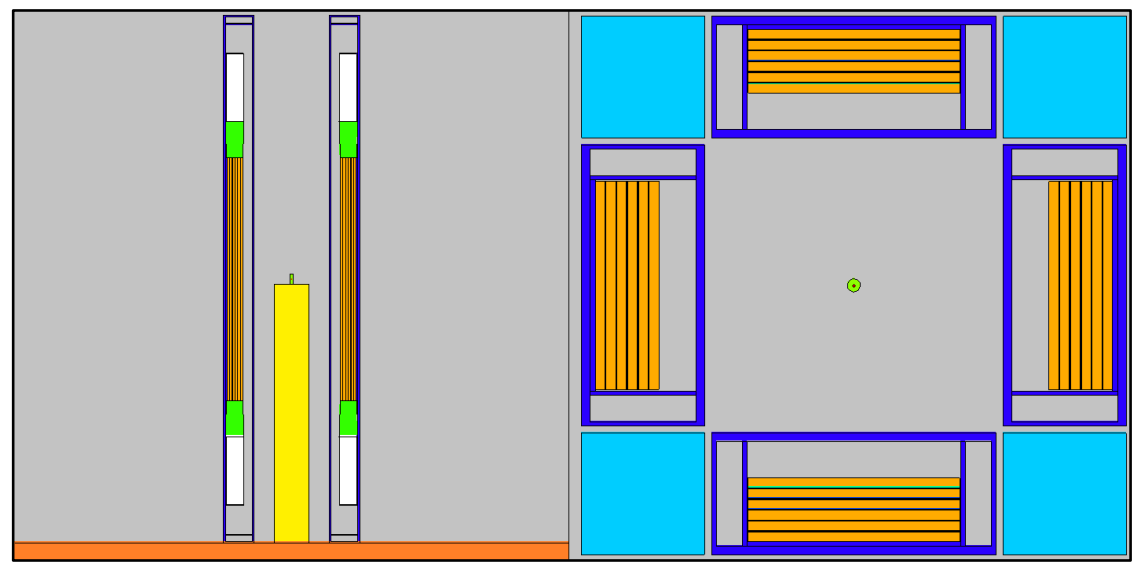

Figure 7.2. PLNS4 with ${ }^{252} \mathrm{Cf}$ source, polyurethane foam source stand, HDPE corners.

Table 7.3. PLNS4 simulations results

\begin{tabular}{|l|l|l|l|l|}
\hline \multicolumn{1}{|c|}{ Data Source } & \multicolumn{1}{|c|}{$\begin{array}{c}\text { Die-away } \\
\text { time }(\boldsymbol{\mu s})\end{array}$} & Simulated TCE (\%) & Predicted $\boldsymbol{\varepsilon}(\%)$ & FoM \\
\hline PLNS4 no stand air corners & 10.4 & $6.88 \pm 0.01$ & $5.37 \pm 0.19$ & $2.76 \pm 0.14$ \\
\hline PLNS4 PUF stand air corners & 10.4 & $6.91 \pm 0.01$ & $5.39 \pm 0.19$ & $2.80 \pm 0.14$ \\
\hline PLNS4 no stand poly corners & 15.5 & $13.11 \pm 0.01$ & $10.22 \pm 0.36$ & $6.75 \pm 0.33$ \\
\hline $\begin{array}{l}\text { PLNS4 PUF stand poly } \\
\text { corners }\end{array}$ & 15.5 & $13.17 \pm 0.01$ & $10.27 \pm 0.36$ & $6.81 \pm 0.34$ \\
\hline
\end{tabular}

* Values for predicted efficiency include the VCF

As seen from Table 7.3, increasing the distance of the detector panels from the source and replacing the cellulose and aluminum stand with PUF or air caused small reductions in the total neutron capture efficiency and die-away time. Adding HDPE moderator significantly increased the total neutron capture efficiency and die-away time. PLNS4 with a PUF source stand is used as the base model for subsequent simulations in this paper because of its compatibility with BWR fuel assembly measurements.

PLNS-2013 and PLNS4 each have a doubles capture rate efficiency versus gate curve giving each of them a characteristic die-away time for given gate and pre-delay values, as seen in Figure 7.3. From Figure 7.3 it can be seen that PLNS and PLNS-4 have die-away times of $10.5 \mu \mathrm{s}$, and PLNS4 doubles has a die-away time of $15.5 \mu \mathrm{s}$. 


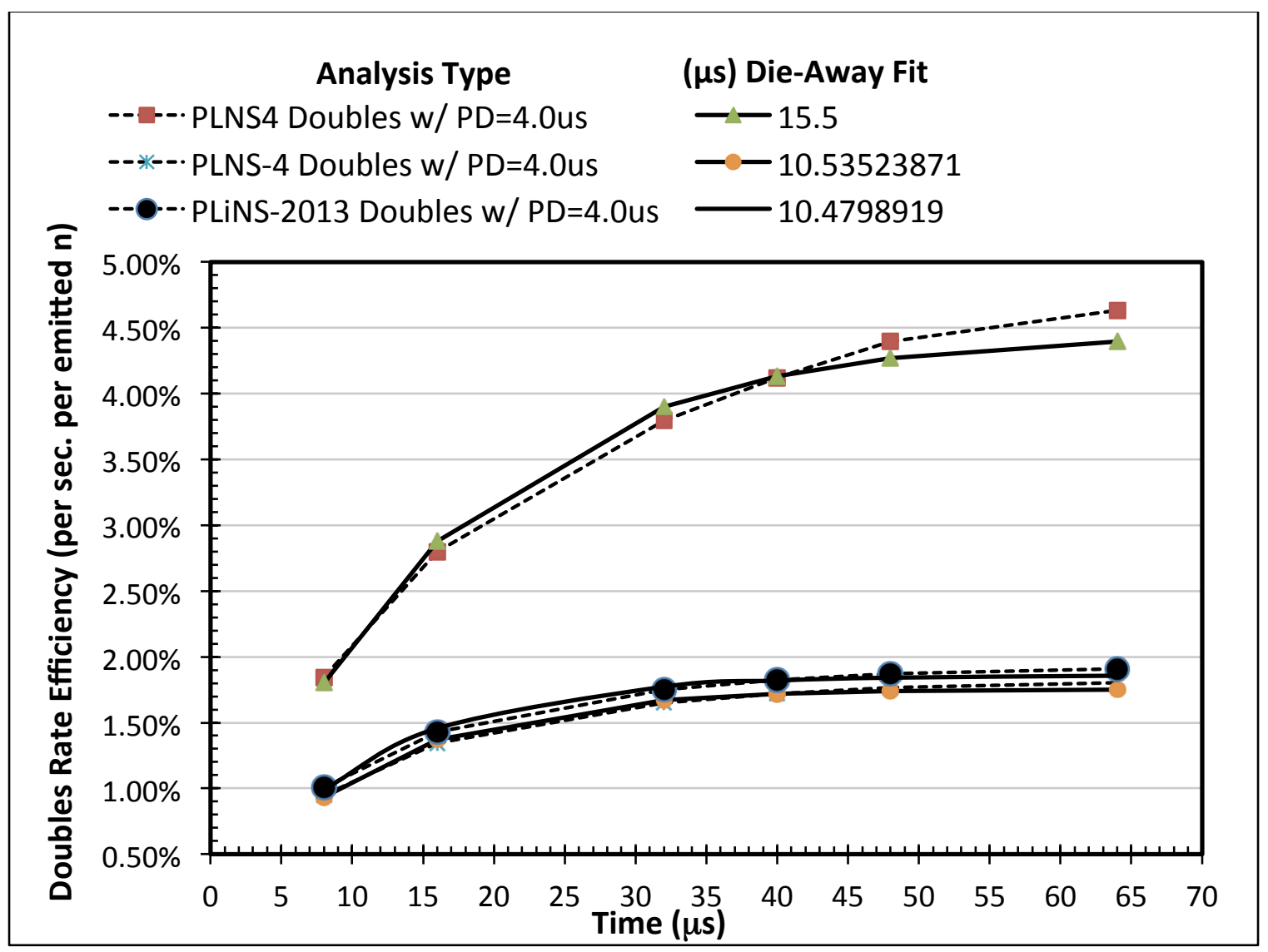

Figure 7.3. Doubles rate efficiency versus gate times with fixed pre-delay and fitted curves. These curves can be used to determine the charactaristic die-away time for conicidences. 


\section{Appendix: Comparison of Position and Energy Profiles}

To test the position and energy dependence of sources within the PLNS system, the source position and source spectrum within the PLNS4 model were varied and simulations ran with and without HDPE corners. For an energy spectrum change, the ${ }^{252} \mathrm{Cf}$ energy spectrum was replaced with a monoenergetic spectrum that approximately doubles in energy from one model to the next. For position changes, the vertical position of the ${ }^{252} \mathrm{Cf}$ source was changed in increments of $2.16 \mathrm{~cm}(0.850 \mathrm{in})$ along the centerline of the detector.

The energy spectrum simulations ranged from $0.01 \mathrm{eV}$ to $10 \mathrm{MeV}$, increasing in energy in steps of two, two, and two and one half times the previous energy point. This ensured three total neutron capture efficiency simulations per order of magnitude. Results from the energy profile simulations can be seen in Figure 8.1. The efficiency decreased from a peak of $\sim 45 \%$ at around $1 \mathrm{eV}$ to near zero at $10 \mathrm{MeV}$.

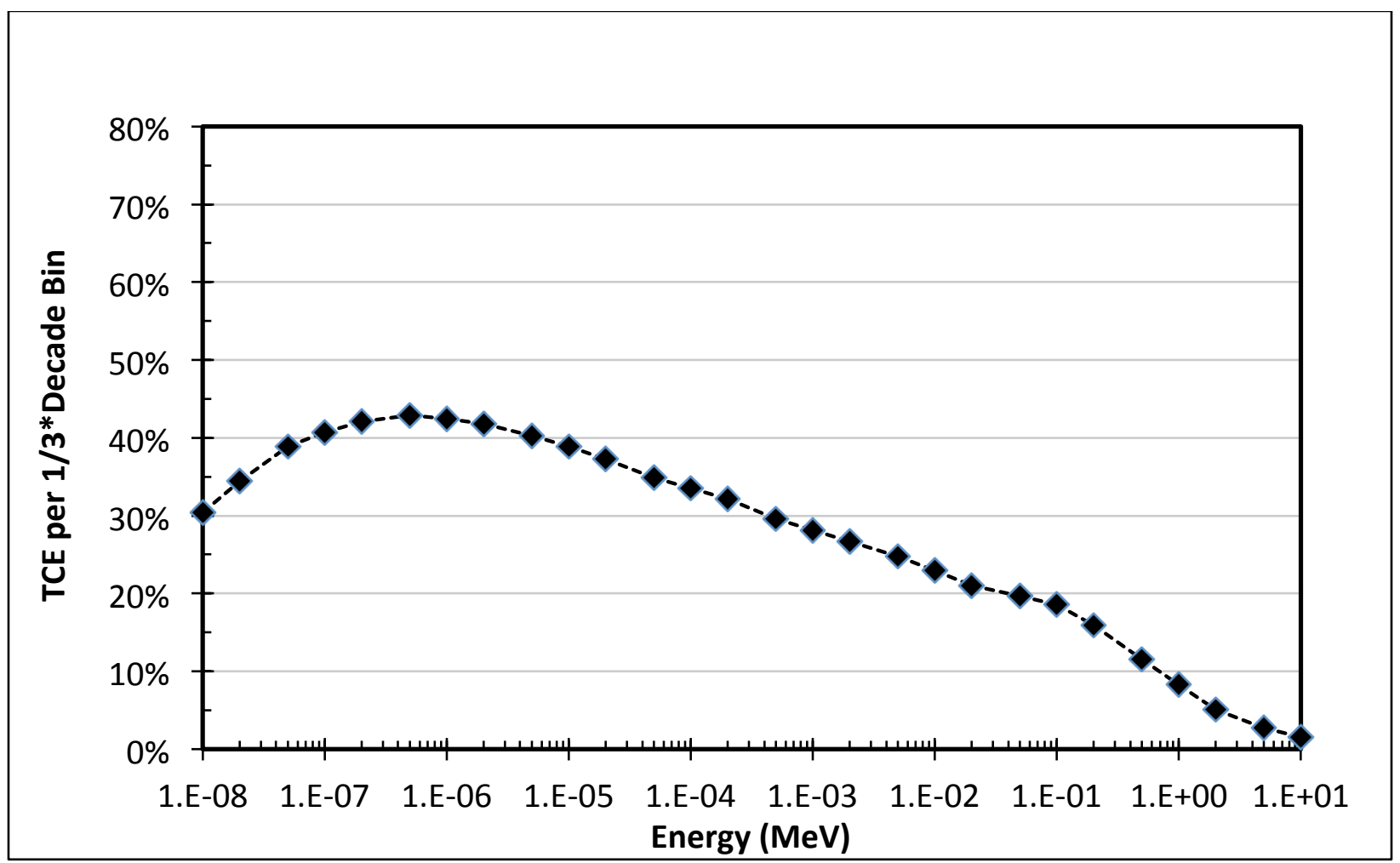

Figure 8.1. Total Capture Efficiency (TCE) vs. Neutron Energy for PLNS4 without HDPE corners.

The average neutron energy from spontaneous ${ }^{252} \mathrm{Cf}$ fission is $2.348 \mathrm{MeV}$. A visual inspection of Figure 8.1 indicates that $2.348 \mathrm{MeV}$ monoenergetic neutrons would have a total neutron capture efficiency of approximately $5 \%$, which is similar to the $7.74 \%$ total neutron capture efficiency simulated for PLNS-4 with a steel encapsulated ${ }^{252} \mathrm{Cf}$ source.

The source positions of the vertical profile simulations ranged from $-23.00 \mathrm{~cm}$ to $+18.00 \mathrm{~cm}$ about the center of the detection chamber. A total of 20 positions were simulated in $2.16 \mathrm{~cm}$ (0.850 in) increments. $\mathrm{A}^{252} \mathrm{Cf}$ source was used in all vertical profile simulations. The results from the vertical position profile can be seen in Figure 8.2. 


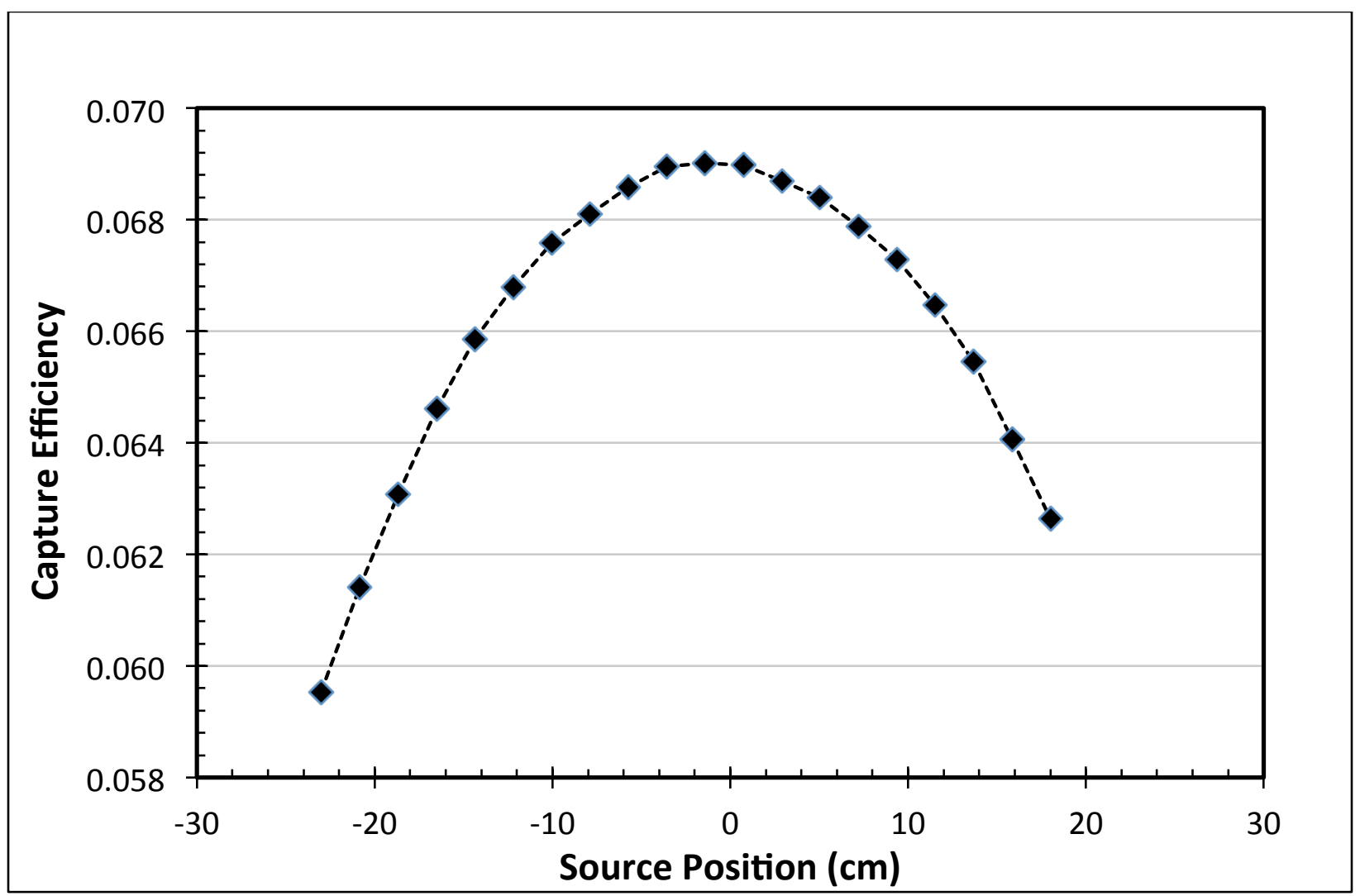

Figure 8.2 TCE vs. Source Height relative to chamber center without HDPE corners.

Approximately symmetric capture efficiency about the origin can be seen from Figure 8.2. A slight shift of the peak in total neutron capture efficiency can be seen towards lower positions. This is expected since the floor is composed of concrete, which provides some neutron reflection and moderation.

The results of these simulations suggest that the PLNS is under moderated, and its efficiency for detection of a fission spectrum source, like ${ }^{252} \mathrm{Cf}$, could be improved by addition of moderator. One way to do this is to increase the number of detection modules to the PLNS system, which is planned for future development. Another way to improve efficiency is to add high-density polyethylene (HDPE) in the corners of the PLNS.

The PLNS4 model was modified to include sequentially increasing numbers HDPE columns in the corners of the detector, as depicted in Figure 8.3, to provide moderation and reflection.

Results from the sequential addition of HDPE blocks to PLNS4 can be seen in Figure 8.4. 


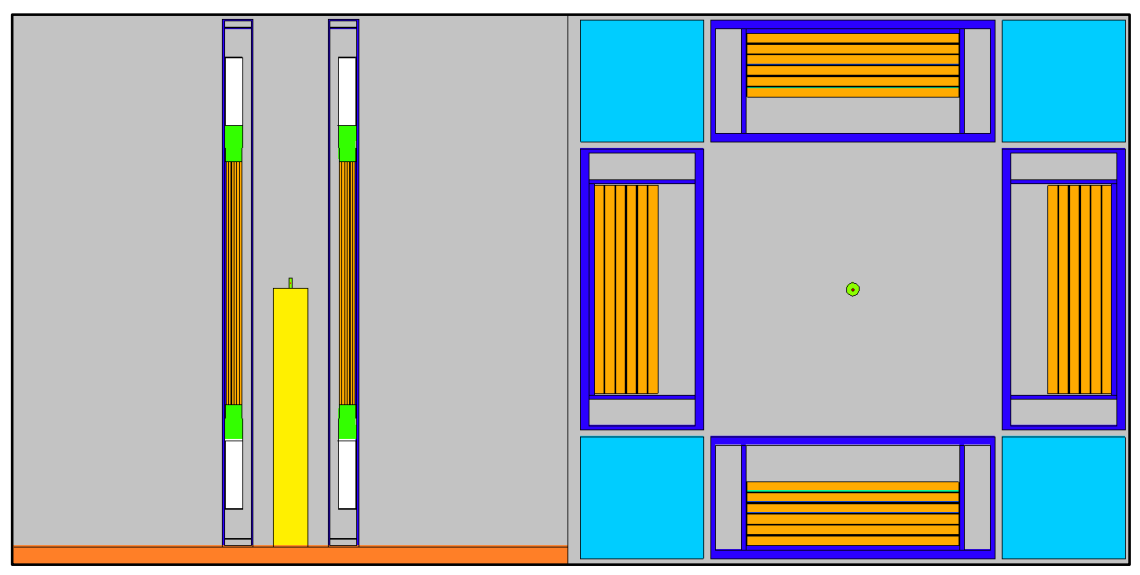

Figure 8.3. PLNS4 with four HDPE corner blocks for moderation and a PUF source stand.

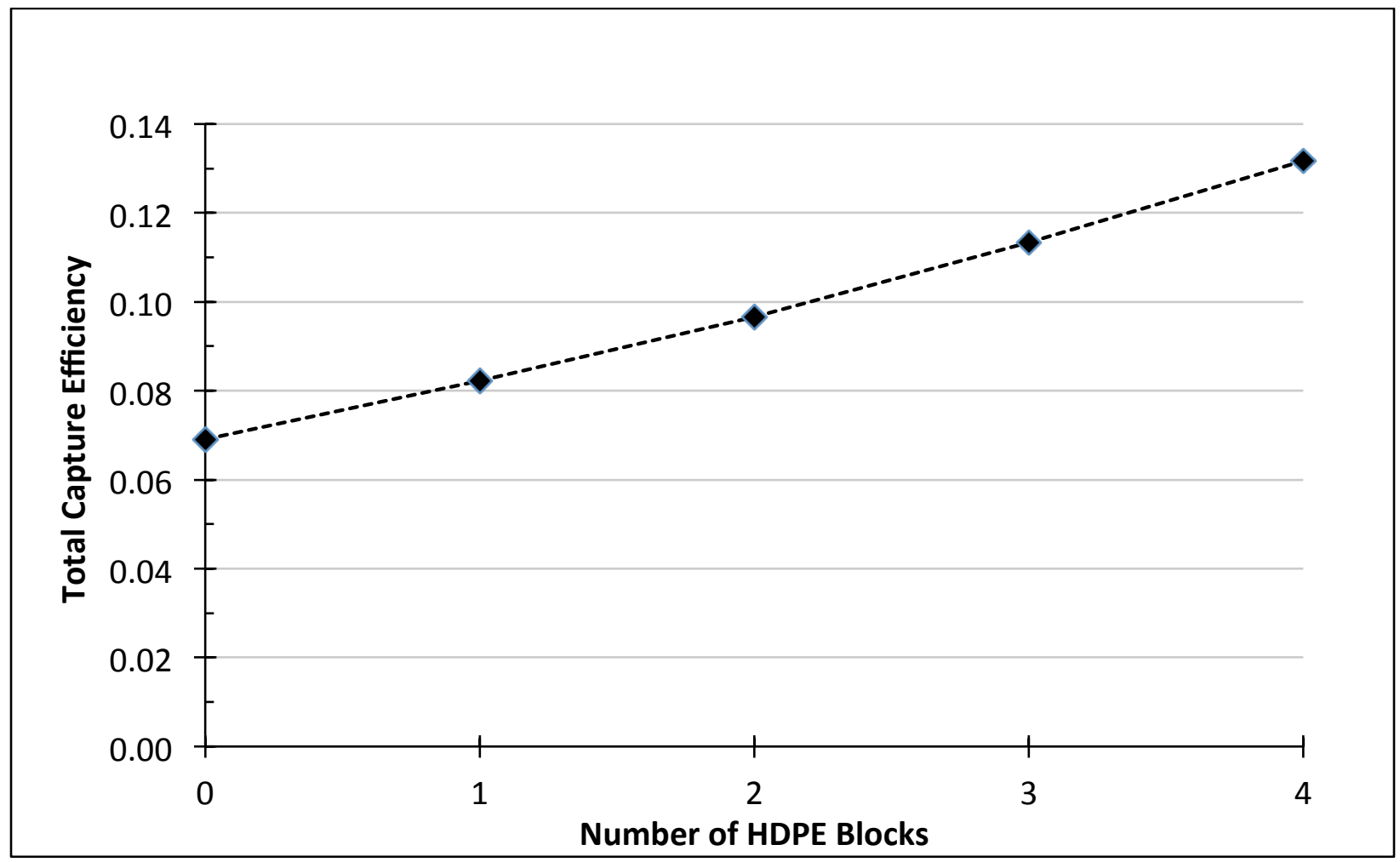

Figure 8.4. Total Capture Efficiency of PLNS4 with the addition of HDPE corner blocks.

From Figure 8.4 it can be seen that the addition of HDPE blocks to the corners of PLNS4 can approximately double neutron capture efficiency of ${ }^{252} \mathrm{Cf}$ sources at the center of the system.

A height and energy profile was performed for the PLNS4 with HDPE blocks in all four corners, as depicted in Figure 8.4. Results from these simulations can be seen in Figure 8.5 and 8.6.

Comparing the total capture efficiency vs. neutron energy, with and without HDPE, and the total capture efficiency vs. source height, with and without HDPE, it can be seen that inclusion of HDPE corners significantly improves total neutron capture efficiency for the PLNS4. 


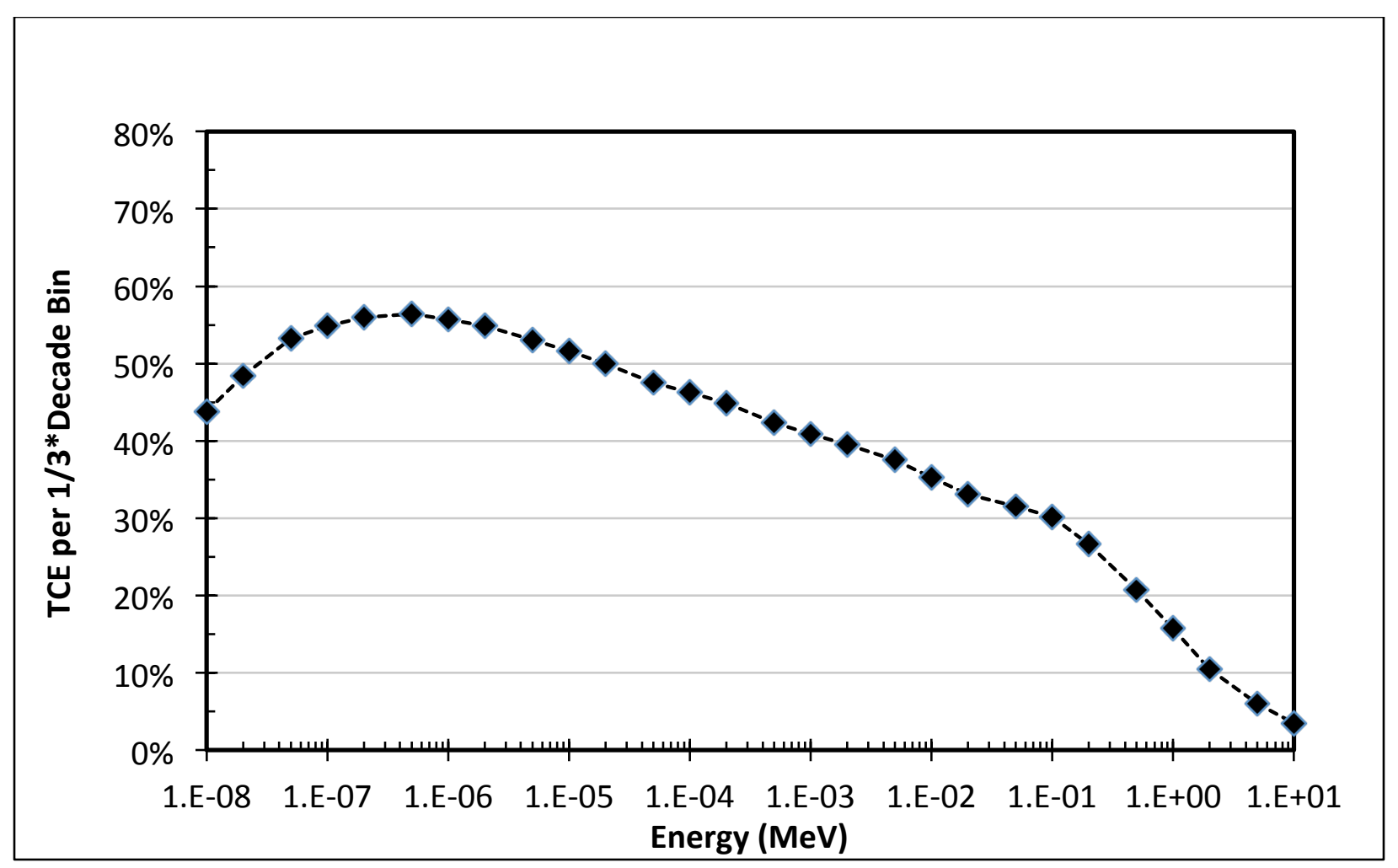

Figure 8.5 TCE vs. Neutron Energy for PLNS4 with HDPE corners.

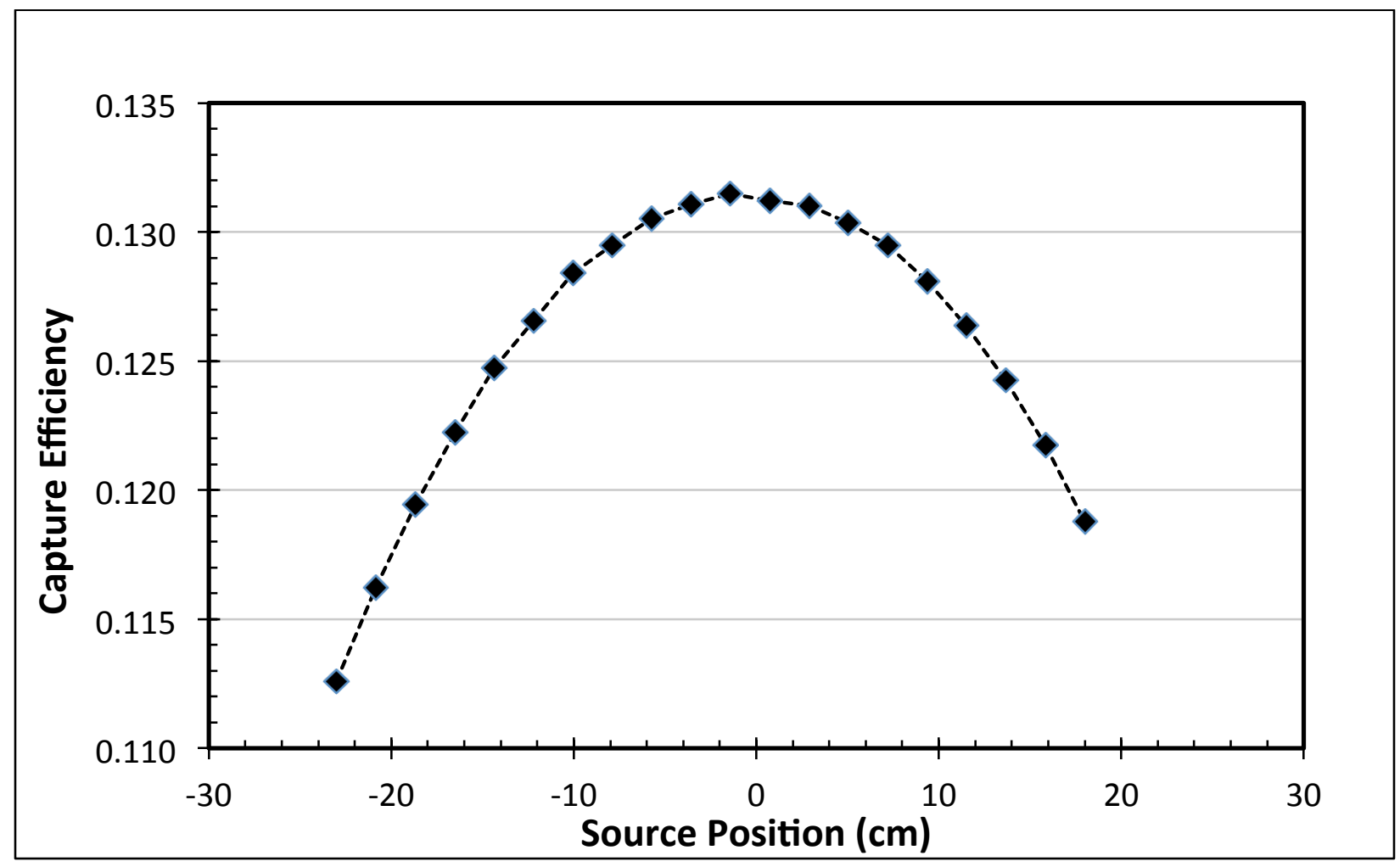

Figure 8.6. TCE vs. Source Height relative to chamber center with HDPE corners. 


\section{Appendix: Numerical Values for Variations of the PLNS4 Model}

The PLNS4 model was modified with additional HDPE blocks to act as neutron moderators and reflectors to enhance the total neutron capture efficiency and figure-or-merit (FoM). Results for these modifications can be seen in Table 9.1 along with previous UNCL-II and PLNS4 results for comparison. Each of these modifications has a corresponding Figure depicting a schematic of the model, as listed in the table. The VCF value used to convert from TCE to efficiency $\varepsilon$ was 0.78 .

Table 9.1. Results of changes to PLNS4 compared to the unmodified PLNS4 and UNCL-II.

\begin{tabular}{|c|c|c|c|c|c|}
\hline Model / Modification & Figure & $\begin{array}{l}\text { Die-away } \\
\text { Time }(\mu s)\end{array}$ & $\begin{array}{c}\text { Simulated } \\
\text { TCE }(\%)\end{array}$ & $\begin{array}{l}\text { Predicted } \varepsilon \\
\quad(\%)\end{array}$ & FoM \\
\hline UNCL-II (measured)* & 4.2 & 58 & - & 15.3 & 4.0 \\
\hline Unmodified PLNS4 & 2.2 & 15.5 & $13.17 \pm 0.01$ & $10.27 \pm 0.36$ & $6.81 \pm 0.34$ \\
\hline PLNS4 with HDPE Lining & 9.1 & 19.0 & $18.89 \pm 0.01$ & $14.73 \pm 0.52$ & $11.44 \pm 0.57$ \\
\hline PLNS4 with HDPE Backing & 9.2 & 17.8 & $17.79 \pm 0.01$ & $13.87 \pm 0.49$ & $10.81 \pm 0.54$ \\
\hline $\begin{array}{l}\text { PLNS4 with HDPE Lining } \\
\text { and Backing }\end{array}$ & 9.3 & 20.7 & $23.68 \pm 0.01$ & $18.47 \pm 0.65$ & $16.45 \pm 0.81$ \\
\hline $\begin{array}{l}\text { PLNS4 with HDPE thick } \\
\text { Lining and Backing }\end{array}$ & 9.4 & 23.3 & $27.50 \pm 0.01$ & $21.45 \pm 0.75$ & $19.71 \pm 0.98$ \\
\hline PLNS4 reversed & 9.5 & 14.8 & $14.76 \pm 0.01$ & $11.51 \pm 0.40$ & $8.94 \pm 0.44$ \\
\hline $\begin{array}{l}\text { PLNS4 reversed with HDPE } \\
\text { Lining }\end{array}$ & 9.6 & 17.7 & $21.08 \pm 0.01$ & $16.44 \pm 0.58$ & $15.25 \pm 0.76$ \\
\hline $\begin{array}{l}\text { PLNS4 reversed with HDPE } \\
\text { Backing }\end{array}$ & 9.7 & 17.8 & $19.93 \pm 0.01$ & $16.44 \pm 0.58$ & $15.25 \pm 0.76$ \\
\hline $\begin{array}{l}\text { PLNS4 reversed with HDPE } \\
\text { Lining and Backing }\end{array}$ & 9.8 & 20.1 & $26.34 \pm 0.01$ & $20.55 \pm 0.72$ & $21.03 \pm 1.04$ \\
\hline $\begin{array}{l}\text { PLNS4 reversed with HDPE } \\
\text { thick Lining and Backing }\end{array}$ & 9.9 & 22.6 & $30.30 \pm 0.01$ & $23.63 \pm 0.83$ & $24.76 \pm 1.23$ \\
\hline
\end{tabular}

* From [Menlove et al. 1990] using ${ }^{252} \mathrm{Cf}$ centered in sample chamber

$* *$ Values for predicted efficiency include the VCF 


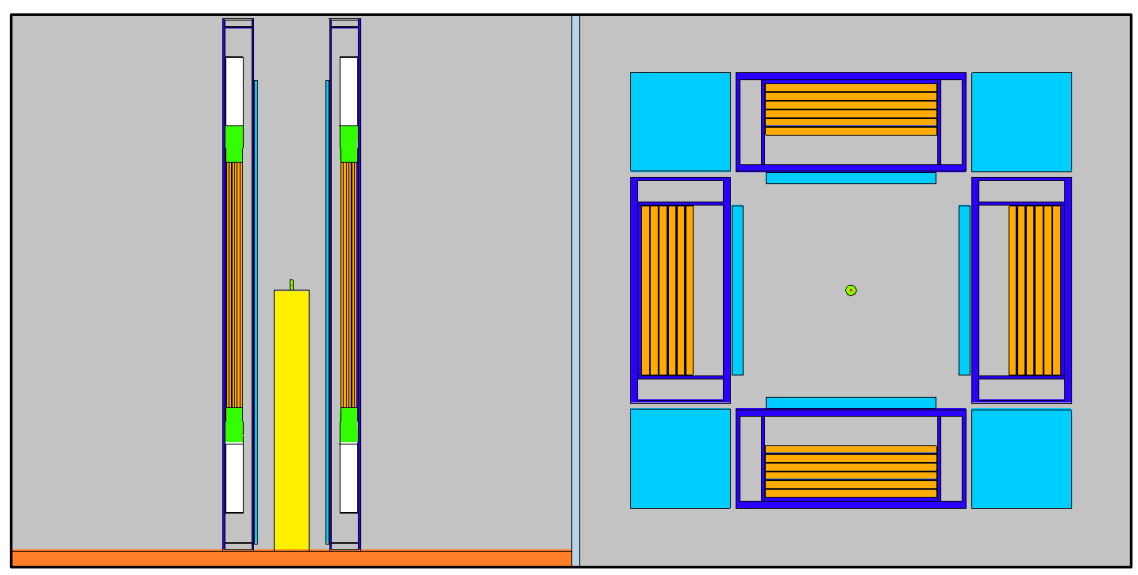

Figure 9.1. PLNS4 with $1.0 \mathrm{~cm}$ HDPE lining.

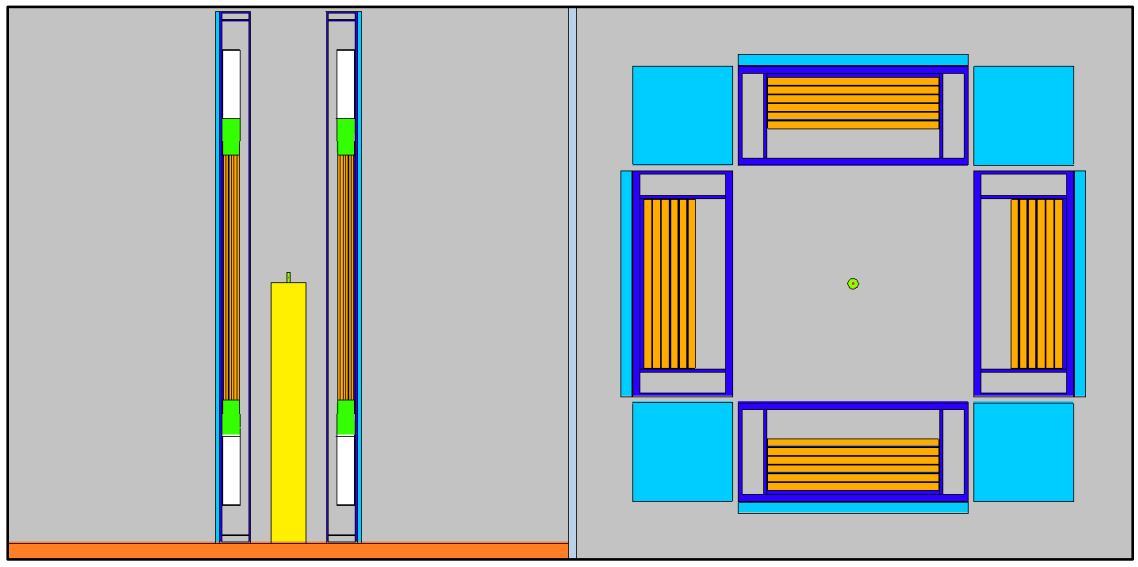

Figure 9.2. PLNS4 with $1.0 \mathrm{~cm}$ HDPE backing.

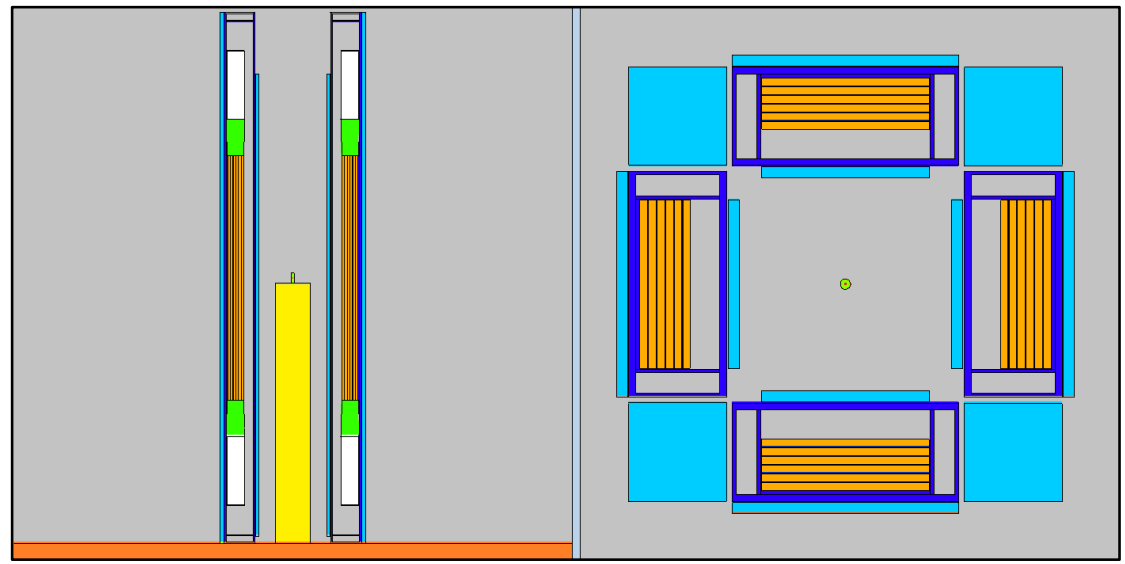

Figure 9.3. PLNS4 with $1.0 \mathrm{~cm}$ HDPE lining and backing. 


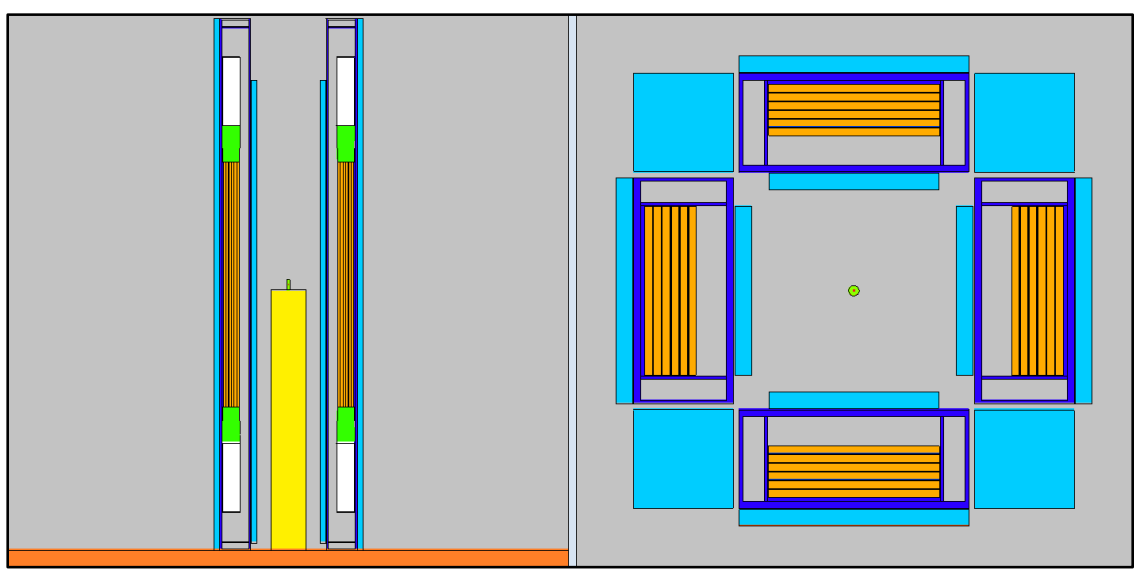

Figure 9.4. PLNS4 with $1.5 \mathrm{~cm}$ HDPE lining and backing.

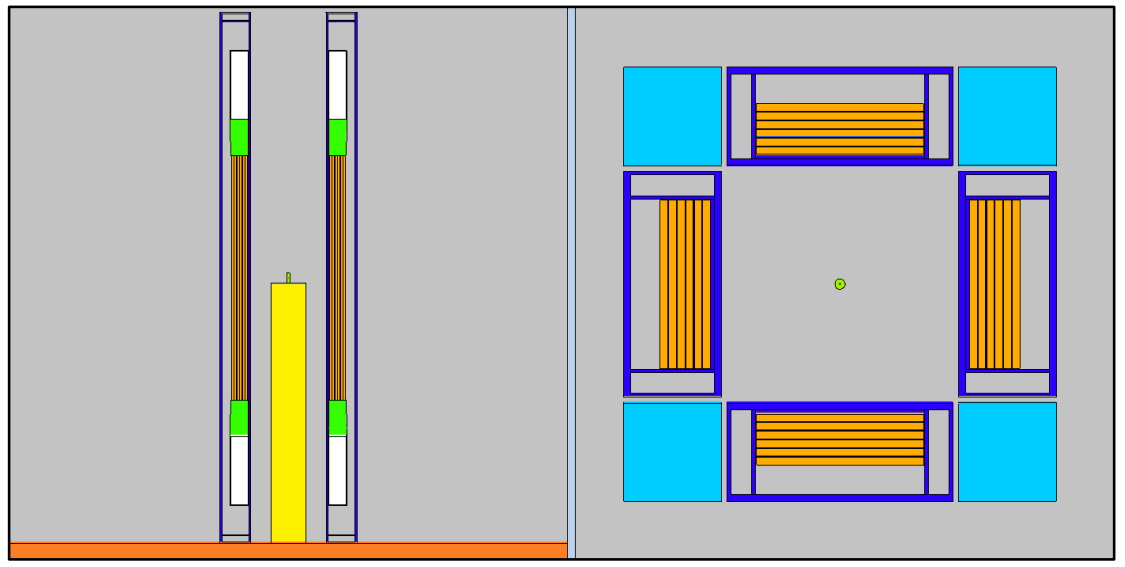

Figure 9.5. PLNS4 reversed.

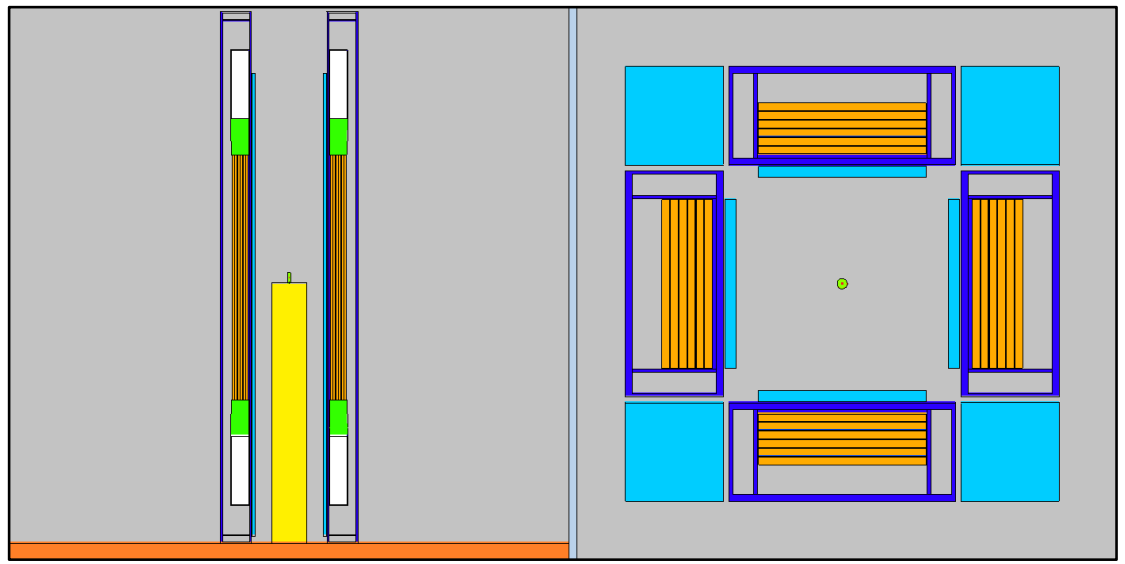

Figure 9.6. PLNS4 reversed with $1.0 \mathrm{~cm}$ HDPE lining. 


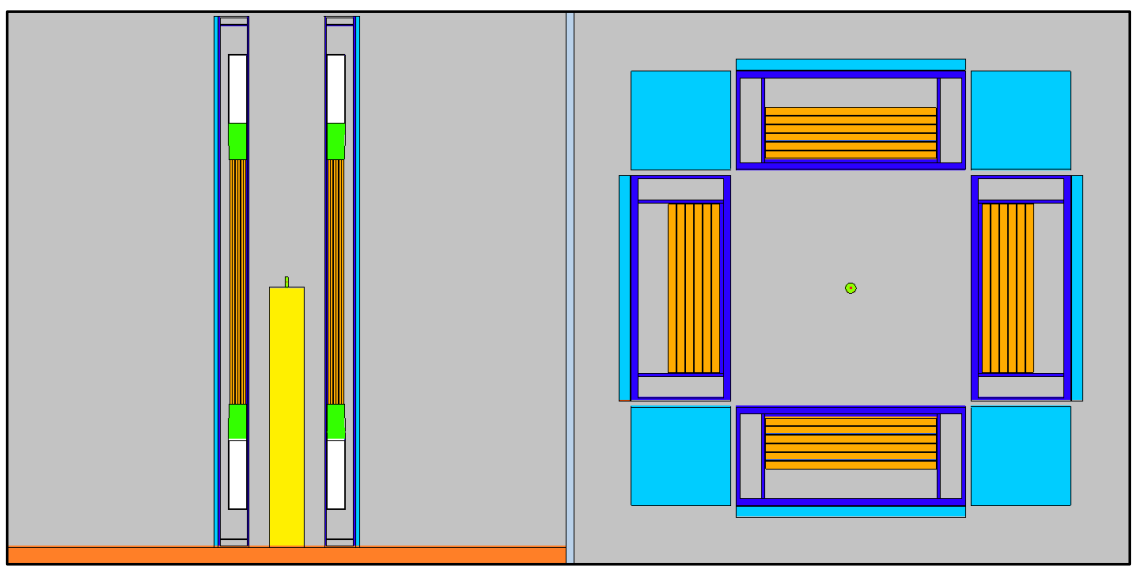

Figure 9.7. PLNS4 reversed with $1.0 \mathrm{~cm}$ HDPE backing.

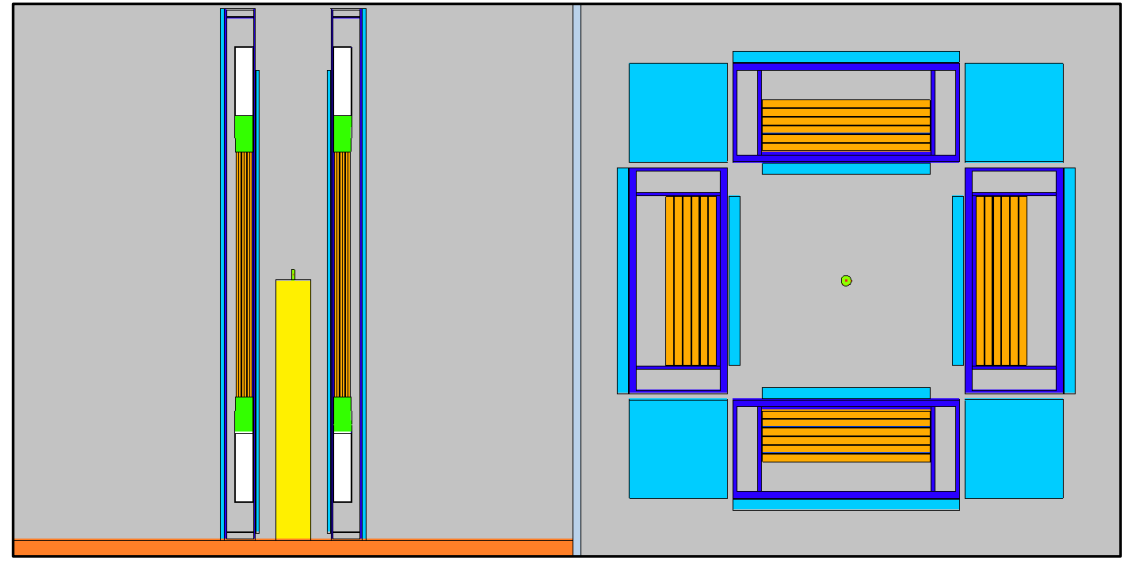

Figure 9.8. PLNS4 reversed with $1.0 \mathrm{~cm}$ HDPE lining and backing.

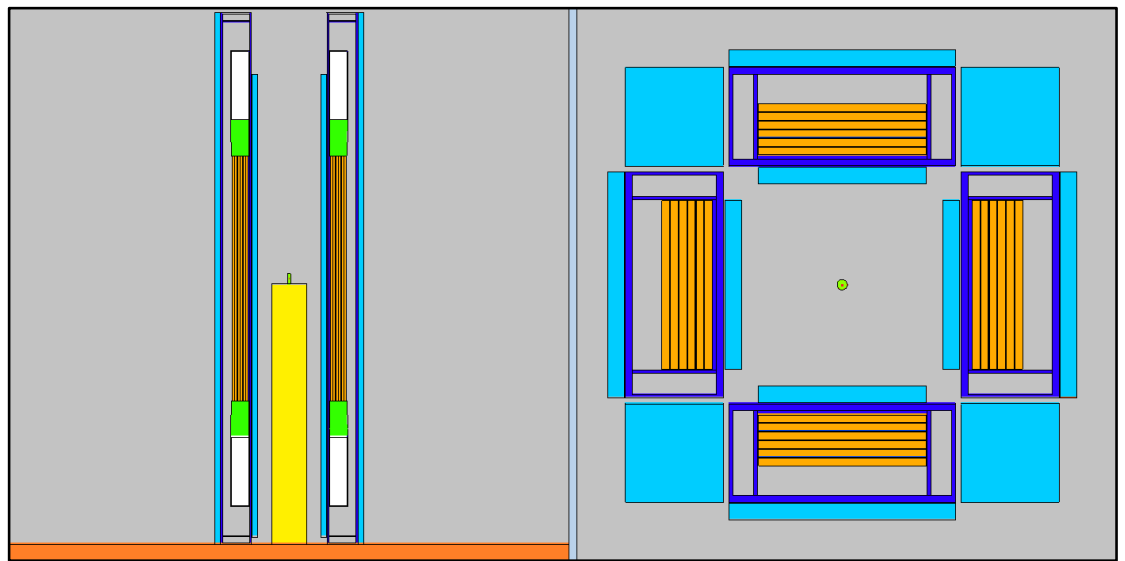

Figure 9.9. PLNS4 reversed with $1.5 \mathrm{~cm}$ HDPE lining and backing.

Of the models simulated, PLNS4 with reversed panels and thickened HDPE lining and back, as depicted in Figure 9.9, showed the greatest promise for development with $\varepsilon=23.6, \tau=22.6$, and FoM $=24.8$.

The PLNS4 was then modified by removing one detector panel and fully replacing that space with HDPE to better match an active configuration, referred to as PLNS3. The HDPE backing and lining were varied 
and simulated performance results were recorded, as can be seen in Table 9.2. Each of these

modifications has a corresponding Figure depicting a schematic of the model, as listed in the table. The VCF value used to convert from TCE to efficiency $\varepsilon$ was 0.78 .

Table 9.2. Results of changes to PLNS3 compared to the unmodified PLNS4 and UNCL-II.

\begin{tabular}{|l|c|c|c|c|c|}
\hline \multicolumn{1}{|c|}{ Model / Modification } & Figure & $\begin{array}{c}\text { Die-away } \\
\text { Time }(\boldsymbol{\mu s})\end{array}$ & $\begin{array}{c}\text { Simulated } \\
\text { TCE (\%) }\end{array}$ & $\begin{array}{c}\text { Predicted } \boldsymbol{\varepsilon} \\
\mathbf{( \% )}\end{array}$ & FoM \\
\hline UNCL-II (measured)* & 4.2 & 58 & - & 15.3 & 4.0 \\
\hline PLNS3 & 9.10 & 17.8 & $12.52 \pm 0.01$ & $9.76 \pm 0.34$ & $5.37 \pm 0.27$ \\
\hline $\begin{array}{l}\text { PLNS3 with HDPE Lining } \\
\text { and Backing }\end{array}$ & 9.11 & 21.9 & $19.47 \pm 0.01$ & $15.19 \pm 0.53$ & $10.54 \pm 0.52$ \\
\hline PLNS3 reversed & 9.12 & 17.4 & $13.89 \pm 0.01$ & $10.83 \pm 0.38$ & $6.73 \pm 0.33$ \\
\hline $\begin{array}{l}\text { PLNS3 reversed with HDPE } \\
\text { Lining and Backing }\end{array}$ & 9.13 & 21.1 & $21.40 \pm 0.01$ & $16.69 \pm 0.58$ & $13.20 \pm 0.65$ \\
\hline
\end{tabular}

* From [Menlove et al. 1990] using ${ }^{252} \mathrm{Cf}$ centered in sample chamber

** Values for predicted efficiency include the VCF

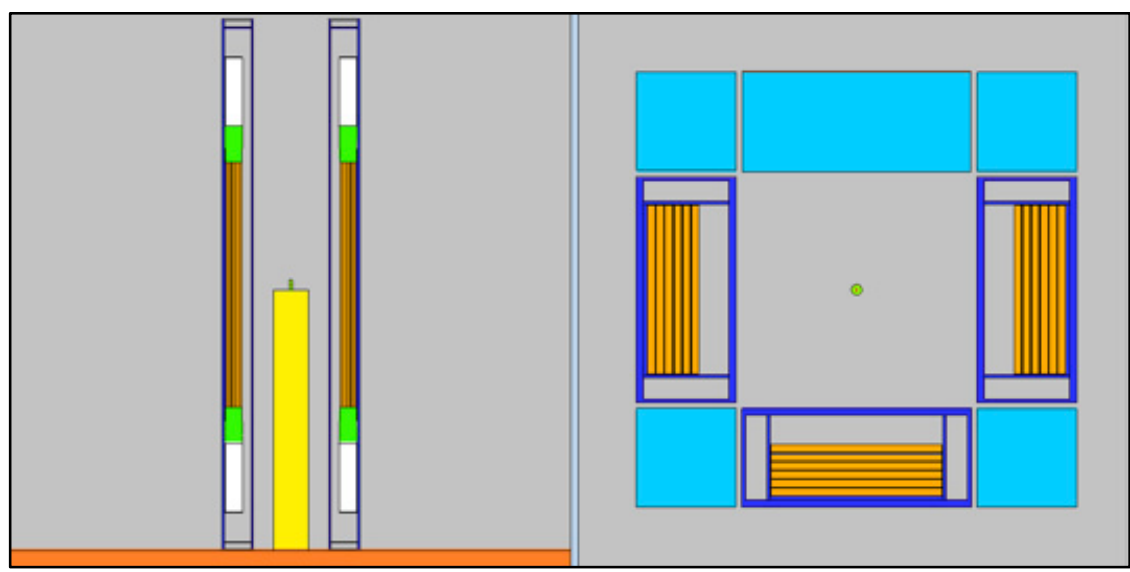

Figure 9.10. PLNS3.

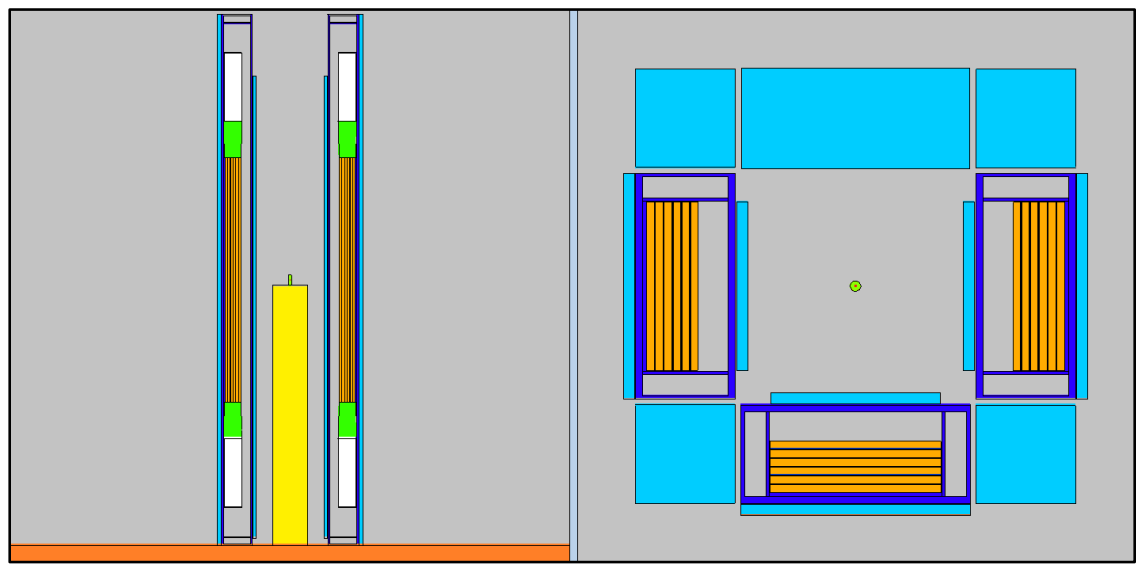

Figure 9.11. PLNS3 with $1.0 \mathrm{~cm}$ HDPE lining and backing. 


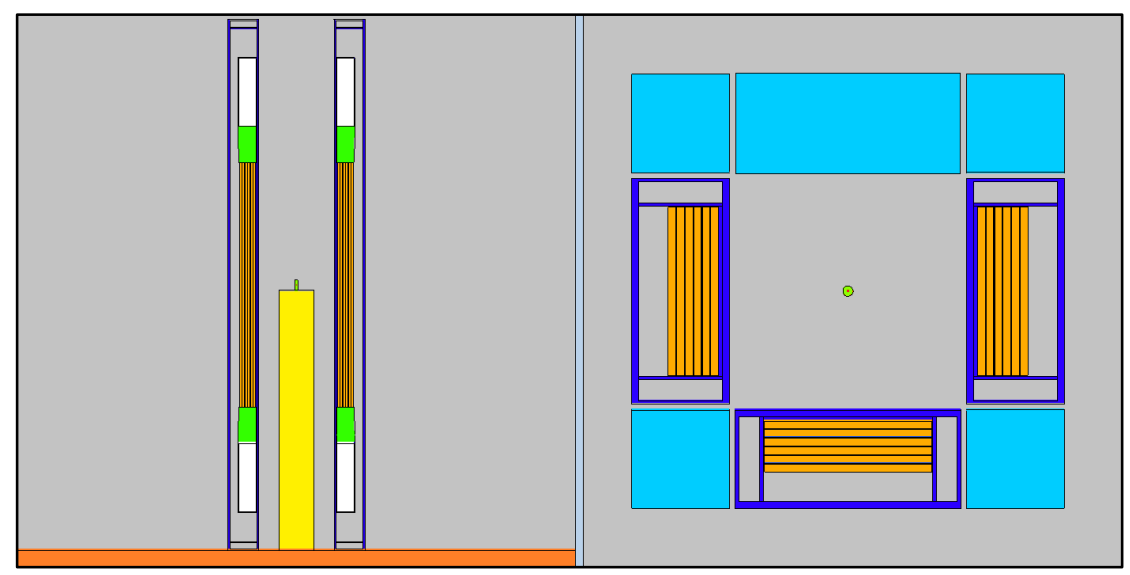

Figure 9.12. PLNS3 reversed.

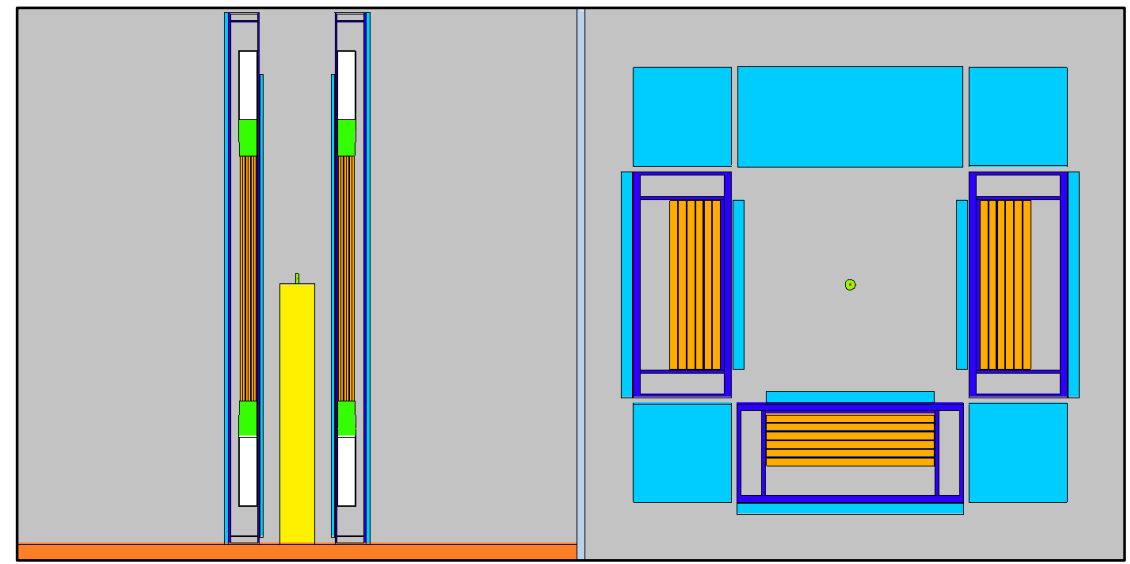

Figure 9.13. PLNS3 reversed with $1.0 \mathrm{~cm}$ HDPE lining and backing.

Of the PLNS3 models simulated, the PLNS3 with reversed panels and thickened HDPE backing and lining, as depicted in Figure 9.13, showed the greatest promise for development with $\varepsilon=16.7, \tau=21.1$, and $\mathrm{FoM}=13.2$.

From the simulation results given in Table 9.1 and Table 9.2 several modifications can be seen that show promise as potential ways to enhance the FoM of the PLNS4 sufficiently to meet or exceed the performance of the UNCL-II system. Utilizing promising features, the PLNS4 model was modified with a front block, a lining, a backing, and corner wedges. To maintain the improved neutron capture efficiency, while reducing unnecessary increases in die-away time, the moderating material was modified to only cover the active height of the detector system. A cavity was included in the front section for an AmLi source to improve the active configuration performance. This model, as depicted in Figure 9.14, will be referred to as PLNS3A. Each of the HDPE components was then sequentially replaced with polyvinyl toluene (PVT) to determine the performance effects of increasing the carbon to hydrogen ratio in the moderator. Results from these simulations can be seen in Table 9.3. Each of these modifications has a corresponding Figure depicting a schematic of the model, as listed in the table. The VCF value used to convert from TCE to efficiency $\varepsilon$ was 0.78 . 
Table 9.3. Results of PLNS3.

\begin{tabular}{|c|c|c|c|c|c|}
\hline Model / Modification & Figure & $\begin{array}{l}\text { Die-away } \\
\text { Time }(\mu s)\end{array}$ & $\begin{array}{l}\text { Simulated } \\
\text { TCE }(\%) \\
\end{array}$ & $\begin{array}{c}\text { Predicted \& } \\
(\%)\end{array}$ & FoM \\
\hline PLNS3A & 9.14 & 15.6 & $17.55 \pm 0.02$ & $13.69 \pm 0.48$ & $11.99 \pm 0.59$ \\
\hline PLNS3A with PVT Backing & 9.15 & 15.2 & $16.84 \pm 0.02$ & $13.14 \pm 0.46$ & $11.37 \pm 0.56$ \\
\hline PLNS3A with PVT Front & 9.16 & 15.5 & $17.37 \pm 0.02$ & $13.55 \pm 0.47$ & $11.85 \pm 0.59$ \\
\hline PLNS3A with PVT Lining & 9.17 & 14.8 & $16.75 \pm 0.02$ & $13.06 \pm 0.46$ & $11.49 \pm 0.57$ \\
\hline PLNS3 with PVT Wedges & 9.18 & 15.2 & $16.78 \pm 0.02$ & $13.09 \pm 0.46$ & $11.29 \pm 0.56$ \\
\hline $\begin{array}{l}\text { PLNS3A with Backing }-0.5 \\
\mathrm{~cm}\end{array}$ & 9.19 & 15.2 & $16.58 \pm 0.01$ & $12.93 \pm 0.45$ & $10.97 \pm 0.54$ \\
\hline $\begin{array}{l}\text { PLNS3A with Backing }+0.5 \\
\mathrm{~cm}\end{array}$ & 9.20 & 15.8 & $18.06 \pm 0.02$ & $14.09 \pm 0.49$ & $12.54 \pm 0.62$ \\
\hline PLNS3A with Front $-1.0 \mathrm{~cm}$ & 9.21 & 15.6 & $17.39 \pm 0.02$ & $13.57 \pm 0.48$ & $11.80 \pm 0.58$ \\
\hline PLNS3A with Front $-2.0 \mathrm{~cm}$ & 9.22 & 15.6 & $17.14 \pm 0.02$ & $13.37 \pm 0.47$ & $11.49 \pm 0.57$ \\
\hline PLNS3A with Front $+1.0 \mathrm{~cm}$ & 9.23 & 15.6 & $17.64 \pm 0.02$ & $13.76 \pm 0.48$ & $12.11 \pm 0.60$ \\
\hline $\begin{array}{l}\text { PLNS3A with PVT Front - } \\
1.0 \mathrm{~cm}\end{array}$ & 9.24 & 15.5 & $17.11 \pm 0.02$ & $13.34 \pm 0.47$ & $11.52 \pm 0.57$ \\
\hline $\begin{array}{l}\text { PLNS3A with PVT Front - } \\
2.0 \mathrm{~cm}\end{array}$ & 9.25 & 15.4 & $16.75 \pm 0.02$ & $13.07 \pm 0.46$ & $11.09 \pm 0.55$ \\
\hline $\begin{array}{l}\text { PLNS3A with PVT Front } \\
+1.0 \mathrm{~cm}\end{array}$ & 9.26 & 15.5 & $17.55 \pm 0.02$ & $13.69 \pm 0.48$ & $12.09 \pm 0.60$ \\
\hline $\begin{array}{l}\text { PLNS3A with Lining }-0.5 \\
\mathrm{~cm}\end{array}$ & 9.27 & 14.8 & $15.96 \pm 0.01$ & $12.45 \pm 0.44$ & $10.47 \pm 0.52$ \\
\hline $\begin{array}{l}\text { PLNS3A with Lining }+0.5 \\
\mathrm{~cm}\end{array}$ & 9.28 & 16.4 & $18.75 \pm 0.02$ & $14.63 \pm 0.51$ & $13.03 \pm 0.64$ \\
\hline $\begin{array}{l}\text { PLNS3A with Front, Lining, } \\
\text { and Backing }+0.5 \mathrm{~cm}\end{array}$ & 9.29 & 16.6 & $19.29 \pm 0.02$ & $15.04 \pm 0.53$ & $13.62 \pm 0.67$ \\
\hline $\begin{array}{l}\text { PLNS3A with Front, Lining, } \\
\text { and Backing }+1.0 \mathrm{~cm}\end{array}$ & 9.30 & 17.4 & $20.61 \pm 0.02$ & $16.07 \pm 0.56$ & $14.83 \pm 0.73$ \\
\hline $\begin{array}{l}\text { PLNS3A with Lining, and } \\
\text { Backing }+1.5 \mathrm{~cm} \text { and Front } \\
+1.0 \mathrm{~cm}\end{array}$ & 9.31 & 18.0 & $21.23 \pm 0.02$ & $16.56 \pm 0.58$ & $15.20 \pm 0.75$ \\
\hline $\begin{array}{l}\text { PLNS3A reversed with } \\
\text { Lining, and Backing }+1.5 \\
\mathrm{~cm} \text { and Front }+1.0 \mathrm{~cm} \\
(\text { PLNS3A-R1) }\end{array}$ & 9.32 & 18.0 & $23.48 \pm 0.02$ & $18.32 \pm 0.64$ & $18.67 \pm 0.92$ \\
\hline
\end{tabular}

* Values for predicted efficiency include the VCF 


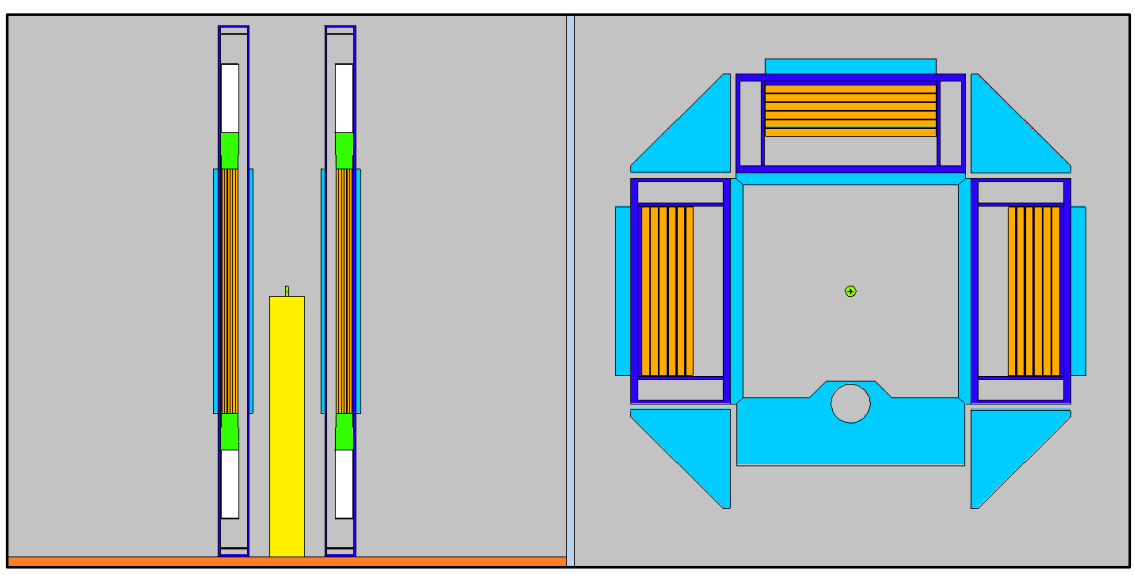

Figure 9.14. PLNS3A.

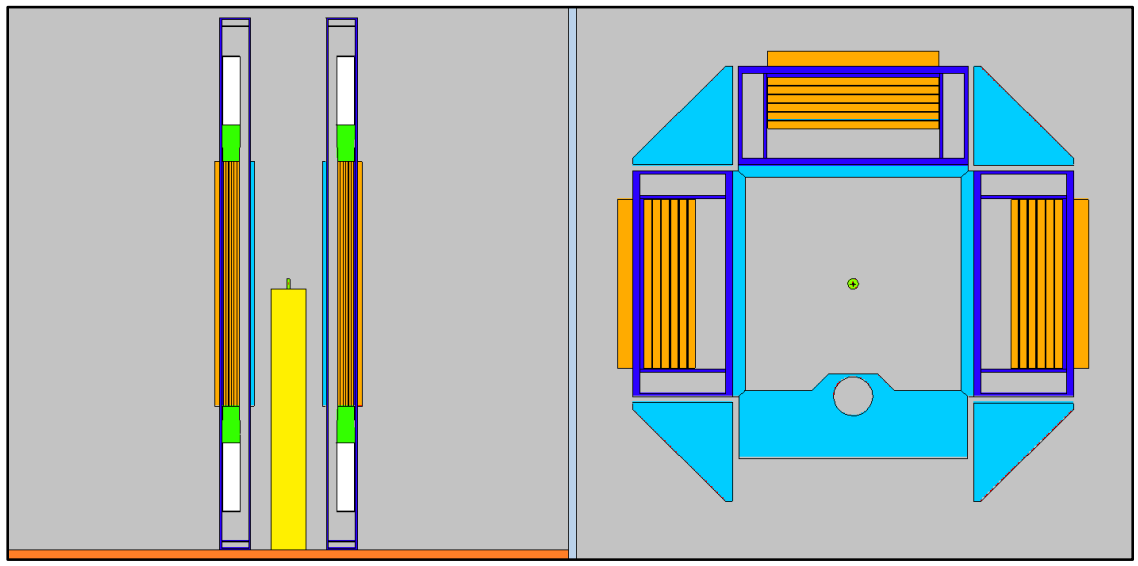

Figure 9.15. PLNS3A with PVT backing.

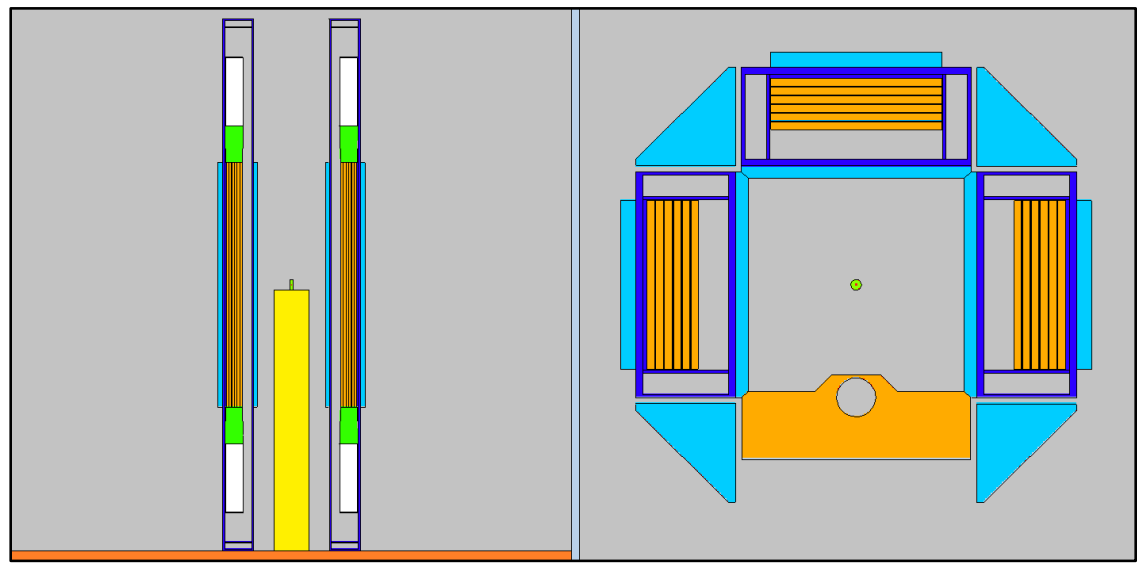

Figure 9.16. PLNS3A with PVT front. 


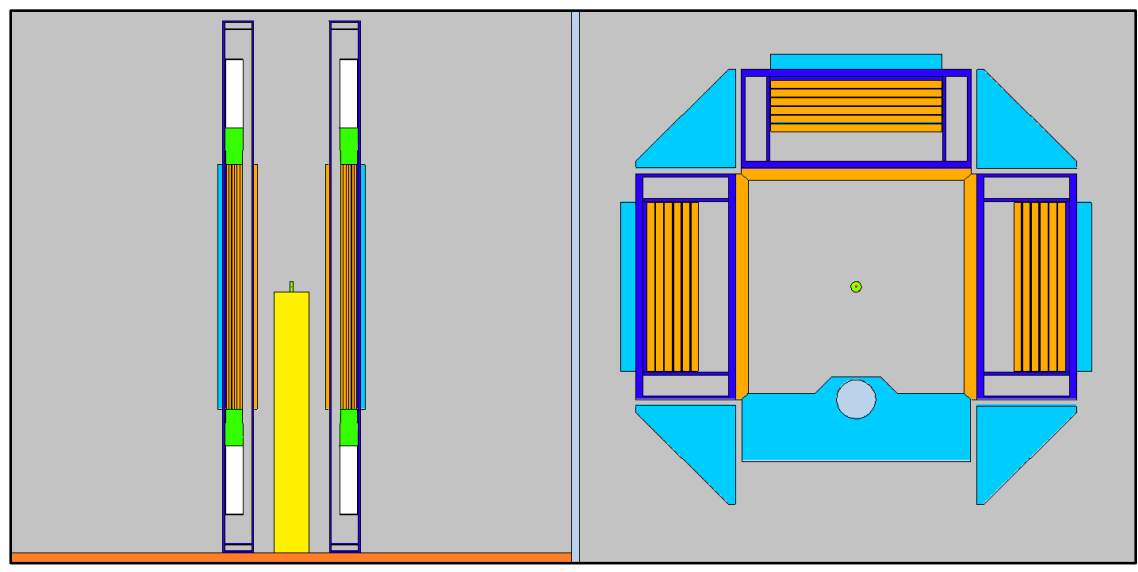

Figure 9.17. PLNS3A with PVT lining.

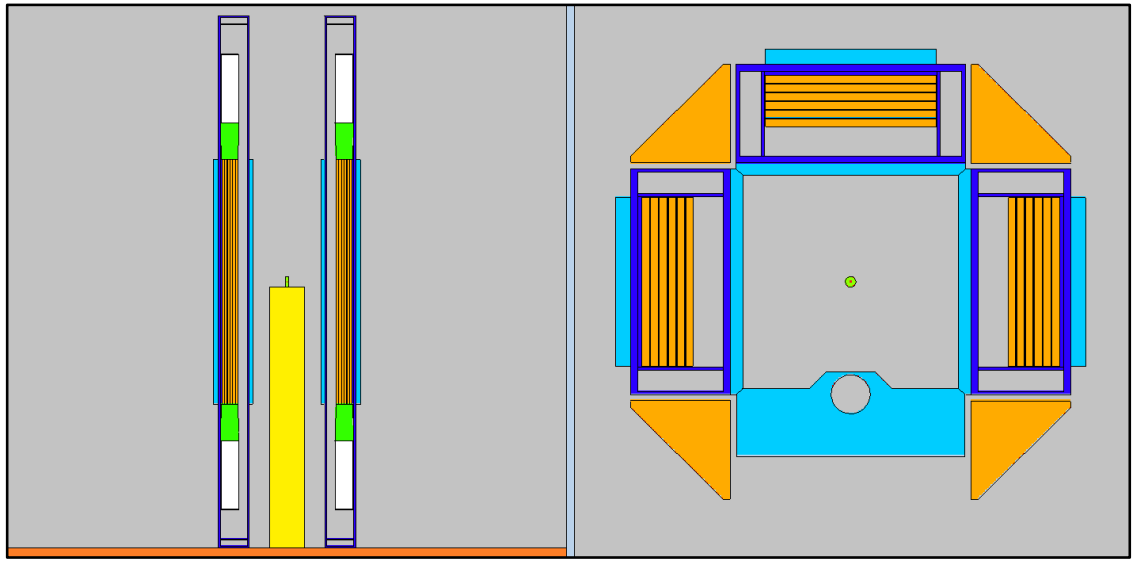

Figure 9.18. PLNS3A with PVT wedges.

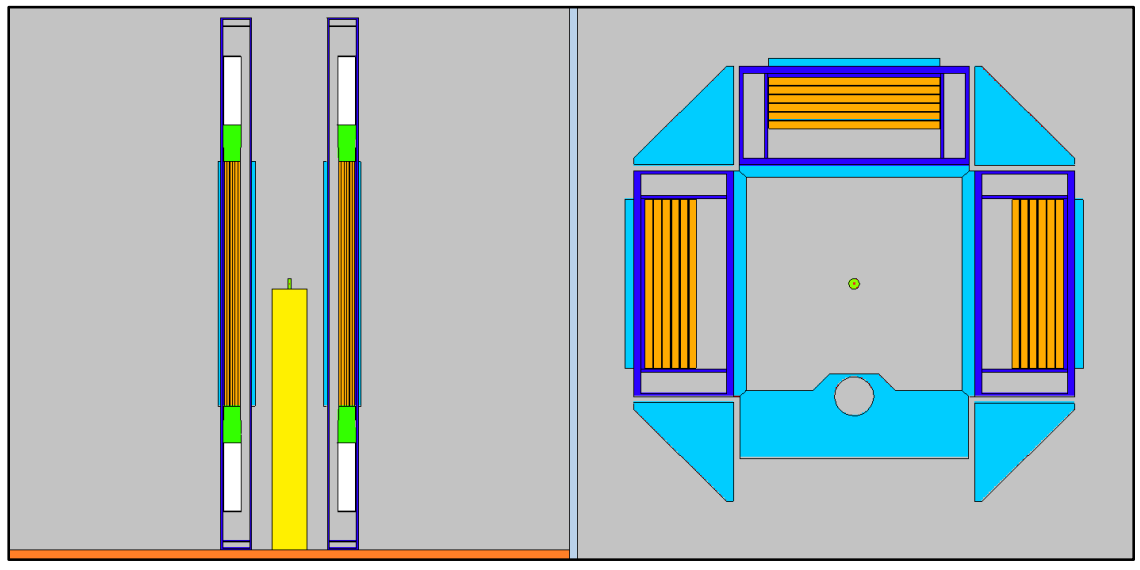

Figure 9.19. PLNS3A with $\mathbf{- 0 . 5} \mathrm{cm}$ to backing. 


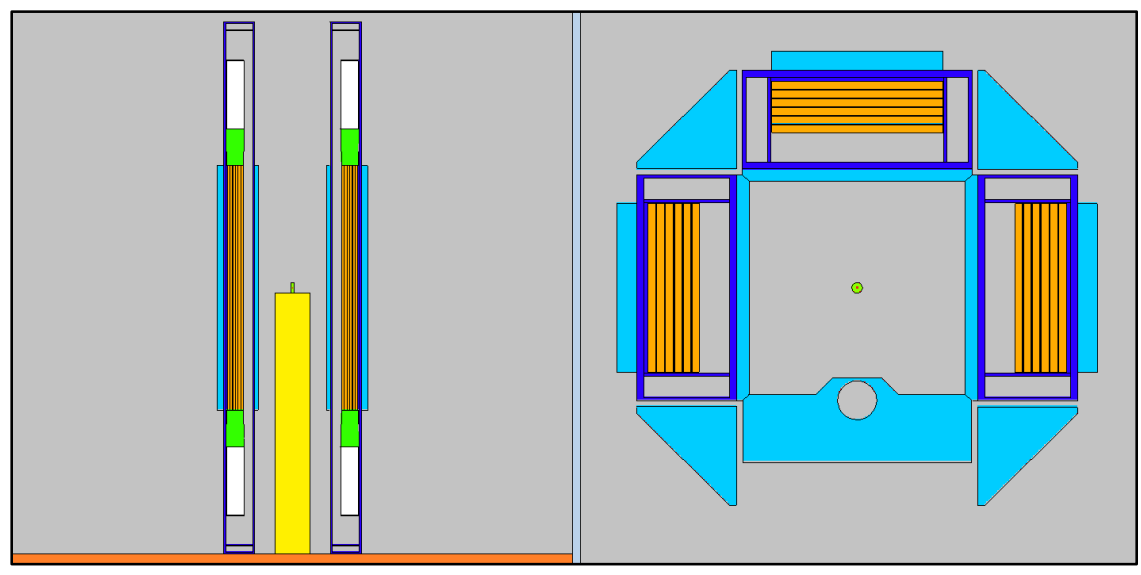

Figure 9.20. PLNS3A with $+0.5 \mathrm{~cm}$ to backing.

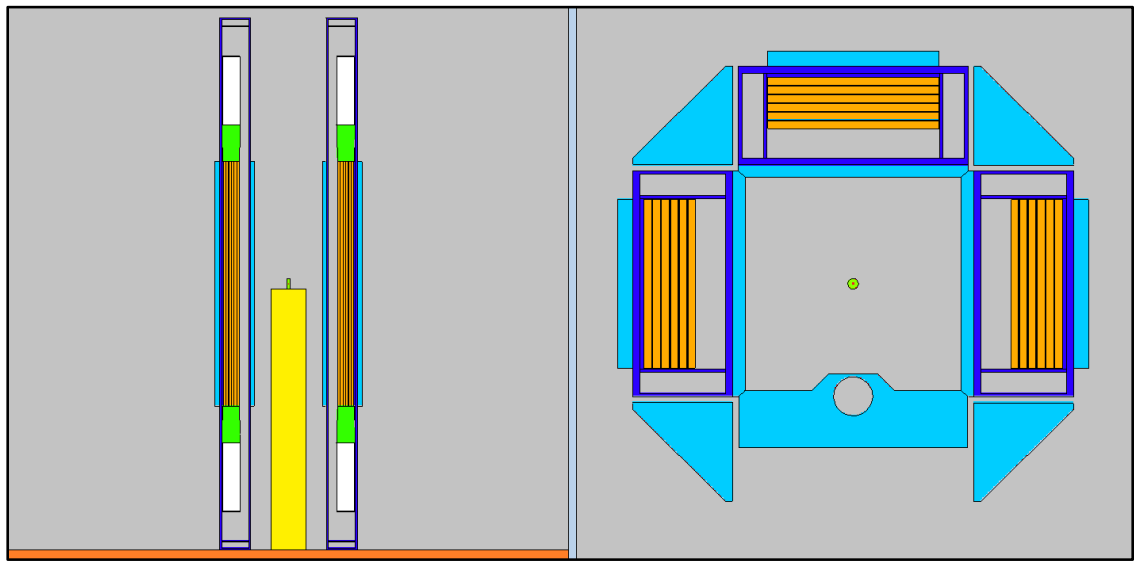

Figure 9.21. PLNS3A with $-1.0 \mathrm{~cm}$ to front.

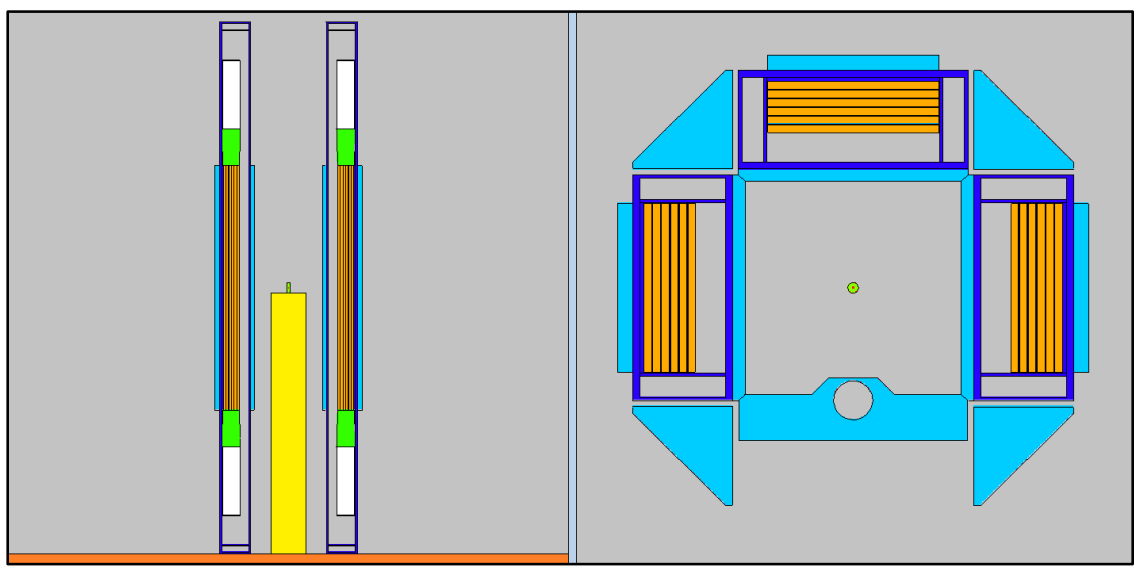

Figure 9.22. PLNS3A with -2.0 to front. 


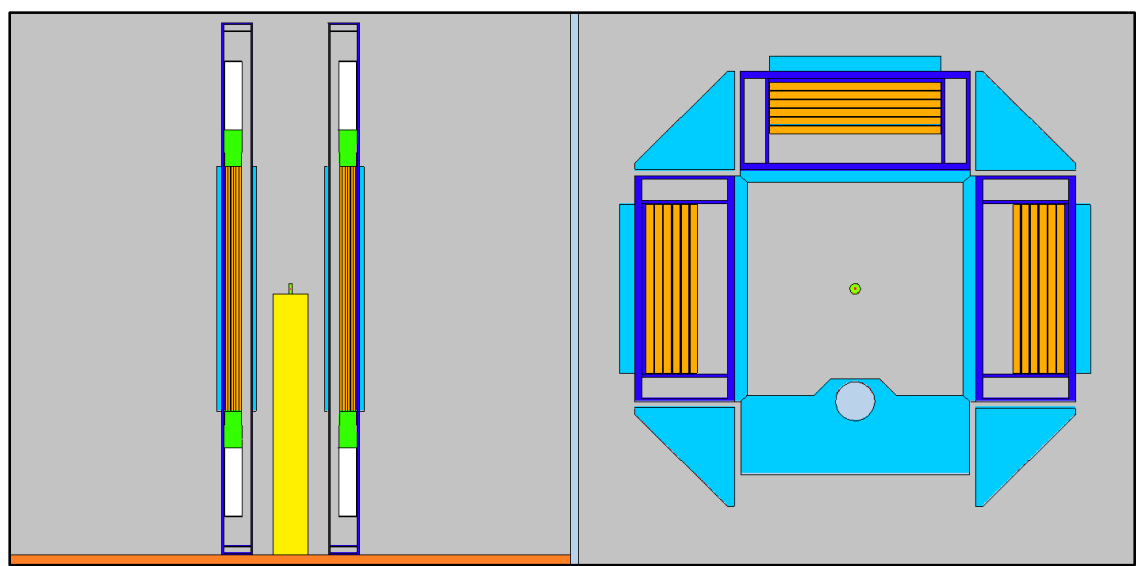

Figure 9.23. PLNS3A with $+1.0 \mathrm{~cm}$ to front.

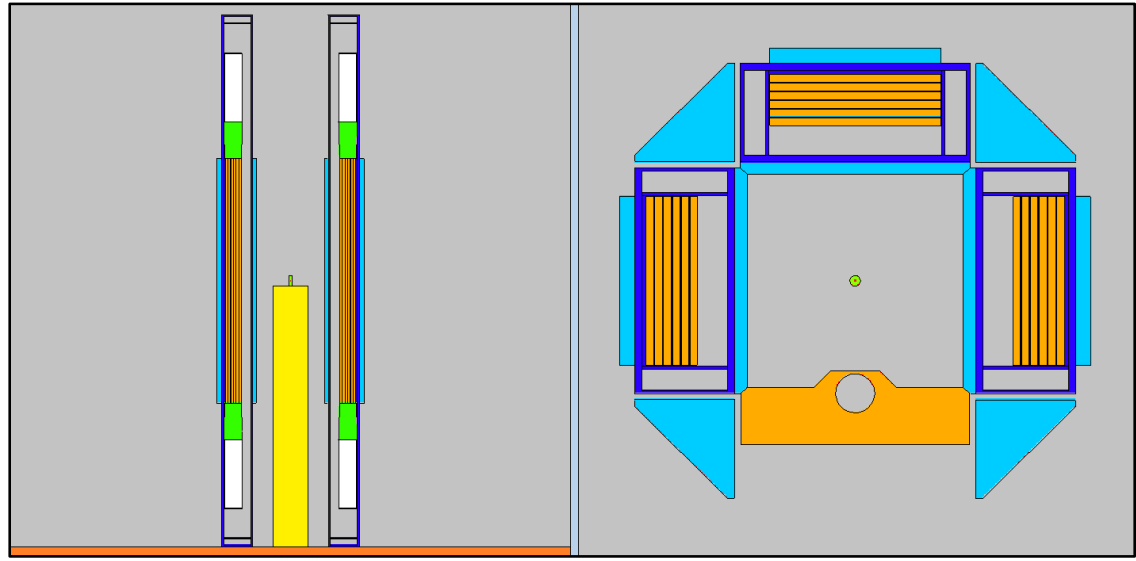

Figure 9.24. PLNS3A with $-1.0 \mathrm{~cm}$ to PVT front.

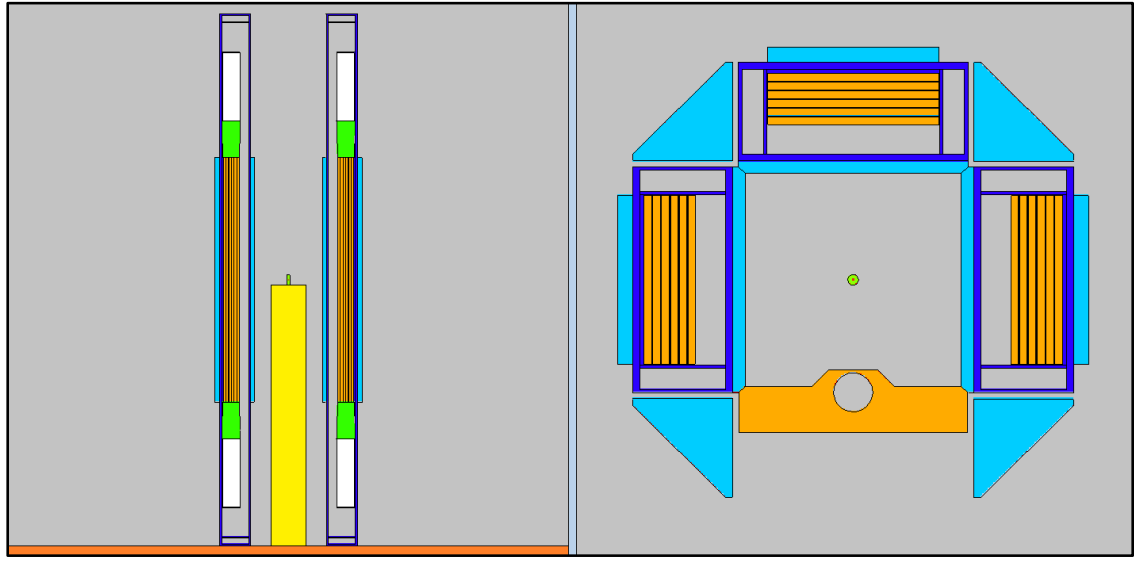

Figure 9.25. PLNS3A with $-\mathbf{2 . 0} \mathrm{cm}$ to $P V T$ front. 


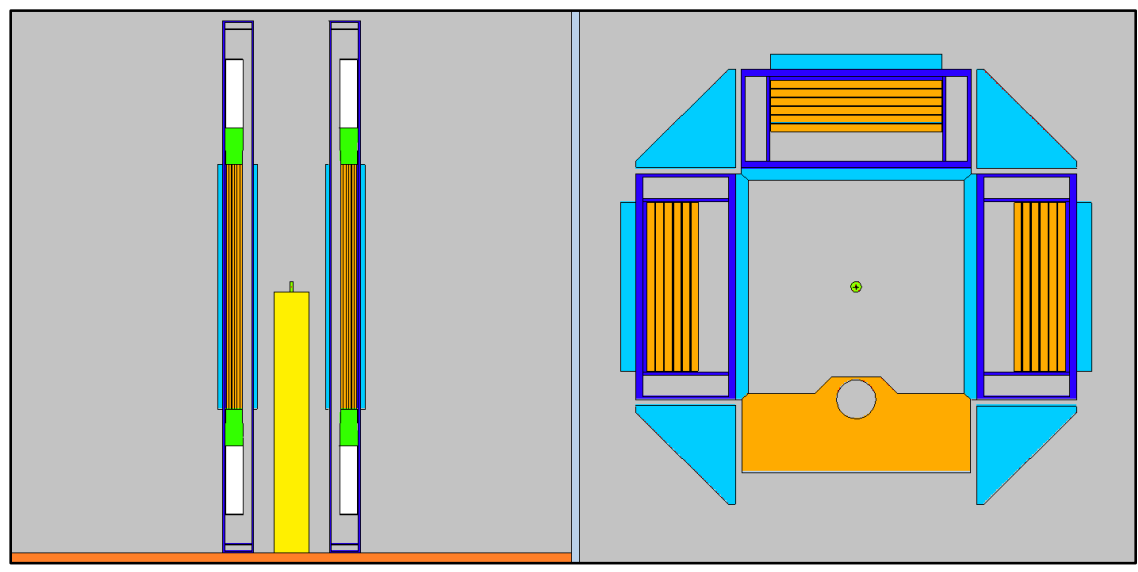

Figure 9.26. PLNS3A with $+1.0 \mathrm{~cm}$ to PVT front.

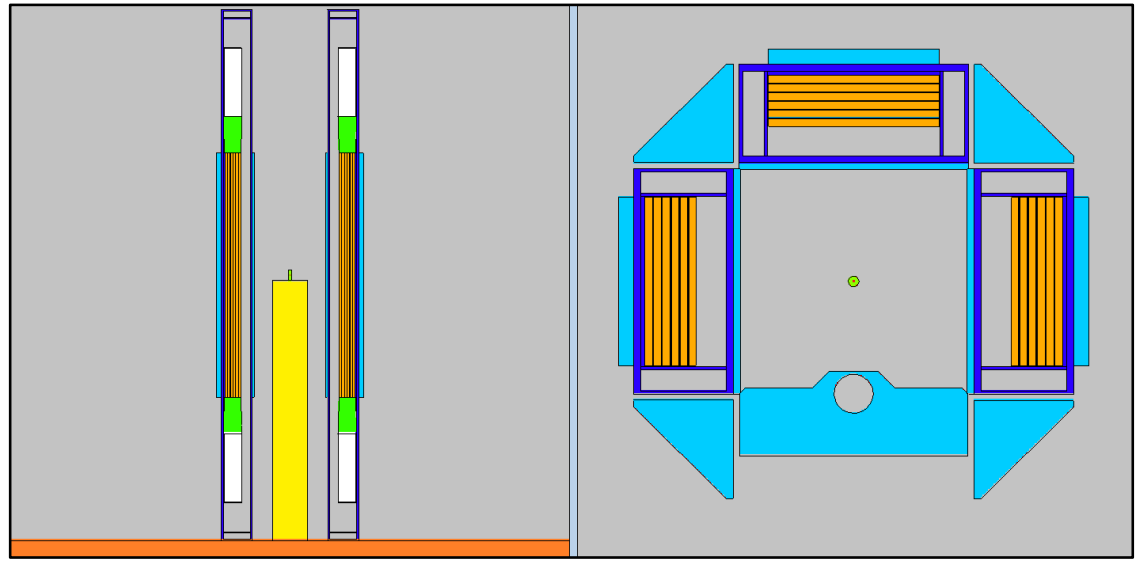

Figure 9.27. PLNS3A with $-0.5 \mathrm{~cm}$ to lining.

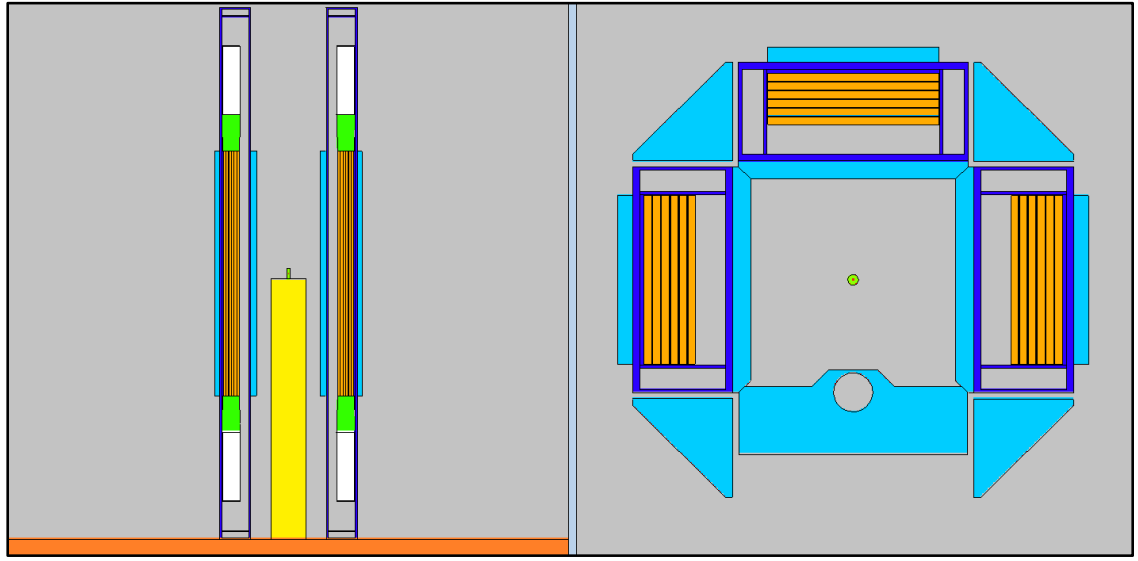

Figure 9.28. PLNS3A with $+0.5 \mathrm{~cm}$ to lining. 


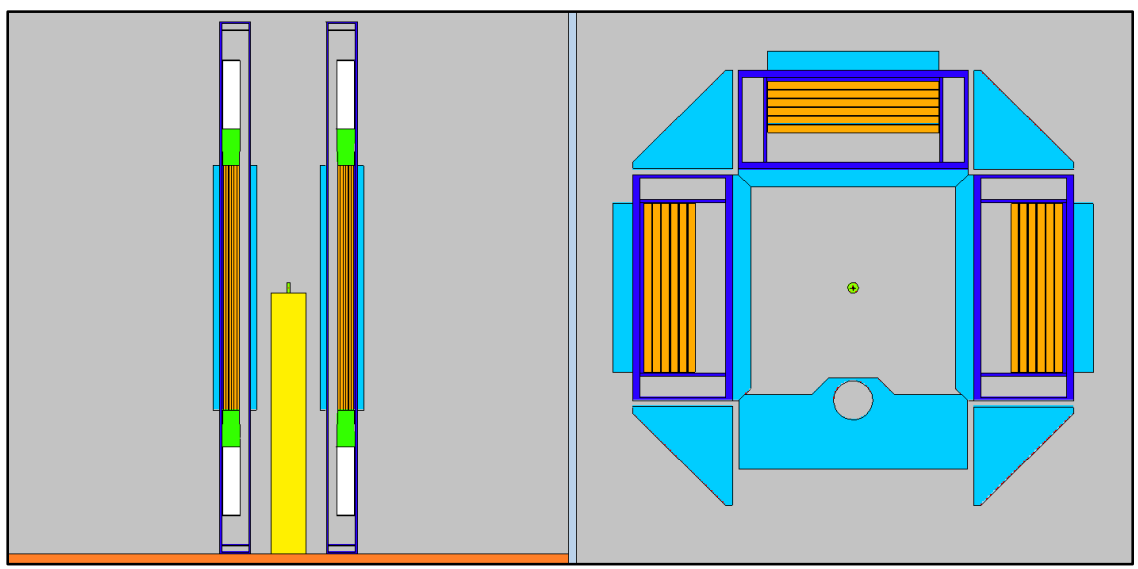

Figure 9.29. PLNS3A with $+0.5 \mathrm{~cm}$ to front, lining, and backing.

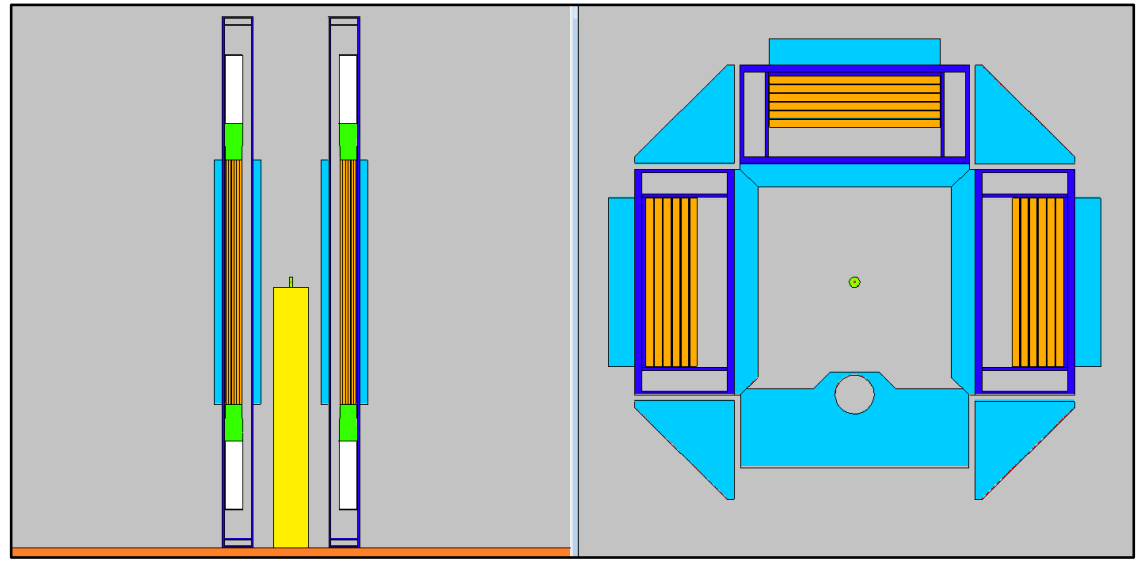

Figure 9.30. PLNS3A with $+1.0 \mathrm{~cm}$ to front, lining, and backing.

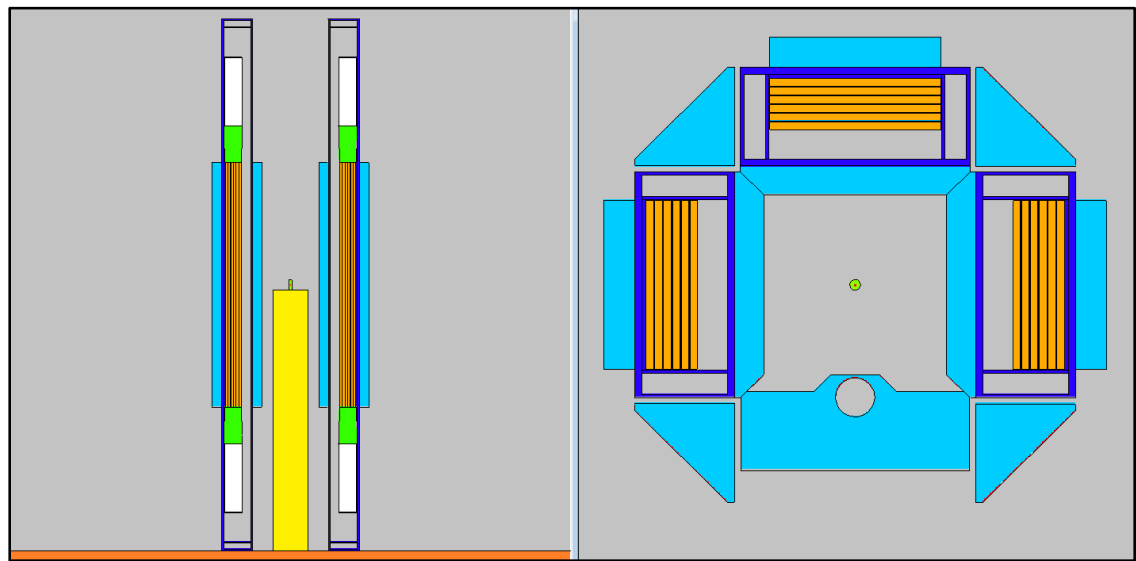

Figure 9.31. PLNS3A with $+1.0 \mathrm{~cm}$ to front, and $+1.5 \mathrm{~cm}$ to lining and backing. 


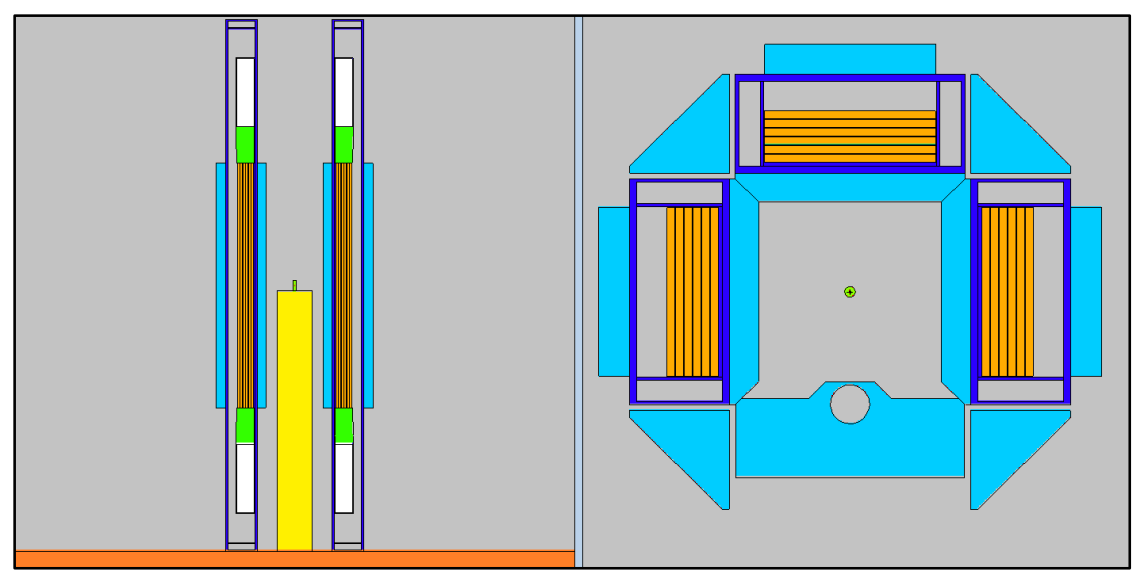

Figure 9.32. PLNS3A reversed with $+1.0 \mathrm{~cm}$ to front, and $+1.5 \mathrm{~cm}$ to lining and backing.

Because of the promising performance of the PLNS3A with reversed detector panels and thickened lining, backing, and front, as depicted in Figure 9.32, with $\varepsilon=18.3, \tau=18.0$, and FoM $=18.7$, this model was chosen for use in later simulations involving LEU fuel. This model will be referred to as PLNS3A$\mathrm{R} 1$ because it is the first major revision of the PLNS3A system. 


\section{Appendix: Studies for Examining Fuel in PLNS Coincidence Counter}

The LEU fuel model was put into the PLNS4 model and simulations were run with an AmLi neutron source in the corner of the system. A schematic of PLNS4 with a LEU fuel array can be seen in Figure 10.1. These simulations were performed without any additional moderator to establish a baseline of performance for the PLNS4 in relations to a LEU fuel array.

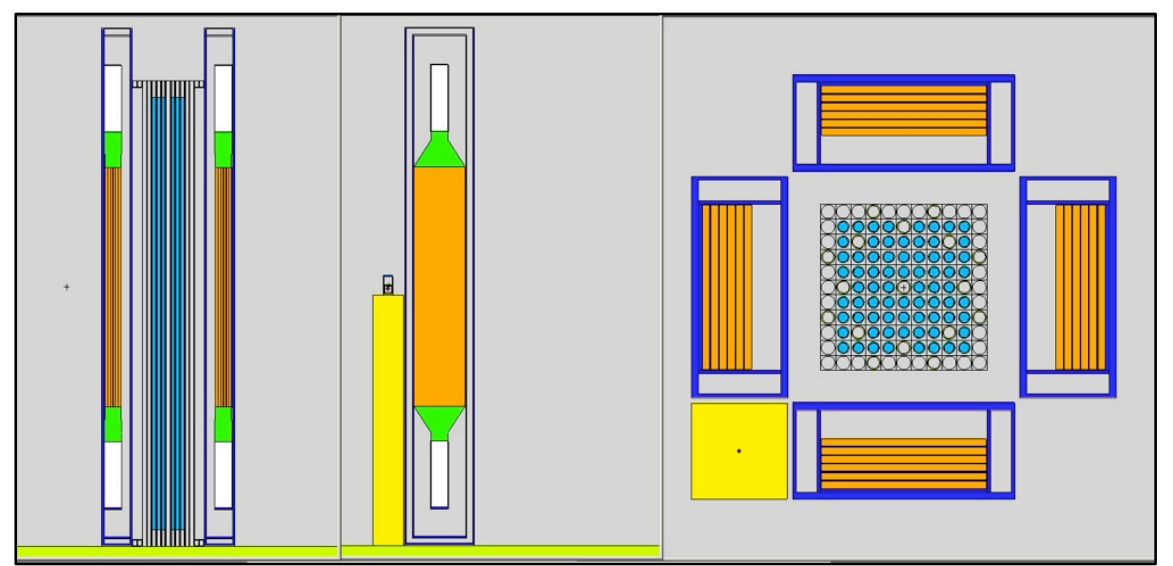

Figure 10.1. PLNS4 with LEU fuel array and AmLi source in one corner.

PLNS4 was simulated with LEU fuel enriched to $3.19 \%$ and $4.50 \mathrm{w} \%{ }^{235} \mathrm{U}$ with a polyurethane foam source stand. A model of PLNS4 without a fuel array, only relying on neutrons from an AmLi source in one corner, was simulated to provide a basis of comparison for the effects of adding the fuel arrays.

Results from simulating PLNS4 with LEU fuel can be seen in Table 10.1. These are simulation results for TCE, with no VCF applied.

Table 10.1. Simulation results of LEU fuel in PLNS4

\begin{tabular}{|l|l|l|}
\hline Fuel Enrichment & $\begin{array}{l}\text { Total cps/emitted } \\
\text { AmLi neutron }(\%)\end{array}$ & $\begin{array}{l}\text { Doubles captured/ emitted } \\
\text { AmLi neutron }(\%)\end{array}$ \\
\hline No Fuel Array & $5.56 \% \pm 0.01$ & N/A \\
\hline $3.19 \mathrm{w} \%{ }^{235} \mathrm{U}$ & $5.77 \% \pm 0.01$ & $0.0020 \% \pm 0.0004$ \\
\hline $4.50 \mathrm{w} \%{ }^{235} \mathrm{U}$ & $5.75 \% \pm 0.01$ & $0.0028 \% \pm 0.0004$ \\
\hline
\end{tabular}

* Values do not include the VCF

The addition of a LEU fuel arrays into an unmoderated PLNS4 produces a modest increase in total and doubles neutron captures.

The fuel model was put into the PLNS4 model, with HDPE blocks added to the corners of the system, and simulations were run with the AmLi neutron source. Simulations were run with $3.19 \mathrm{w} \%{ }^{235} \mathrm{U}$ and $4.50 \mathrm{w} \%$ ${ }^{235} \mathrm{U}$ fuel assemblies and with one to four AmLi sources. A schematic of PLNS4 with four HDPE blocks 
and four AmLi sources can be seen in Figure 10.2. These are simulation results for TCE, with no VCF applied.

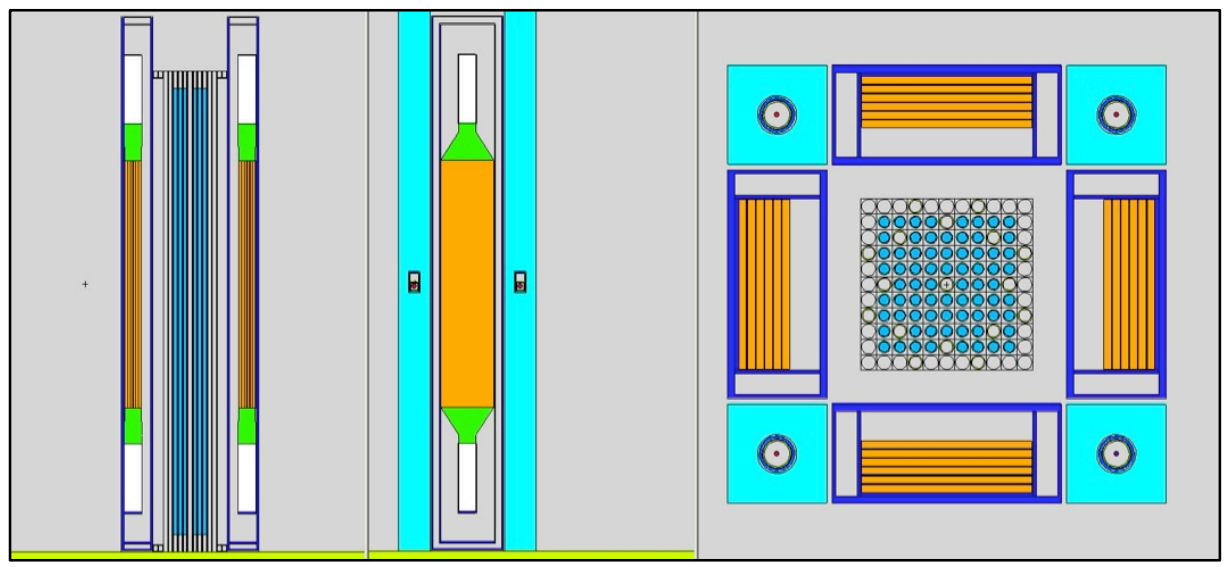

Figure 10.2. PLNS4 with full LEU fuel array, four HDPE reflectors, and four AmLi sources.

Table 10.2. Simulation results for PLNS4

\begin{tabular}{|c|c|c|l|l|}
\hline $\begin{array}{c}{ }^{235} \mathbf{U} \\
\text { Enrichment }\end{array}$ & $\begin{array}{c}\text { Number of } \\
\text { HDPE Blocks }\end{array}$ & $\begin{array}{c}\text { Number of } \\
\text { AmLi Sources }\end{array}$ & $\begin{array}{c}\text { Total cps/emitted AmLi } \\
\text { neutron (\%) }\end{array}$ & $\begin{array}{c}\text { Doubles captured/ } \\
\text { AmLi neutron (\%) }\end{array}$ \\
\hline 3.19 & 0 & 1 & $5.77 \pm 0.01$ & $0.0020 \pm 0.0002$ \\
\hline 3.19 & 1 & 1 & $11.6 \pm 0.01$ & $0.0137 \pm 0.0004$ \\
\hline 3.19 & 2 & 1 & $12.2 \pm 0.01$ & $0.0186 \pm 0.0005$ \\
\hline 3.19 & 3 & 1 & $12.6 \pm 0.01$ & $0.0231 \pm 0.0005$ \\
\hline 3.19 & 4 & 1 & $13.2 \pm 0.01$ & $0.0300 \pm 0.0006$ \\
\hline 3.19 & 4 & 2 & $13.6 \pm 0.01$ & $0.0339 \pm 0.0006$ \\
\hline 3.19 & 4 & 3 & $13.4 \pm 0.01$ & $0.0323 \pm 0.0006$ \\
\hline 3.19 & 4 & 4 & $13.2 \pm 0.01$ & $0.0304 \pm 0.0006$ \\
\hline 4.50 & 0 & 1 & $5.75 \pm 0.01$ & $0.0028 \pm 0.0002$ \\
\hline 4.50 & 1 & 1 & $11.6 \pm 0.01$ & $0.0165 \pm 0.0004$ \\
\hline 4.50 & 2 & 1 & $12.2 \pm 0.01$ & $0.0222 \pm 0.0005$ \\
\hline 4.50 & 3 & 1 & $12.5 \pm 0.01$ & $0.0269 \pm 0.0006$ \\
\hline 4.50 & 4 & 1 & $13.2 \pm 0.01$ & $0.0353 \pm 0.0006$ \\
\hline 4.50 & 4 & 2 & $13.5 \pm 0.01$ & $0.0404 \pm 0.0007$ \\
\hline 4.50 & 4 & 3 & $13.3 \pm 0.01$ & $0.0383 \pm 0.0007$ \\
\hline 4.50 & 4 & 4 & $13.2 \pm 0.01$ & $0.0364 \pm 0.0006$ \\
\hline$*$
\end{tabular}

* Values do not include the VCF 
The addition of multiple AmLi sources, as seen in Table 10.2, had no significant effect on the uncertainty of total capture efficiency or the doubles capture efficiency. The addition of HDPE significantly increased the total neutron capture efficiency of PLNS4 for all fuel enrichments and numbers of sources. The doubles capture efficiency was increased by approximately an order of magnitude through the addition of HDPE, but remained below values simulated for the UNCL-II.

The addition of HDPE blocks increased singles and doubles neutron counts as depicted in Figure 10.3 (singles) and Figure 10.4 (doubles).

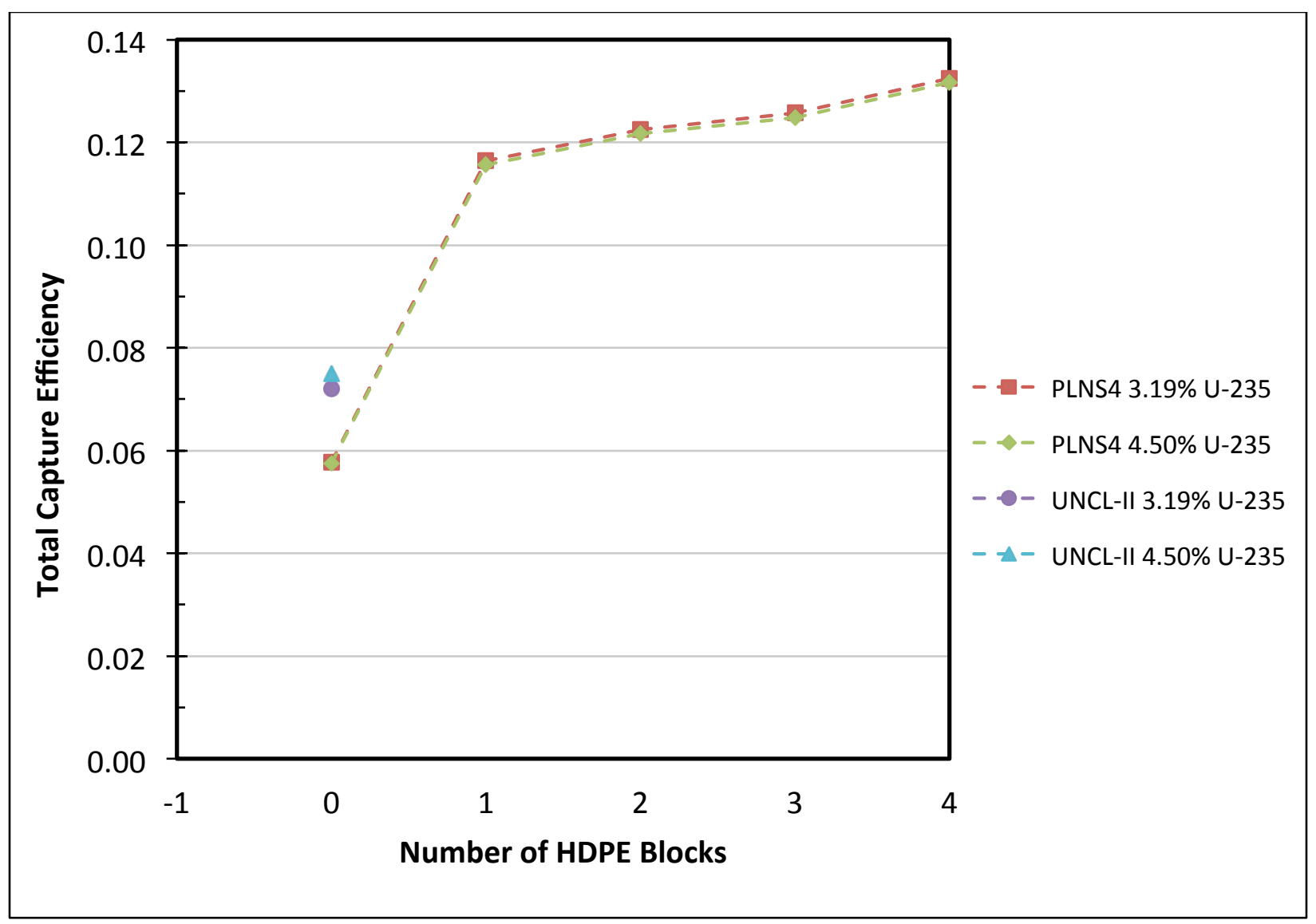

Figure 10.3. Total Capture Efficiency of PLNS4 versus number of HDPE blocks and LEU fuel compared to UNCL-II. 


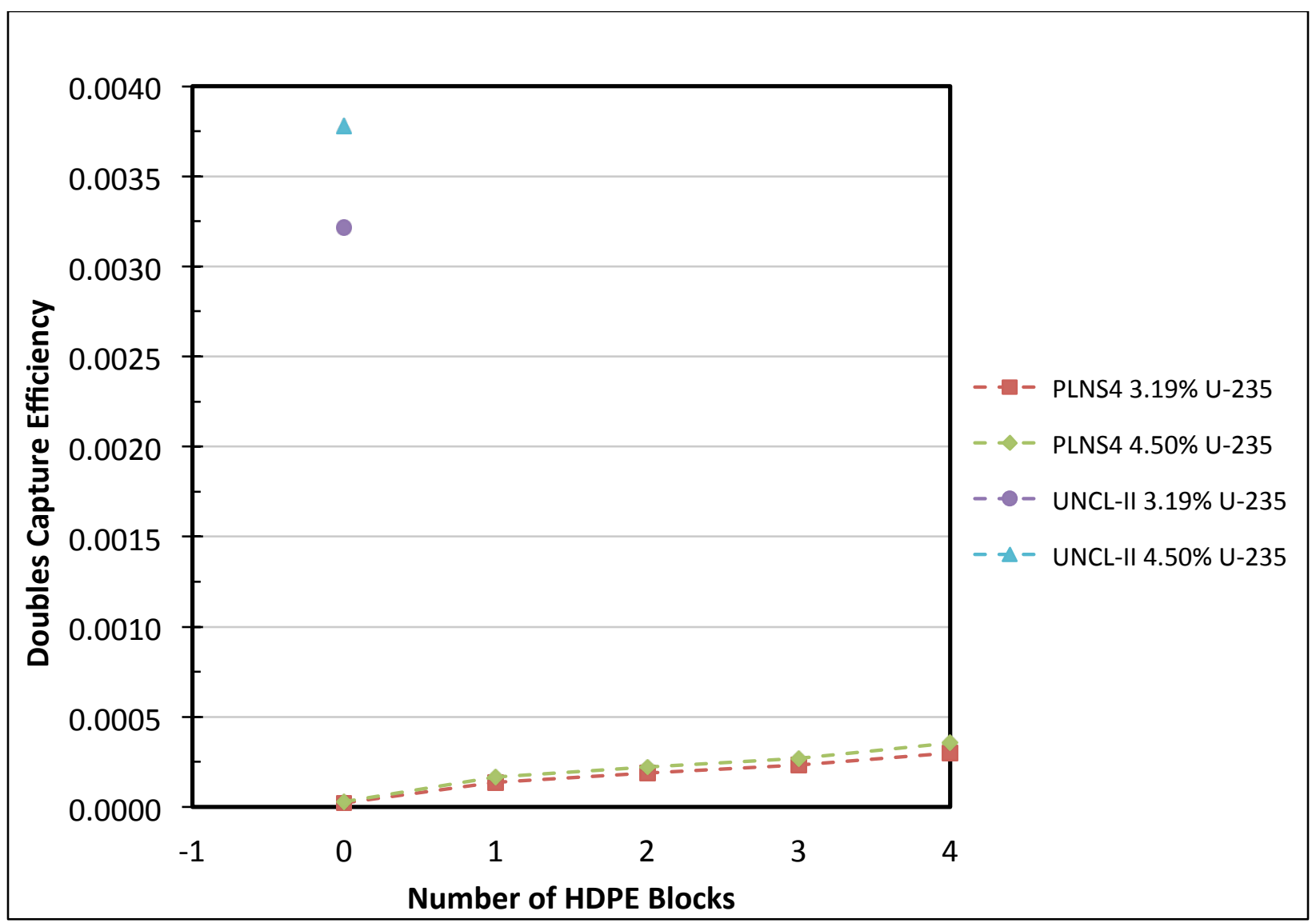

Figure 10.4. Doubles capture efficiency of PLNS4 versus number of HDPE blocks and LEU compared to UNCL-II.

Adding the first HDPE block to the PLNS4 model resulted in nearly doubling the total capture efficiency, with additional blocks providing more modest increases in total capture efficiency. The addition of HDPE blocks provided a nearly linear increase in doubles capture efficiency and a very significant relative increase in double capture efficiency, improving doubles capture efficiency by an order of magnitude, although the absolute doubles capture efficiency remained very low. 


\section{Acknowledgements}

The United States Department of Energy Office of Nuclear Safeguards and Security (NA-241) supported this work. Pacific Northwest National Laboratory is operated for the United States Department of Energy under contract DE-AC05-76RLO 1830. We thank Prof. Azaree Lintereur for her review comments on this report. 


\section{References}

Asou M, J Porta. 1997. Prospects for poisoning reactor cores of the future. Nuclear Engineering and Design 168, pp. 261-270.

Croft S, A Favalli, MT Swinhoe, CD Rael. 2011. "State Of The Art Monte Carlo Modeling Of Active Collar Measurements And Comparison With Experiment." Los Alamos National

Durmazucar HH, U Colak, B Sarikaya, G Gurduz. 2001. Burnup characteristics and performance of boron nitride and boron coated urania and urania-gadolinia fuels. Nuclear Engineering and Design 203, pp. 57-64.

Ely JH, ER Siciliano, MT Swinhoe, AT Lintereur. 2013. Modeling and Simulation Optimization and Feasibility Studies for the Neutron Detection without Helium-3 Project. PNNL-22228. Pacific Northwest National Laboratory, Richland, Washington.

Ely JH, M Bliss, RT Kouzes, AT Lintereur, SM Robinson, ER Siciliano, MT Swinhoe, ML Woodring. 2013a. Final Technical Report for the Neutron Detection without Helium-3 Project. PNNL-23011. Pacific Northwest National Laboratory, Richland, Washington.

Ensslin, N, WC Harker, MS Krick, DG Langner, MM Pickrell, JE Stewart. 1998. Application Guide to Neutron Multiplicity Counting. LA-13422-M. Los Alamos National Laboratory.

Espinosa-Paredes G, JR Guzmán. 2011. Reactor physics analysis for the design of nuclear fuel lattices with burnable poisons. Nuclear Engineering and Design 241, pp. 5039-5054.

Evans LG, MT Swinhoe, HO Menlove, P Schwalbach, P De Baere, MC Browne. 2013. A new fast neutron collar for safeguards inspection measurements of fresh low enriched uranium fuel assemblies containing burnable poison rods. Nuclear Instruments and Methods in Physics Research A, 729, pp. 740746.

Jo CK, Y Kim, JM Noh. 2009. Burnable poison for reactivity management in a very high temperature reactor. Annals of Nuclear Energy 36, pp. 298-304.

Kloosterman JL. 2003. Application of boron and gadolinium burnable poison particles in $\mathrm{UO}_{2}$ and $\mathrm{PuO}_{2}$ fuels in HTRs. Annals of Nuclear Energy 30, pp. 1807-1819.

Kouzes RT. 2009. The ${ }^{3}$ He Supply Problem. PNNL-SA-18388. Pacific Northwest National Laboratory, Richland, Washington.

Kouzes RT, JH Ely, LE Erikson, WJ Kernan, AT Lintereur, ER Siciliano, DL Stephens, DC Stromswold, RM Van Ginhoven, and ML Woodring. 2010. Neutron detection alternatives to for ${ }^{3}$ He homeland security. Nuclear Instruments and Methods in Physics Research A, 623, pp. 1035-1045.

Kouzes RT, JH Ely, AT Lintereur, ER Siciliano. 2012. Introduction to Neutron Coincidence Counter Design Based on Boron-10. PNNL-21090. Pacific Northwest National Laboratory, Richland, Washington.

Kouzes RT, JH Ely, AT Lintereur, ER Siciliano. 2013. Boron-ABUNCL Prototype Models and Initial Active Testing. PNNL-22424. Pacific Northwest National Laboratory, Richland, Washington.

Lintereur AT, JH Ely, RT Kouzes, LE Erikson, and DC Stromswold. 2009. Coated Fiber Neutron Detector Test. PNNL-18919. Pacific Northwest National Laboratory, Richland, Washington.

Lintereur AT, RT Kouzes, JH Ely, LE Erikson, and ER Siciliano. 2010. Boron Lined Neutron Detector Measurements. PNNL-18938. Pacific Northwest National Laboratory, Richland, Washington. 
Lintereur AT, JH Ely, RT Kouzes, ER Siciliano, MT Swinhoe, and ML Woodring. 2012. Alternatives to Helium-3 for Neutron Multiplicity Counters. PNNL-SA-92075. IEEE Transaction on Nuclear Science (to be published).

Lintereur AT, ER Siciliano, RT Kouzes, and JH Ely. 2012a. Boron-10 Lined Proportional Counter Model Validation. PNNL-21501. Pacific Northwest National Laboratory, Richland, Washington.

Massih AR, S Persson, Z Weiss. 1992. Modelling of (U, Gd)O, fuel behaviour in boiling water reactors. Journal of Nuclear Materials 188, pp. 323-330.

Menlove HO, JE Stewart, SZ Qiao, TR Wenz, PD Verrecchia. 1990. "Neutron Collar Calibration and Evaluation for Assay of L WR Fuel Assemblies Containing Burnable Neutron Absorbers." Los Alamos National Laboratory Report LA-11965-MS.

Mikus JM. 2014. Power distribution gradients in WWER type cores and fuel failure root causes. Nuclear Engineering and Design 267, pp. 207-217.

Pelowitz DB (ed.). 2011. MCNPX User's Manual, Version 2.7.0. LANL Report LA-CP-11-00438. Los Alamos National Laboratory, Los Alamos, New Mexico.

Reilly, Doug, N Ensslin, H Smith Jr, S Kreiner. 1991. Passive Nondestructive Assay of Nuclear Materials. Los Alamos National Laboratory NRC FIN A7241.

Rogers T, J Ragusa, S Schultz, R St. Clair. 2009. Optimization of PWR fuel assembly radial enrichment and burnable poison location based on adaptive simulated annealing. Nuclear Engineering and Design 239, pp. 1019-1029.

Rogers JL, JH Ely, RT Kouzes, AT Lintereur, and ER Siciliano. 2012. Uranium Neutron Coincidence Collar Model Utilizing Boron-10 Lined Tubes. PNNL-21750. Pacific Northwest National Laboratory, Richland, Washington.

Schlieck M, HD Berger, A Neufert. 2001.Optimized gadolinia concepts for advanced in-core fuel management in PWRs. Nuclear Engineering and Design 205, pp. 191-198.

Siciliano ER, JH Ely, RT Kouzes, and ML Woodring. 2010. Simulating Boron-Based Detectors with $M C N P X$. PNNL-SA-71579. Pacific Northwest National Laboratory, Richland, Washington.

Siciliano ER, JL Rogers, JE Schweppe, AZ Lintereur, RT Kouzes. 2012. Uranium Neutron Coincidence Collar Model Utilizing ${ }^{3}$ He. PNNL-21581. Pacific Northwest National Laboratory, Richland, Washington.

Siciliano ER, AT Lintereur, RT Kouzes, and JH Ely. 2013. Boron-10 ABUNCL Models of Fuel Testing. PNNL-22947. Pacific Northwest National Laboratory, Richland, Washington.

Soba A, M Lemes, ME González, A Denis, L Romero. 2014. Simulation of the behaviour of nuclear fuel under high burnup conditions. Annals of Nuclear Energy 70, pp. 147-156.

Tagziria H, M Looman. 2012. The ideal neutron energy spectrum of ${ }^{241} A m L i(\alpha, n)^{10} B$ sources. Applied Radiation and Isotopes vol. 10, issue 10, pp 2395-2402.

van Dam, H. 2000. Long-term control of excess reactivity by burnable particles. Annals Of Nuclear Energy, Vol. 27, pp. 733-743.

Yamate K, M Mori, T Ushiop M Kawamura. 1997. Design of a gadolinia bearing mixed-oxide fuel assembly for pressurized water reactors. Nuclear Engineering and Design 170, pp. 35-51.

Yilmaz S, K Ivanov, S Levine, M Mahgerefteh. 2006. Application of genetic algorithms to optimize burnable poison placement in pressurized water reactors. Annals of Nuclear Energy 33, pp. 446-456. 


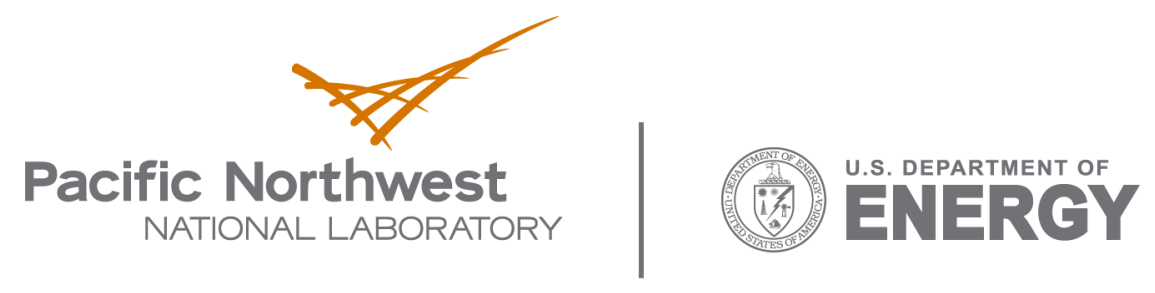

902 Battelle Boulevard

P.O. Box 999

Richland, WA 99352

1-888-375-PNNL (7665)

www.pnl.gov 